\title{
Critical issues in donation after circulatory death
}

Citation for published version (APA):

Wind, J. (2016). Critical issues in donation after circulatory death. [Doctoral Thesis, Maastricht University]. Datawyse / Universitaire Pers Maastricht. https://doi.org/10.26481/dis.20160219jw

Document status and date:

Published: 01/01/2016

DOI:

10.26481/dis.20160219jw

Document Version:

Publisher's PDF, also known as Version of record

\section{Please check the document version of this publication:}

- A submitted manuscript is the version of the article upon submission and before peer-review. There can be important differences between the submitted version and the official published version of record.

People interested in the research are advised to contact the author for the final version of the publication, or visit the DOI to the publisher's website.

- The final author version and the galley proof are versions of the publication after peer review.

- The final published version features the final layout of the paper including the volume, issue and page numbers.

Link to publication

\footnotetext{
General rights rights.

- You may freely distribute the URL identifying the publication in the public portal. please follow below link for the End User Agreement:

www.umlib.nl/taverne-license

Take down policy

If you believe that this document breaches copyright please contact us at:

repository@maastrichtuniversity.nl

providing details and we will investigate your claim.
}

Copyright and moral rights for the publications made accessible in the public portal are retained by the authors and/or other copyright owners and it is a condition of accessing publications that users recognise and abide by the legal requirements associated with these

- Users may download and print one copy of any publication from the public portal for the purpose of private study or research.

- You may not further distribute the material or use it for any profit-making activity or commercial gain

If the publication is distributed under the terms of Article $25 \mathrm{fa}$ of the Dutch Copyright Act, indicated by the "Taverne" license above, 

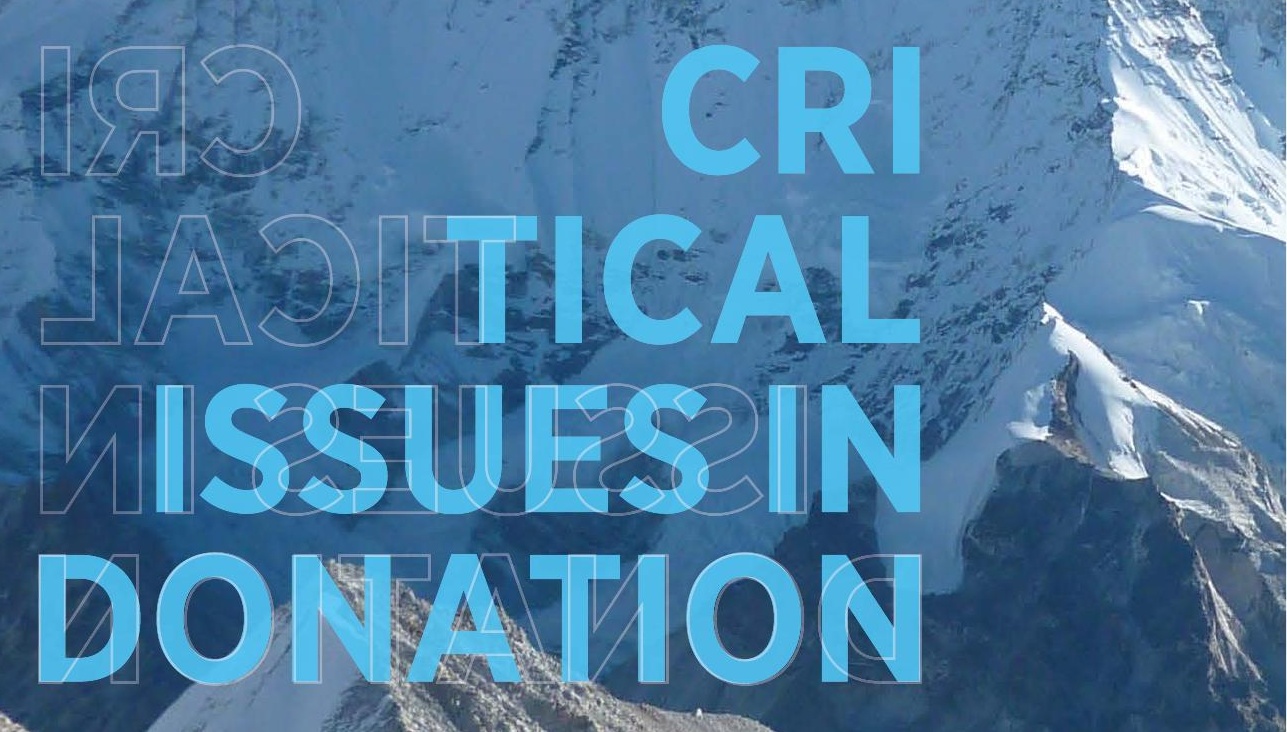

AETER CIRCUIATORY DEATH

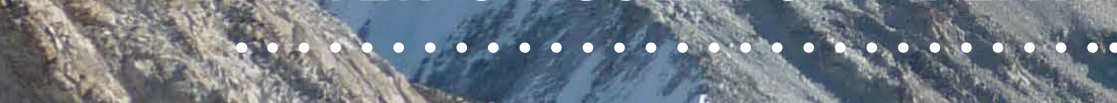

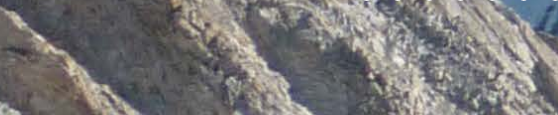

2.

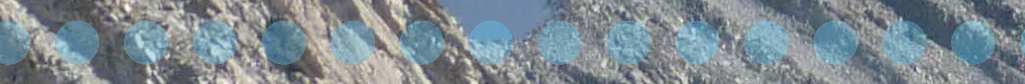

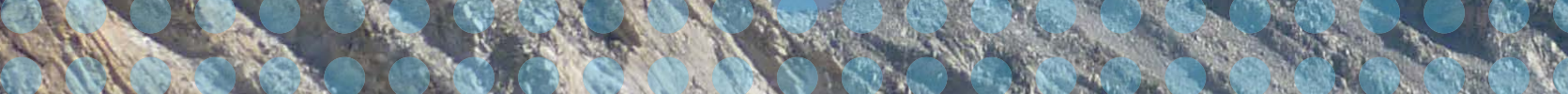

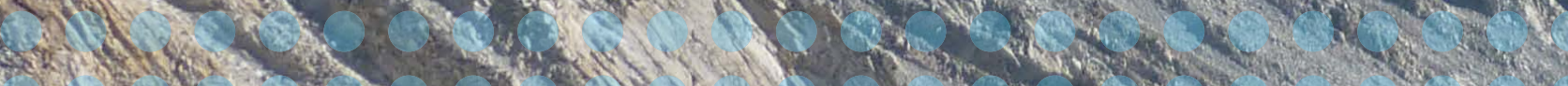
$2 x^{2}$. at A.

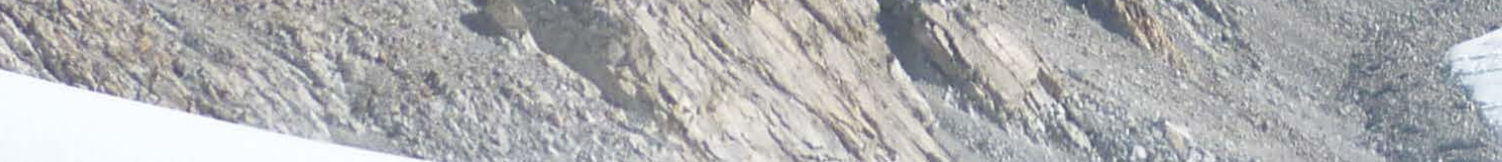

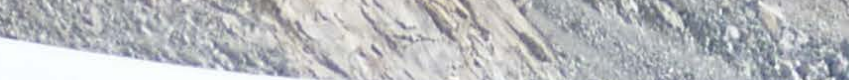


${ }^{0}$ Copyright Tineke Wind, Maastricht 2015

Layout: Tiny Wouters

Cover: Muis Mücher

Printed by: Datawyse | Universitaire Pers Maastricht

ISBN: 9789461595249

Printing of this thesis was financially supported by : Astellas, Organ Recovery Systems, stichting onderzoek intensive care (STOIC), Nederlandse Transplantatie Vereniging, Nierstichting, Maastricht Universitair Medisch Centrum. 


\title{
Critical issues in donation after circulatory death
}

\author{
PROEFSCHRIFT \\ ter verkrijging van de graad van doctor \\ aan de Universiteit Maastricht \\ op gezag van de Rector Magnificus, \\ Prof. dr. L.L.G. Soete, \\ volgens het besluit van het College van Decanen, \\ in het openbaar te verdedigen \\ op vrijdag 19 februari 2016 om 14:00 uur
}

door

Jentina Wind

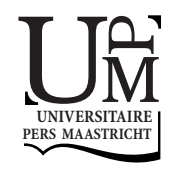




\section{Promotor}

Prof. dr. L.W.E. van Heurn

\section{Copromotor}

Dr. W.N.K.A. van Mook

\section{Beoordelingscommissie}

Prof. dr. G.W.H. Schurink (voorzitter)

Prof. dr. G.M.W.R. de Wert

Prof. dr. D. Ysebaert, Universiteit Antwerpen

Prof. dr. J.H. Zwaveling, Maxima Medisch Centrum Eindhoven 
Aan mijn ouders

Voor Dick, Daan en Kas 



\section{Content}

Chapter 1 General introduction 9

Chapter 2 Higher organ donation consent rates by relatives of potential 25 uncontrolled donors versus potential controlled donors after death Nephrology Dialysis Transplant 2012;27:4219-23

Chapter 3 Prediction of time of death after withdrawal of life-sustaining treatment in potential donors after cardiac death

Critical Care Medicine 2012;40:766-9

Chapter 4 Determination of death after circulatory arrest by intensive care physicians Journal of Critical care, in press

Chapter 5 Preservation of kidneys from controlled donors after cardiac death British Journal of Surgery 2011;98:1260-6

Chapter 6 Preservation techniques for donors after cardiac death kidneys Current Opinion in Organ Transplantation 2011;16:157-161

Chapter 7 Family satisfaction of organ donors versus non-donors in the Intensive Care Unit submitted

Chapter 8 Variability in protocols on donation after circulatory death in Europe Critical Care 2013;17:R217

Chapter 9 Ethical, legal and societal issues and recommendations for controlled and uncontrolled donation after circulatory death Transplant International, accepted for publication

Samenvatting

Valorisation addendum

List of publications

Dankwoord 



\section{1}

General introduction 



\section{General introduction}

Transplantation of an organ from one person to another is an accepted medical treatment for end stage organ failure. It is the therapy of choice for many patients with end-stage renal failure, increases survival compared to long-term dialysis treatment and improves the quality of life. ${ }^{1}$ Unfortunately, an ongoing universal shortage of donor organs relative to the demand for transplantation exists. ${ }^{2}$ Several ways to expand the donor pool and to increase the available organs for transplantation have been explored and developed since the first organ transplantation. Next to the growing number of living kidney donors ${ }^{3,4}$ and the use of brain dead donors with expanded criteria for donation, such as donors with more advanced age and donors with co morbidity, ${ }^{5}$ the use of organs from donors after circulatory death (DCD) is expanding rapidly throughout the world in an effort to decrease the gap between demand and supply.

Liberal use of kidneys from DCD donors holds the potential to increase the number of kidney donors by 2,5 to 4 times, which, in theory is sufficient to stabilize or even reduce the waiting lists for kidney transplantation. ${ }^{6-8}$ However, in contrast to organs from brain dead donors, organs from DCD donors suffer from warm ischemic injury during the period from circulatory arrest until preservation of the organs. As a consequence of this injury, an increased incidence of delayed graft function (DGF) and primary non function (PNF) is seen compared to kidney transplantation from conventional brain dead donors. ${ }^{9,10}$ These early complications have restricted the expansion of DCD kidney donation to its full potential.

This thesis focuses on the donation after circulatory death process, to identify critical issues in this process and to see where there is room for improvement to facilitate expansion of the DCD programme. This chapter will therefore consecutively give an overview and background on donation after circulatory death, address factors hampering further expansion of the contemporary DCD kidney donation programme, after which the research questions underlying the results of the studies in this thesis are addressed.

\section{History of organ donation}

The first successful human organ transplantation was performed in 1954 by Dr. Joseph Murray, a later Nobel prize Laureate; he transplanted a kidney from a living donor to his identical twin brother. ${ }^{11}$ Because donor and recipient were genetically identical, rejection of the organ in the recipient did not occur. This kidney from a living donor also hardly suffered from ischemic damage. In 1963, the first successful deceased donor kidney transplantation was reported by Merril and Murray. The transplanted kidney was procured after circulatory arrest, had delayed graft function and functioned for one 
year. ${ }^{12}$ In this era, many kidney transplants failed within a short period after transplantation, due to poor organ quality caused by warm ischemia or rejection problems. $^{13}$

With the introduction of machine perfusion in the late sixties, kidney preservation improved and special preservation solutions for cold storage resulted in better graft survival. ${ }^{14}$ Another important change in transplantation was caused by the adaption of the 'Harvard' brain death criteria in 1968 as criterion for death. ${ }^{15}$ Donation after brain death became the standard resulting in better outcomes. Continuing organ perfusion until procurement made that the organs had not suffered from warm ischemic injury, in contrast to organs from DCD donors. ${ }^{16}$ In addition, other organs, like liver and heart could also be transplanted. Because of the better quality of the organs of brain death donors, the use of DCD donors declined in the 1970s. Transplantation results further improved, due to the introduction of the immunosuppressive drug cyclosporine, and acute rejections decreased and graft survival further improved. ${ }^{17}$

As a consequence of the improvement of the clinical outcomes of kidney transplantation, waiting lists started to increase in the 1980s, because more patients with end-stage renal disease opted for transplantation. ${ }^{18}$ The increasing wait lists led to a renewed interest in the use of organs from DCD donors in order to expand the donor pool of organs for transplantation. ${ }^{19,20}$ Several transplant centers, including the Maastricht University Medical Centre, have since the 1980s popularized DCD transplantation. Improvement of donor preparation and organ preservation methods made the clinical outcome of DCD kidney transplantation comparable to DBD grafts. $^{9,21-27}$

Next to DCD kidney transplantation, DCD transplantation of the liver, lung and pancreas has been increasingly performed in the past decade. The results of DCD liver transplantation are comparable with DBD liver transplantation, with equal equivalent 1-year and 3-year graft survival and patient survival, although a higher risk of biliary strictures in DCD livers is noted. ${ }^{28}$ The number of DCD lung transplantations is nowadays still relatively low; a number of transplant centers show comparable outcomes for DCD and DBD lung transplantation. DCD lung transplantation nevertheless offers a good opportunity to reduce the donor lung shortage. ${ }^{29}$

Another notable development is the progress in prevention and treatment of the conditions that lead to brain death, which has led to a decline in the actual numbers of brain dead patients. In the Netherlands, a decline of $30 \%$ in the number of DBD donors is seen from 915 in the period 1995 to 1999, to 637 in the period 2005 to 2009. ${ }^{30}$ In the same time period, the number DCD donors increased from 118 in the first period, to 453 in the second period (282\%). In 2013, the number of DCD donors (59\%) exceeded the number of DBD donors (41\%) in the Netherlands (Figure 1.1). ${ }^{31}$ 


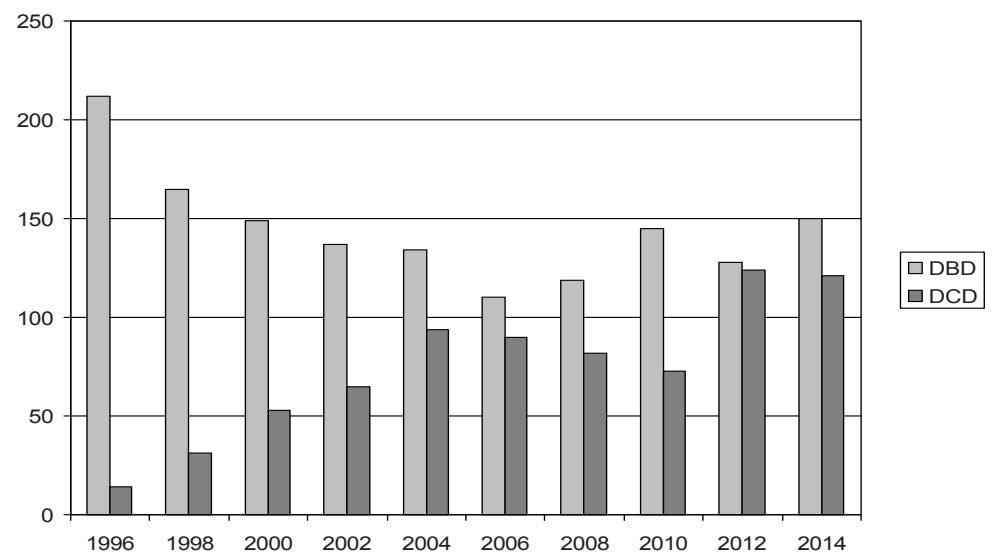

Figure 1.1 Number of DBD and DCD donors in the Netherlands from 1996 until 2014.

\section{Donation after circulatory death}

During the first international conference on non-heart-beating donation in Maastricht in 1995, four types of DCD donors were categorized, according to their period of warm ischemia (Table 1.1). ${ }^{32}$ Maastricht category 1 donors are patients who are declared dead outside the hospital and are transferred to the hospital with the purpose of organ donation. There are only a few donation programs that have implemented this category, mainly in France and Spain. ${ }^{27,33}$ Maastricht category 2 donors are patients who die in the hospital after unsuccessful resuscitation, mostly in the emergency departments. Both category 1 and 2 occur unexpectedly and therefore are referred to as uncontrolled donors, category 2 donation is performed in only a few centers in the Netherlands because of the complex and demanding infrastructure required. Maastricht category 3 donors are patients in the Intensive Care Unit (ICU) who do not meet brain dead criteria, but for whom further treatment is considered futile which is therefore withdrawn. These patients, in whom circulatory arrest is awaited for, are referred to as so called controlled donors. The donation procedure of the DCD category 3 donors can be scheduled and legal and logistic requirements can be met before treatment withdrawal. Maastricht category 4 donors are brain-dead donors who die of unexpected cardiac arrest before organ procurement. Currently, the majority of DCD donors in the Netherlands, the USA, UK and Belgium are category 3 donors. ${ }^{34,35}$

This generally accepted nomenclature has nevertheless undergone some changes since the first conference; non-heart beating donation was initially changed into donation after cardiac arrest and is nowadays most commonly referred to as donation after circulatory arrest. 
Table 1.1 The Maastricht categories of donation after circulatory death.

\begin{tabular}{lll}
\hline Category & Definition & Type \\
1 & Dead on arrival & Uncontrolled \\
2 & Unsuccessful resuscitation & Uncontrolled \\
3 & Awaiting circulatory arrest & Controlled \\
4 & Circulatory arrest while brain dead & Controlled/uncontrolled \\
\hline
\end{tabular}

\section{Ethical aspects}

Several basic ethical principles concerning deceased organ donation can be distinguished. ${ }^{36-38}$ The most important ethical as well as legal principle is the so called dead donor rule; organ donors must be dead before organ recovery. The organ procurement itself may not be the direct cause the death of the donor. ${ }^{39,40}$ The diagnosis of death, based on cardiopulmonary criteria in DCD and neurological criteria in DBD donation, is based on the irreversible loss of the capacity for consciousness, combined with the irreversible loss of the capacity to breathe. In both DCD and DBD donation death is a result of the irreversible loss of these functions in the brain. ${ }^{41}$ Irreversibility requires an observation time, in which the functions will not resume. In the context of DCD there is time pressure to diagnose death, DCD requires that death is declared at the earliest possible time after circulatory arrest that is scientifically, ethically, and professionally acceptable to minimize warm ischaemic time. ${ }^{42}$ On the other hand the dead donor rule is not allowed to be violated. Several ethical commentaries have stated that controlled DCD violates the dead donor rule, because when cardiopulmonary resuscitation (CPR) would be initiated, the circulatory arrest may be reversed. ${ }^{38,43,44}$ But, in the context of withdrawal of the life sustaining treatment in the ICU, CPR is not intended. Therefore, within the transplant community consenses defines irreversibility as cessation of function without the capacity of spontaneous recovery. ${ }^{45,46}$ A continuous observation of irreversibility of asystole, apnoea and unresponsiveness during a period of five minutes is accepted in most countries that perform DCD as evidence for death; the Ethics Committee of the American College of Critical Care Medicine stated that no less than 2 minutes is acceptable, but no more than 5 minutes is necessary (no-touch period), between circulatory arrest and the start of organ preservation messures. ${ }^{47}$

Another ethical principle in organ donation is the clear separation between the team that is responsible for the treatment of the patient and the transplant team of the donor (organs). Critical care professionals must ensure that the decision to withdraw the medical treatment of the patient is made separately from and before any decision to donate organs. ${ }^{48}$ Care for the patient must never be compromised for the benefit of the potential recipients. Interventions which e.g. aim to minimize warm ischemic injury to donor organs, like treatment withdrawal in the operating room (OR) instead of in the ICU 
and cannulation before death, can all compromise the end-of life care of the patient. ${ }^{42}$ Performance of the latter is therefore not practised in the Netherlands.

In the Netherlands and the United Kingdom it is common practice to withdraw treatment in the ICU with the family of the patient at the bedside, to provide continuity of care to the patient and family. After determining death, the donor is transported to the OR, which results in similar transplant outcomes as withdrawal in the OR. ${ }^{49}$ In countries with an active controlled DCD programme, like the Netherlands and the UK, the DCD procedure is accepted as normal part of the end-of-life care for the patient. ${ }^{42,50,51}$ Nevertheless, end-of life care in the ICU patient seems to be different, compared to published general guidelines, if organ donation follows death. ${ }^{52-54}$ Protocols for donation after circulatory death are important, they should be discussed and approved by medical ethical committees of each institution that performs DCD. ${ }^{35,55}$

\section{Legal aspects}

Legislation concerning organ donation varies worldwide. In the Netherlands, the Dutch Organ Donation Act exists since 1998, and includes a national Donor Register (DR), based on an opting-in consent system. ${ }^{56}$ Organ donation is only allowed with consent of the donor as registered in the DR or, if not registered, consent of the family. It is mandatory for the physician, to consult the DR if the patient is a potential donor. The DR should be consulted when death is expected within 12 hours or after death (in case of a potential uncontrolled DCD donor) and before conversation with the relatives.

Throughout the world, legislation concerning DCD donation likewise differs; in some countries, like the Netherlands and the UK it is possible to start preservation measures in uncontrolled donors after consulting the DR, but before consent is obtained from the family, which makes this donation possible. ${ }^{57,58}$ In Germany, procurement of organs from deceased donors can be performed only after formal declaration of brain death, which rules out any type of DCD donation.

\section{The donation after circulatory death process}

\section{Donor recognition}

The donation process starts with the early recognition of the potential donor by the treating physician. Review of medical records shows that not all potential donors are recognized as such and that some are therefore lost for donation. ${ }^{59,60}$ The World Health Organisation published a critical pathway for organ donation (Figure 1.2), as an initiative to identify the common challenges faced by both developing and developed countries, 
and to make recommendations to governments, international organizations, and healthcare professionals on how to maximize deceased donation. ${ }^{61}$

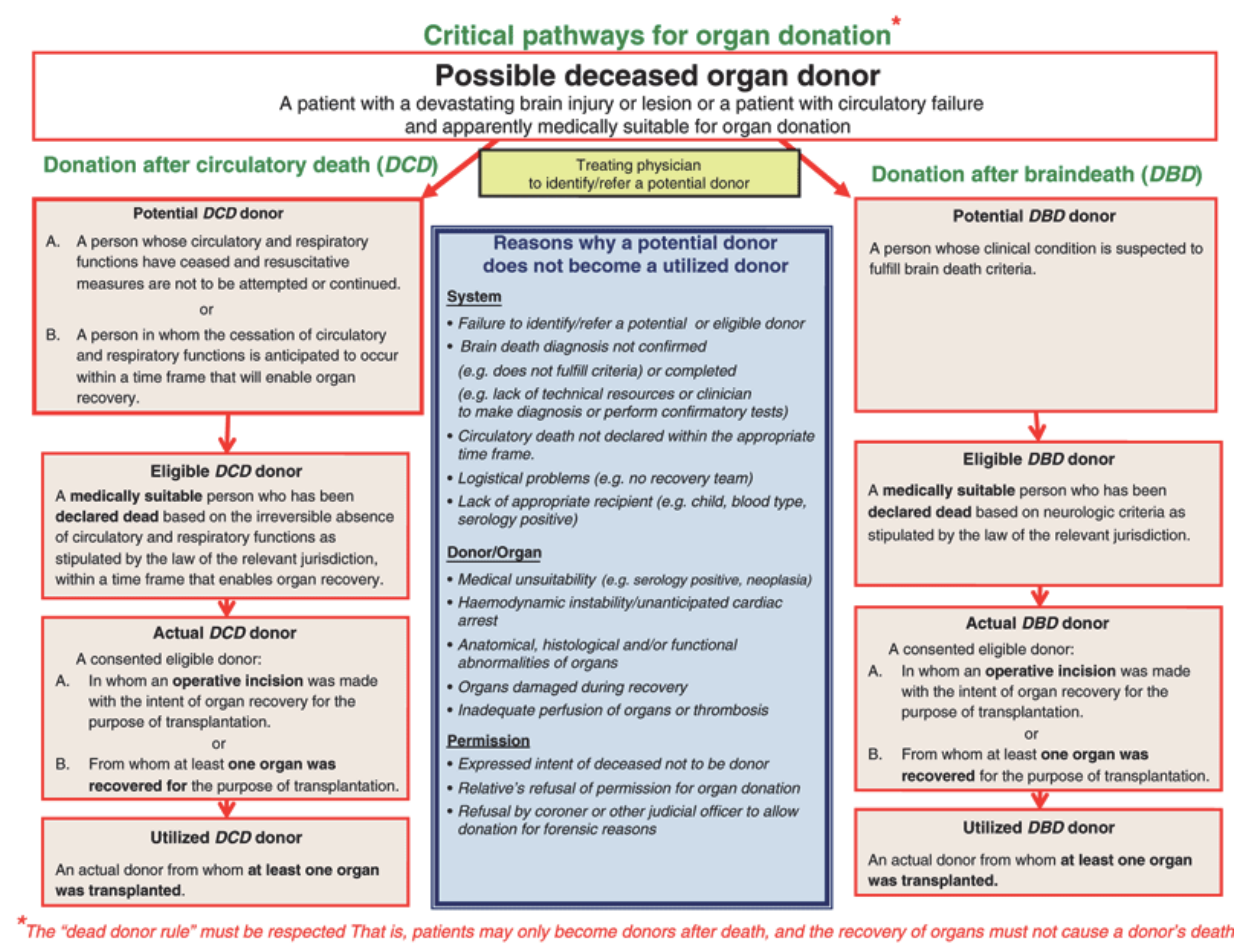

Figure 1.2. The critical pathway for deceased organ donation.

\section{Consent}

After recognition of the potential donor, consent must be obtained. The registration in the Donor Register is obtained before the relatives are approached. In case of a nonregistered donor, family refusal for organ donation is a major problem. ${ }^{59}$ Several factors are associated with relatives' willingness to donate, including the decoupling the pronouncement of death and request for donation, patient and family characteristics, the available time to consider donation, seniority of the requestor. ${ }^{62,63}$

\section{Coordination}

Early in the process of donation, the transplant coordinator is notified; he or she coordinates the donation process, organises the examinations to determine organ suitability for donation, refers the donor to Eurotransplant, provides information to the 
family about the donation process and the follow-up, and arranges a surgical procurement team.

Until withdrawal of treatment in a controlled DCD donor, careful monitoring and supportive treatment is in the interest of both the potential donor and the recipients. In this phase, patient management mainly focuses on cardiovascular and cardio-pulmonary status, and normal blood pressure, normovolemia, and normal oxygenation are preferably maintained.

\section{Withdrawal of treatment}

Withdrawal of active treatment should proceed in accordance with accepted practice of the intensive care unit, preferably according to a standardized protocol. ${ }^{64}$ This includes stopping mechanical ventilation, inotropes and extubating the patient, but starting the infusion of opioids and sedatives to ensure that the patient is pain-free and not distressed.

\section{End of life care}

A standardized check list is available for withdrawal of life support, and this may improve quality of end-of-life care in the ICU. ${ }^{65}$ Although the need of the patient is the primary focus of the health care staff, growing consensus that a family-centered approach is particularly important in end-of-life care now emerges. ${ }^{53}$ Families of the dying need to be kept informed about what to expect during the dying process. Close observation of the dying process is also important from the perspective of measurement of ischemic injury; the functional warm ischemia time begins when the patient's systolic arterial pressure decreases below $50 \mathrm{mmHg}$, the arterial oxygen saturation decreases below $70 \%$, or both and which ends with cold perfusion. ${ }^{42}$

\section{Determination of death}

The intensive care physician determines death, based on cardiorespiratory criteria. Although circulatory criteria are the most commonly used and accepted criteria for determination of death, with the introduction of DCD programmes, and reported autoresuscitation (spontaneous return of circulation after circulatory arrest) much controversy surrounds the precise time that needs to elapse after the onset of circulatory arrest before death can be declared. ${ }^{66,67}$ Contrast to the criteria for brain death, $^{68}$ which are generally well defined and accepted resulting in clear protocols, clearly defined uniform criteria for determination of circulatory death are lacking. Variation consequently exists in available protocols. ${ }^{47,69-71}$

A DCD program inevitably includes a certain number of potential donors who do not die within the defined established period. From the perspective of organ donation and 
respecting the patient's and relatives wish regarding organ donation it is desirable to minimize this number. This is also important considering the substantial necessary logistic preparations for controlled DCD including a surgical retrieval team and operating theater which are on standby after treatment has been withdrawn.

After determination of death, the donor is transported to the OR, where the organ preservation starts and organ retrieval executed.

\section{Organ preservation}

Organs from DCD donors are subjected to a period of warm ischemia, from circulatory arrest until organ preservation and it is important to reduce this time period to a minimum. During the period of warm ischemia, cell death pathways are activated which may cause graft injury at reperfusion ${ }^{72}$ and which is associated with reduced graft survival. ${ }^{73,74}$ There are several methods to reduce warm ischemic injury in both controlled and uncontrolled DCD donors. Rapid cooling of the organs is an essential part of most methods. ${ }^{75-78}$ This can be done either by intravascular cooling with in situ perfusion via a double-balloon triple-lumen catheter for procurement of kidneys ${ }^{79,80}$ and which our group has generally used over the past decades, or by direct aortic cannulation of the aorta after rapid laparotomy. In situ preservation is a minimally invasive technique and can be performed fast in the emergency room or IC. It provides additional time to meet legal, medical and logistical requirements for organ procurement from uncontrolled DCD donors. For controlled donors, more time is available to arrange the logistical requirements for rapid laparotomy and direct aortic cannulation in the operating room, also other abdominal organs beside kidneys can be procured. ${ }^{81}$ Newer techniques to reduce warm ischemic injury are based on reestablishment of blood flow by extracorporeal circulation or by mechanical resuscitation, which are mainly performed in France and Spain in uncontrolled DCD donors. ${ }^{82-88}$ 


\section{Aims of the thesis}

The aim of the studies presented in this thesis is to increase scientific insight into critical aspects of the processes involved in organ donation after circulatory death, and potentially contribute to its optimization. Therefore the following aspects were specifically studied:

- The impact of the context and moment of death on the consent rate for donation

- The way death is determined after circulatory arrest by intensive care physicians and the prediction of time of death after withdrawal of treatment

- The available preservation methods for DCD kidneys

- The performance of donation after circulatory death within Europe and the ethical, legal and psychosocial aspects during the different phases of the process of both controlled and uncontrolled DCD

- The satisfaction of families of patients who died in the ICU; those who became donors compared to those who did not donate after death

\section{Outline of the thesis}

In Chapter 2, the consent rates of families of donors who died unexpectedly and donors in whom death was expected in the Maastricht University Medical Center, the Netherlands were compared, using retrospective data.

In Chapter 3 a prospective multicentre study to identify DCD donor characteristics that affect the interval between withdrawal of life sustaining treatment and circulatory death was performed.

The practise of determination of death after circulatory arrest by Dutch intensive care physicians was studied in Chapter 4. The aim of the study was to describe current practise, next to identify the policies and guidelines, which are available to physicians, to determine the perceived need for standardization of practise and to determine the reported occurrence of autoresuscitation after circulatory arrest.

In Chapter 5 and Chapter 6, the focus is on preservation methods of DCD kidneys;

in Chapter 5 two preservation methods were compared in a retrospective cohort study: in situ preservation with a double-balloon triple-lumen catheter and direct cannulation of the aorta after rapid laparotomy. In Chapter 6 the techniques currently used to preserve kidneys from donors after circulatory death were reviewed.

The process of withdrawal of life support in Intensive care patients is different if a donation procedure follows after death, because the preparation for organ donation 
takes time and neccecitates tests to assess organ quality. The impact of organ donation on the satisfaction of the family is therefore studied in Chapter 8.

In many European countries, donation after circulatory death (DCD) has become an accepted strategy to reduce the shortage of organs for transplantation. The use and number of DCD donors varies between countries. In Chapter 7 the available protocols for DCD in Europe are evaluated, as in Chapter 9 the ethical, legal and psychosocial aspects during the different phases of the process of both controlled and uncontrolled DCD from a European perspective are provided. 


\section{References}

1. Wolfe RA, Ashby VB, Milford EL, Ojo AO, Ettenger RE, Agodoa LY, Held PJ, Port FK. Comparison of mortality in all patients on dialysis, patients on dialysis awaiting transplantation, and recipients of a first cadaveric transplant. N Engl J Med 1999;341:1725-30.

2. Eurotransplant. Annual Report 2011/Eurotransplant International Foundation Leiden www.eurotransplant.org. 2012.

3. Terasaki PI, Cecka JM, Gjertson DW, Takemoto S. High survival rates of kidney transplants from spousal and living unrelated donors. N Engl J Med 1995;333:333-6.

4. Roodnat JI, Kal-van Gestel JA, Zuidema W, van Noord MA, van de Wetering J, IJzermans JN, Weimar W. Succesful expansion of the living donor pool by alternative living donation programs. Am J Transplant 2009;9:2150-6.

5. Merion RM, Ashby VB, Wolfe RA, Distant DA, Hulbert-Shearon TE, Metzger RA, Ojo AO, Port FK. Decreased donor characteristics and the survival benefit of kidney transplantation. JAMA 2005;294: 2726-33.

6. Daemen JW, Oomen AP, Kelders WP, Kootstra G. The potential pool of non-heart-beating kidney donors. Clin Transplant 1997;11:149-54.

7. Daemen JH, de Wit RJ, Bronkhorst MW, Yin M, Heineman E, Kootstra G. Non-heart-beating donor program contributes 40\% of kidneys for transplantation. Transplant Proc 1996;28:105-6.

8. Terasaki P, Cho YW, Cecka JM. Strategy for eliminating the kidney shortage. Clin Transpl 1997:265-7.

9. Wijnen RM, Booster MH, Stubenitsky BM, de Boer J, Heineman E, Kootstra G. Outcome of transplantation of non-heart-beating donor kidneys. Lancet 1995;345:1067-70.

10. Nicholson ML, Metcalfe MS, White SA, Waller JR, Doughman TM, Horsburgh T, Feehally J, Carr SJ, Veitch PS. A comparison of the results of renal transplantation fron non-heart-beating donation, conventional cadaveric, and living donors. Kidney Int 2000;58:2585-91.

11. Merrill JP, Murray JE, Harrison JH, Guild WR. Successful homotransplantation of the human kidney between identical twins. J Am Med Assoc 1956;160:277-82.

12. Merrill JP, Murray JE, Takacs FJ, Hager EB, Wilson RE, Dammin GJ. Successful transplantation of kidney from a human cadaver. JAMA 1963;185:347-53.

13. Murray JE, Gleason R, Bartholomay A. Human Kidney Transplant Conference. Transplantation 1964; 2:147-55.

14. Belzer FO, Ashby BS, Gulyassy PF, Powell M. Successful seventeen-hour preservation and transplantation of human-cadaver kidney. N Engl J Med 1968;278:608-10.

15. A Definition of Irreversible Coma: Report of the Ad Hoc Committee of the Harvard Medical School to Examine the Definition of Brain Death JAMA 1968;205:337-40.

16. Rosenthal JT, Shaw BW, Jr., Hardesty RL, Griffith BP, Starzl TE, Hakala TR. Principles of multiple organ procurement from cadaver donors. Ann Surg 1983;198:617-21.

17. Rosenthal JT, Hakala TR, Iwatsuki S, Shaw BW, Jr., Starzl TE. Cadaveric renal transplantation under cyclosporine-steroid therapy. Surg Gynecol Obstet 1983;157:309-15.

18. Spital A. The shortage of organs for transplantation. Where do we go from here? N Engl J Med 1991; 325:1243-6.

19. Donaldson RA, Douglas JF, Kennedy JA, Loughridge WG, McGeown MG. Non-heart beating organ donors. Old technique should be renewed. BMJ 1994;308:1104.

20. Kootstra G, Wijnen R, van Hooff JP, van der Linden CJ. Twenty percent more kidneys through a non-heart beating program. Transpl Proc 1991;23:910-1.

21. Weber M, Dindo D, Demartines N, Ambuhl PM, Clavien PA. Kidney transplantation from donors without a heartbeat. N Engl J Med 2002;347:248-55.

22. Cho YW TP, Cecka JM, Gjertson DW. Transplantation of kidneys from donors whose hearts have stopped beating. N Engl J Med 1998;338:221-5.

23. Cooper JT, Chin LT, Krieger NR, Fernandez LA, Foley DP, Becker YT, Odorico JS, Knechtle SJ, Kalayoglu M, Sollinger HW, D'Alessandro AM. Donation after cardiac death: the university of wisconsin experience with renal transplantation. Am J Transplant 2004;4:1490-4. 
24. Gok MA, Buckley PE, Shenton BK, Balupuri S, El-Sheikh MA, Robertson H, Soomro N, Jaques BC, Manas DM, Talbot D. Long-term renal function in kidneys from non-heart-beating donors: A single -center experience. Transplantation. 2002;74:664-9.

25. Barlow AD MM, Johari Y, Elwell R, Veitch PS, Nicholson ML. Case-matched comparison of long-term results of non-heart beating and heart-beating donor renal transplants. Br J Surg 2009;96:685-91.

26. Snoeijs MG, Winkens B, Heemskerk MB, Hoitsma AJ, Christiaans MH, Buurman WA, van Heurn LW. Kidney transplantation from donors after cardiac death: A 25-year experience. Transplantation 2010;90: 1106-12.

27. Sanchez-Fructuoso Al. Kidney transplantation from non-heart-beating donors. Transplant Proc 2007;39: 2065-7.

28. Dubbeld J, Hoekstra H, Farid W, Ringers J, Porte RJ, Metselaar HJ, Baranski AG, Kazemier G, van den Berg $A P$, van Hoek B. Similar liver transplantation survival with selected cardiac death donors and brain death donors. Br J Surg 2010;97:744-53.

29. Erasmus ME, Verschuuren EA, Nijkamp DM, Vermeyden JW, van der Bij W. Lung transplantation from nonheparinized category III non-heart-beating donors. A single-centre report. Transplantation 2010;89: 452-7.

30. Kompanje EJ, de Groot YJ, Bakker J. Is organ donation from brain dead donors reaching an inescapable and desirable nadir? Transplantation 2011;91:1177-80.

31. Dutch Transplant Foundation. Annual report 2010. http://www.transplantatiestichting.nl/winkel/ntsjaarverslag-2010.

32. Kootstra G, Daemen JH, Oomen AP. Categories of non-heart-beating donors. Transplant Proc 1995;27: 2893-4.

33. Fieux F, Losser MR, Bourgeois E, Bonnet F, Marie O, Gaudez F, Abboud I, Donay JL, Roussin F, Mourey F, Adnet F, Jacob L. Kidney retrieval after sudden out of hospital refractory cardiac arrest: a cohort of uncontrolled non heart beating donors. Crit Care 2009;13:R141.

34. Morrissey PE, Monaco AP. Doantion after circulatory death: current practices, ongoing challenges, and potential improvements. Transplantation. 2014;97:258-64.

35. Dominguez-Gil B, Haase-Kromwijk B, Van Leiden H, Neuberger J, Coene L, Morel P, et al. Current situation of donation after circulatory death in European countries. Transpl Int 2011;24:676-86.

36. Aulisio MP, Devita M, Luebke D. Taking values seriously: Ethical challenges in organ donation and transplantation for critical care professionals. Crit Care Med 2007;35(2 Suppl):S95-101.

37. Ethics Committee, American College of Critical Care Medicine; Society of Critical Care Medicine. Recommendations for nonheartbeating organ donation. A position paper by the Ethics Committee, American College of Critical Care Medicine, Society of Critical Care Medicine. Crit Care Med 2001; 29:1826-31.

38. Youngner SJ, Arnold RM. Ethical, psychosocial, and public policy implications of procuring organs from non-heart-beating cadaver donors. JAMA 1993;269:2769-74.

39. Robertson JA. The dead donor rule. Hastings Cent Rep 1999;29:6-14.

40. Truog RD, Miller FG. The dead donor rule and organ transplantation. N Engl J Med 2008;359:674-5.

41. Gardiner D, Shemie S, Manara A, Opdam H. International perspective on the diagnosis of death. $\mathrm{Br}$ Anaesth 2012;108 Suppl 1:i14-28.

42. Manara AR, Murphy PG, O'Callaghan G. Donation after circulatory death. Br J Anaesth 2012;108 Suppl 1: i108-i21.

43. Rady MY, Verheijde JL, McGregor J. Organ donation after circulatory death: the forgotten donor? Crit Care 2006;10:166.

44. RM. V. Donating hearts after cardiac arrest-reversing the irreversible. N Engl J Med 2008;359:672-3.

45. Bernat JL, D'Alessandro AM, Port FK, Bleck TP, Heard SO, Medina J, et al. Report of a National Conference on Donation after cardiac death. Am J Transplant 2006;6:281-91.

46. Bernat JL. How the distinction between "irreversible" and "permanent" illuminates circulatoryrespiratory death determination. J Med Philos 2010;35:242-55.

47. A position paper by the Ethics Committee, American College of Critical Care Medicine, Society of Critical Care Medicine. Crit Care Med 2001;29:1826-31.

48. Ozark S DM. Non-heartbeating organ donation: ethical controversies and medical considerations. Int Anesthesiol Clin 2001;39:103-16. 
49. Johnson SR, Pavlakis M, Khwaja K, Karp SJ, Curry M, Curran CC, Monaco AP, Hanto DW. Intensive care unit extubation does not preclude extrarenal organ recovery from donors after cardiac death. Transplantation. 2005;80:1244-50.

50. Ridley S, Bonner S, Bray K, Falvey S, Mackay J, Manara A. UK guidance for non-heart-beating donation. Br J Anaesth 2005;95:592-5.

51. Wunsch H, Harrison DA, Harvey S, Rowan K. End of life decisions: a cohort study of the withdrawal of all active treatment in intensive care units in the United Kingdom. Intensive Care Med. 2005;31:823-31.

52. Truog RD, Cist AF, Brackett SE, Burns JP, Curley MA, Danis M, DeVita MA, Rosenbaum SH, Rothenberg DM, Sprung CL, Webb SA, Wlody GS, Hurford WE. Recommendations for end-of-life care in the intensive care unit: The Ethics Committee of the Society of Critical Care Medicine. Crit Care Med 2001;29:2332-48.

53. Truog RD, Campbell ML, Curtis JR, Haas CE, Luce JM, Rubenfeld GD, Rushton CH, Kaufman DC; American Academy of Critical Care Medicine. Recommendations for end-of-life care in the intensive care unit: a consensus statement by the American College of Critical Care Medicine. Crit Care Med 2008;36:953-63.

54. Rady MY, Verheijde JL, McGregor J. Organ procurement after cardiocirculatory death: a critical analysis. J Intensive Care Med 2008;23:303-12.

55. Kootstra G. Statement on non-heart-beating donor programs. Transplant Proc 1995;27:2965.

56. Gevers S JA, Friele R. Consent systems for post mortem organ donation in Europe. Eur J Health Law 2004;11:175-86.

57. Bos MA. Ethical and legal issues in non-heart-beating organ donation. Transplantation 2005;79:1143-7.

58. Rudge CJ. Organ donation in the United KIngdom. Kidney Int 2006;70:2045-6.

59. Jansen NE, van Leiden HA, Haase-Kromwijk BJ, Hoitsma AJ. Organ donation performance in the Netherlands 2005-08; medical record review in 64 hospitals. Nephrol Dial Transplant 2010;25:1992-7.

60. Kompanje EJ BJ, Slieker FJ, ljzermans JN, Maas Al. Organ donations and unused potential donations in traumatic brain injury, subarchnoid haemorrhage and intracerebral heamorrhage. Int Care Med 2006; 32:217-22.

61. Domínguez-Gil B, Delmonico FL, Shaheen FA, Matesanz R, O'Connor K, Minina M, Muller E, Young K, Manyalich M, Chapman J, Kirste G, Al-Mousawi M, Coene L, García VD, Gautier S, Hasegawa T, Jha V, Kwek TK, Chen ZK, Loty B, Costa AN, Nathan HM, Ploeg R, Reznik O, Rosendale JD, Tibell A, Tsoulfas G, Vathsala A, Noël L. The critical pathway for deceased donation: reportable uniformity in the approach to deceased donation. Transpl Int 2011;24:373-8.

62. Siminoff LA, Gordon N, Hewlett J, Arnold RM. Factors influencing families' consent for donation of solid organs for transplantation. JAMA 2001;286:71-7.

63. Simpkin AL, Robertson LC, Barber VS, Young JD. Modifiable factors influencing relatives' decision to offer organ donation: systematic review. BMJ 2009;338:b991.

64. Orzak S DM. Non-heartbeating organ donation:ethical controversies and medical considerations. Int Anesthesiol Clin 2001;39:103-16.

65. Treece PD, Engelberg RA, Crowley L, Chan JD, Rubenfeld GD, Steinberg KP, Curtis JR. Evaluation of a standardized order form for the withdrawal of life support in the intensive care unit. Crit Care Med. 2004;32:1141-8.

66. Joffe AR. The ethics of donation and transplantation: are definitions of death being distorted for organ transplantation? Philos Ethics Humanit Med 2007;2:28.

67. Bernat JL, Capron AM, Bleck TP, Blosser S, Bratton SL, Childress JF, et al. The circulatory-respiratory determination of death in organ donation. Crit Care Med 2010;38:963-70.

68. Wijdicks EF. Brain death worldwide: accepted fact but no global consensus in diagnostic criteria. Neurology 2002;58:20-5.

69. Shemie SD, Baker AJ, Knoll G, Wall W, Rocker G, Howes D, Davidson J, Pagliarello J, Chambers-Evans J, Cockfield S, Farrell C, Glannon W, Gourlay W, Grant D, Langevin S, Wheelock B, Young K, Dossetor J. National recommendations for donation after cardiocirculatory death in Canada: Donation after cardiocirculatory death in Canada. CMAJ 2006;175:S1.

70. Dhanani S, Hornby L, Ward R, Shemie S. Variability in the determination of death after cardiac arrest: a review of guidelines and statements. J Intensive Care Med 2012;27:238-52.

71. Academy of Medical Royal Colleges: A code of practise for theDiagnosis and Confirmation of Death. London:PPG Design and ProntLtd;2008. http://www.aomrc.org.uk/publications/reports-guidance.html 
72. Wolfs TG, de Vries B, Walter SJ, Peutz-Kootstra CJ, van Heurn LW, Oosterhof GO, Buurman WA. Apoptotic cell death is initiated during normothermic ischemia in human kidneys. Am J Transplant 2005;5:68-75.

73. Shiroki R, Hoshinaga K, Higuchi T, Tsukiashi Y, Kubota Y, Maruyama T, Izumitani M, Horiba M, Naide Y, Kanno T. Prolonged warm ischemia affects long-term prognosis of kidney transplant allografts from nonheart-beating donors. Transplant Proc 1998;30:111-3.

74. Nishikido M, Noguchi M, Koga S, Kanetake H, Matsuya F, Hayashi M, Hori T, Shindo K. Kidney transplantation from nonheartbeating donors: analysis of organ procurement and outcome. Transplant Proc 2004;36:1888-90.

75. Garcia-Rinaldi R, Lefrak EA, Defore WW, Feldman L, Noon GP, Jachimczyk JA, DeBakey ME. In situ preservation of cadaver kidneys for transplantation: laboratory observations and clinical application. Ann Surg 1975;182:576-84

76. Anaise D, Yland MJ, Ishimaru M, Shabtai M, Hurley S, Waltzer WC, Rapaport FT. Organ procurement from non heart-beating cadaver donors. Transplant Proc 1989;21:1211-4.

77. Lloveras J, Puig JM, Cerdà M, Rico N, Mir M, Rovira A, Munné A, Quintana S, Aubia J, Masramon J. Optimizing of in situ renal perfusion of non-heart-beating donors: four-lumen catheter developed for continious perfsion pressure determination. Transplant Proc 1993;25:3169-70.

78. Anaise D, Smith R, Ishimaru M, Waltzer WC, Shabtai M, Hurley S, Rapaport FT. An approach to organ salvage from non-heartbeating cadaver donors under existing legal and ethical requirements for transplantation Transplantation 1990;49:290-4.

79. Booster MH, Wijnen RM, Vroemen JP, van Hooff JP, Kootstra G. In situ preservation of kidneys from nonheart-beating donors--a proposal for a standardized protocol. Transplantation 1993;56:613-7.

80. Snoeijs MG, Dekkers AJ, Buurman WA, van den Akker L, Welten RJ, Schurink GW, van Heurn LW. In situ preservation of kidneys from donors after cardiac death: results and complications. Ann Surg 2007;246: 844-52.

81. Hoogland ER, Snoeijs MG, van Heurn LW. DCD kidney transplantation: results and measures to improve outcome. Curr Opin Organ Transplant 2010;15:177-82.

82. Valero R, Cabrer C, Oppenheimer F, Trias E, Sánchez-Ibáñez J, De Cabo FM, Navarro A, Paredes D, Alcaraz A, Gutiérrez R, Manyalich M. Normothermic recirculation reduces primary graft dysfunction of kidneys obtained from non-heart-beating donors. Transpl Int 2000;13:303-10.

83. Morozumi J, Sakurai E, Matsuno N, Ito M, Yokoyama T, Ohtaka Y, Taguchi H, Arai T, Kumasaka K, Ohta S. Successful kidney transplantation from donation after cardiac death using a load-distributing-band chest compression device during long warm ischemic time. Resuscitation 2009;80:278-80.

84. Gravel MT, Arenas JD, Chenault R 2nd, Magee JC, Rudich S, Maraschio M, DebRoy M, Miller W, Punch JD. Kidney transplantation from organ donors following cardiopulmonary death using extracorporeal membrane oxygenation support. Ann Transplant 2004;9:57-8.

85. Magliocca JF, Magee JC, Rowe SA, Gravel MT, Chenault RH 2nd, Merion RM, Punch JD, Bartlett RH, Hemmila MR. Extracorporeal support for organ donation after cardiac death effectively expands the donor pool. J Trauma 2005;58:1095-101; discussion 101-2.

86. Rudich SM, Arenas JD, Magee JC, Gravel MT, Chenault RH 2nd, Kayler LK, Merion RM, Punch JD. Extracorporeal support of the non-heart-beating organ donor. Transplantation 2002;73:158-9.

87. Nunez JR DRF, Lopez E, Moreno MA, Soria A, Parra D. Non-heart-beating donors: an excellent choice to increase the donor pool. Transplant Proc 2005;37:3651-4.

88. Fieux F, Losser MR, Bourgeois E, Bonnet F, Marie O, Gaudez F, Abboud I, Donay JL, Roussin F, Mourey F, Adnet F, Jacob L. Kidney retrieval after sudden out of hospital refractory cardiac arrest: a cohort of uncontrolled non heart beating donors. Crit Care 2009;13:R141. 


\section{Chapter}

\section{Higher organ donation consent rates by relatives of potential uncontrolled donors versus potential controlled donors after death}

Jentina Wind, Walther N.K.A van Mook, Monique E.C. Willems, L.W. Ernest van Heurn Nephrology Dialysis Transplant 2012;27:4219-23 


\section{Abstract}

\section{Background}

Refusal to consent to organ donation is an important cause of the persisting gap between the number of potential organ donors and effectuated donors. In the Netherlands, organ donors include both uncontrolled donors: donors who die unexpectedly after cardiac death (DCD), after failed resuscitation and donors in whom death can be expected: donors after brain death (DBD) and controlled DCD donors: those who die after withdrawal of treatment. Different donor type implies a different setting in which relatives are requested to consent to organ donation. It is unknown whether the setting influences the eventual decision for donation or not. Therefore, we compared the consent rate in potential donors who died unexpectedly (UD group) and in whom death was expected (ED group).

\section{Methods}

A total of 523 potential organ donors between 2003 and 2011 in the 715-bed Maastricht University Medical Centre, the Netherlands were included. Both the patients' registration in national Donor Register (DR) and the relatives' refusal rate in the two groups were retrospectively assessed using data from the donation application database.

\section{Results}

There were 109 unexpected and 414 expected potential donors. The potential donors in the UD group were younger (mean age 52 versus 55 years, $P=0.032$ ) and more often male (68\% versus $52 \%, P=0.003)$. There were no significant differences in registration in the DR between the groups. The relatives' consent rate in non-registered potential donors, or those who mandated the relatives for that decision, was higher in the UD group ( $53 \%$ versus $29 \%, P<0.001$ ).

\section{Conclusions}

Less than $50 \%$ of the potential donors were registered in the national DR. Therefore, the relatives have an important role in the choice for organ donation. The relatives of potential donors who died unexpectedly consented more often to donation than those in whom death was expected. 


\section{Introduction}

Transplantation is the therapy of choice for many patients with end stage organ renal failure. ${ }^{1}$ However, the number of patients on the waiting list for transplantation exceeds the number of available organs by far. One of the factors limiting the number of organ donors is the refusal of relatives for donation. Since 1998, the national donor register (DR) in the Netherlands was based on the opting-in system. ${ }^{2,3}$ Since then, Dutch citizens older than 12 years have the opportunity to register and document their choice for organ and tissue donation. All citizens reaching the age of 18 years receive a donor form to encourage them to register. The DR provides four options: (1) permission for organ and tissue donation (with a possibility to exclude specific organs or tissues), (2) objection to organ and tissue donation, (3) leave the decision to the relatives and (4) leave the decision to a specific person. According to the 1998 Dutch Organ and Tissue Donation Act, it is mandatory for treating physicians to consult the DR for all deceased patients aged over 12 years who are potential candidates for organ /or tissue donation. The DR can be consulted when death is expected within $12 \mathrm{~h}$ and must be consulted before organ /or tissue donation is discussed with the relatives. Approximately $40 \%$ of the Dutch population older than 12 years is registered in the DR. ${ }^{4}$ Because of this low registration rate, the ultimate donation decision is frequently reposed with the relatives.

Donation after cardiac death (DCD) has been popularized over the past decades in the Netherlands. It has the potential to increase the donor pool 2.5-4 times, thereby substantially reducing the waiting lists for transplantation. ${ }^{5,6}$ In the Maastricht University Medical Centre (MUMC), 60\% of deceased donors are DCD donors, including both controlled and uncontrolled donors. ${ }^{7}$ Uncontrolled donation, which is donation after failed resuscitation is a complicated and demanding procedure with a higher chance of failure. The setting is different from the setting in potential controlled DCD, Maastricht category 3 donors who die after discontinuation of treatment, when further treatment is considered futile. In this group, the moment of withdrawal of treatment can be chosen within certain limits and organ donation can be extensively discussed with the relatives. Also, with relatives of potential brain death donors, patients with signs of brain death and in whom brain death is expected, there is time to explain and discuss donation. In contrast, in potential uncontrolled DCD, Maastricht category 2 donors the decision about organ donation has to be made in a much shorter time frame. Since these differences in setting may affect the relatives' consent rate, we studied whether the consent rate for donation in uncontrolled donors was lower than the already low general consent rate of $\sim 30 \%-40 \%$ in the Netherlands. ${ }^{8}$ This finding would necessitate reevaluation of the uncontrolled DCD programme. 


\section{Materials and methods}

The donation forms, which prospectively register all deceased patients, were retrieved from the Donation Application database for all patients who had died in the MUMC between 1 January 2003 and 1 January 2011. All potential organ donors, as identified by the treating physician, were analysed. Two different groups were compared, based on the moment of death and the time available to discuss donation with the relatives: potential donors with expected death (ED) and unexpected death (UD). The group in which death was expected (ED group) includes potential Maastricht category 3 DCD donors and potential brain dead donors, patients in whom brain death was determined after the consent for donation of the relatives. The patients in the ED group were admitted to the intensive care unit (ICU), coronary care unit, paediatric ICU, or neurological ward. Unexpected potential donors (UD group), included DCD category 2 potential donors, patients who died after failed resuscitation, almost without exception in the Emergency Room. After the declaration of death by the treating physician and a legally mandated 'no touch' period of $5 \mathrm{~min}$, organ preservation with a double balloon triple lumen catheter was started. Simultaneously, the treating physician discussed organ donation with the relatives. In patients in the UD group, death and organ donation were thus both discussed simultaneously in a single conversation. If the relatives objected to donation, preservation measures were discontinued. Dutch legislation enables minor preservation measures after death and after consultation of the DR, but before consent of the relatives is obtained.

In the ED group, the consent for organ donation was also requested by the treating physician. However, in this group, the decision to withdraw treatment or to assess brain death was discussed with the relatives, prior to a separate discussion about organ donation.

We compared the percentage of approached relatives and the consent rates in potential donors in the ED group and UD group, respectively.

Continuous variables were presented as mean \pm standard deviation (SD) if normally distributed, and as median and interquartile range otherwise. Categorical variables were presented as percentages. Baseline donor characteristics, outcome of the Donation Register and the recipient were compared between donor types (UD group versus ED group) with the independent-samples $t$-tests for normally distributed continuous variables, and with $X^{2}$ tests for categorical variables.

Factors associated with objection were analysed with univariable and multivariable logistic regression analysis. A $P$-value $\leq 0.05$ was considered statistically significant. SPSS version 16.0 for windows was used for the analysis (SPSS Inc., Chicago, IL, USA). 


\section{Results}

There were 109 potential donors in the UD group and 414 potential donors in the ED group (Figure 2.1). In 14\% of the UD group and in 15\% of the ED group, the national DR was not consulted $(P=0.813)$. The reason for not consulting the DR was reported in 72 of 78 cases, and included a non-Dutch nationality in eight and age under 12 years in five cases. Other reasons included the known wish of the patient according to the relatives $(n=25)$, and legal reasons $(n=14)$, such as not natural cause of death. Eleven relatives refused organ donation before the DR was consulted.

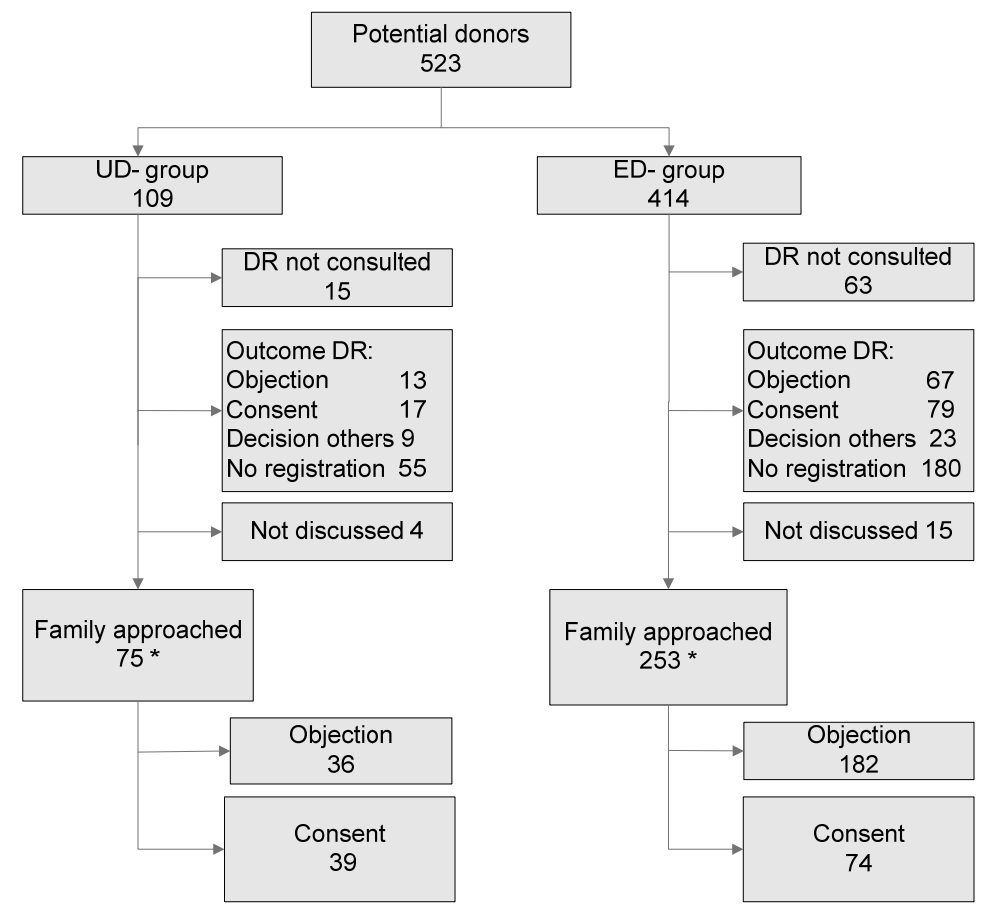

Figure 2.1 Overview of the potential donors to family consent 2003-11. *Family approached excluded objection and consent in the DR.

The potential donor was registered in the DR in $36 \%$ of the UD group (39/109) and in $41 \%$ of the ED group (169/414) (Table 2.1). The registration decision was not significantly different between the two groups; see Table 2.1. 
Table 2.1 Potential donors 'characteristics, outcome of the DR and donation request.

\begin{tabular}{|c|c|c|c|}
\hline Variable & $\begin{array}{l}\text { UD group } \\
(n=109)\end{array}$ & $\begin{array}{l}\text { ED group } \\
(n=414)\end{array}$ & $P$-value \\
\hline Donor age (mean years, $(\mathrm{sd})$ ) & $52(15)$ & $55(15)$ & 0.032 \\
\hline Donor gender (male, \%) & $74(68 \%)$ & $215(52 \%)$ & 0.003 \\
\hline Donation Register consulted & $94(86 \%)$ & $350(85 \%)$ & 0.813 \\
\hline Outcome of consultation of the Donation Register: & & & ns \\
\hline Not registered & $55(58 \%)$ & $180(51 \%)$ & ns \\
\hline Consent & $17(18 \%)$ & $79(23 \%)$ & ns \\
\hline Objection & $13(14 \%)$ & $67(19 \%)$ & ns \\
\hline Decision relatives/specific person & $9(10 \%)$ & $23(7 \%)$ & ns \\
\hline Not consulted & $15(14 \%)$ & $63(15 \%)$ & ns \\
\hline Unknown & & 1 & ns \\
\hline Outcome of donation request*: Consent & $39 / 75(52 \%)$ & $74 / 253(29 \%)$ & $<0.001$ \\
\hline
\end{tabular}

UD group, unexpected death group; ED group, expected death group. In 4 cases in the UD group and 15 cases in the ED group, the donation was not discussed. * Request excluded registration with consent in the DR.

The mean age of patients was lower in the UD group, 52 versus 55 years in the ED group $(P=0.032)$ and there were more male patients in this group, 68\% versus $52 \%(P=0.03)$ (Table 2.1). The final consent rate (thus including both consent in the DR and consent given by the relatives), was 61\% (56/92) in the UD group and $45 \%$ (150/332) in the ED group $(P=0.007)$, which was fully explained by the higher consent percentage of the relatives of donors who were not registered in the DR. After excluding potential donors with 'consent' registered in the DR, the consent rate was 52\% (39/75) UD group and 29\% $(74 / 253)$ in the ED group $(P<0.001)$. Reasons for objection could be categorized as known wish of the deceased, emotional reasons, and religious/cultural/language reasons (Table 2.2). In 35\% of the UD group and $21 \%$ of the ED group, reasons for objection were not fully clarified. In the univariable and multivariable regression analyses, donation in a controlled setting (ED group) and older donor age were independent risk factors for objection to donation (Table 2.3).

Table 2.2 Reasons for relatives' objection to organ donation.

\begin{tabular}{|c|c|c|}
\hline Reason & $\begin{array}{l}\text { UD group } \\
(n=142)\end{array}$ & $\begin{array}{l}\text { ED group } \\
(n=27)\end{array}$ \\
\hline No consent relatives ${ }^{a}$ & $19(44 \%)$ & $125(68 \%)$ \\
\hline Religion/language/culture & $2(6 \%)$ & $2(1 \%)$ \\
\hline Known wish deceased & $4(12 \%)$ & $10(5 \%)$ \\
\hline Missing & $12(35 \%)$ & $39(21 \%)$ \\
\hline
\end{tabular}

${ }^{a}$ Objection of the relatives despite patient consent in registry; $3 x$ in the ED group. 
Table 2.3 Univariable and multivariable regression analyses of factors associated with objection to donation.

\begin{tabular}{|c|c|c|c|c|}
\hline & \multicolumn{2}{|c|}{ Univariable analysis } & \multicolumn{2}{|c|}{ Multivariable analysis } \\
\hline & OR $(95 \% \mathrm{Cl})$ & P-value & OR $(95 \% \mathrm{Cl})$ & $P$-value \\
\hline Donor age & $1.020(1.005-1.035)$ & 0.011 & $1.018(1.003-1.033)$ & 0.021 \\
\hline Donor gender ${ }^{a}$ & $1.107(0.700-1.749)$ & 0.664 & & \\
\hline Donor group ${ }^{b}$ & $2.664(1.572-4.515)$ & $<0.001$ & $2.562(1.505-4.362)$ & 0.001 \\
\hline
\end{tabular}

${ }^{a}$ Reference category are females; ${ }^{b}$ Reference category is the UD group.

\section{Discussion}

This study shows that the consent rate for organ donation in potential organ donors after UD is higher than in potential organ donors in whom death is expected. These findings are in contrast to the expectation that the sudden notification of death and the accompanying immediate request for donation in the same initial meeting with the relatives would result in a higher refusal rate. Our results reveal the opposite; the consent rate was higher in the UD group, while there were no differences between the two groups in the registration outcome of the DR.

There are several possible explanations for the different consent rate for donation after UD and ED. First, the request for donation in the UD group is made after the patient has already died. This is a clear situation for the relatives, precluding doubts that donation may influence either the moment of death or end-of- life care. Furthermore, in the uncontrolled situation the number of relatives present is often smaller when donation is discussed. A larger group of relatives may be associated with more discussion, with a decreasing chance of permission for donation being granted. Finally, different from potential donors in the UD group who die in the emergency department, most potential donors in whom death is expected have been admitted to the ICU. The satisfaction of the perceived quality of care may also have impact on the consent for donation; a negative perception of care is associated with a decrease in consent rate. ${ }^{9,10}$.

In the literature, patient and family characteristics as well as belief in the benefit of organ donation are known to be associated with the relatives' willingness to donate. ${ }^{10}$ Families of young, male, Caucasian patients are more likely to consent. Death due to trauma was also associated with consent. In our study, potential donors after UD were younger and more often male. Older age was associated with objection to donation. Understanding and accepting the concept of brain death by relatives of a potential brain death donor increases the consent rate. ${ }^{9,11}$ Relatives who had prior knowledge of patients' wishes and a positive attitude towards organ donation are more likely to consent. ${ }^{12,13}$ Additional factors that positively correlate with consent for organ donation include the number of conversations, the topics discussed with relatives and the clarity 
with which the available information is presented. ${ }^{9,12}$ Relatives are more likely to consent when professionals mention that donation can help other people and less likely when discussing organ donation is perceived as 'merely' an obligation of the professional. ${ }^{9}$

Time and decoupling the notification of death or testing for brain death and the request for donation are important factors to consent. The consent rate improves when there is sufficient time for the relatives to make a decision. ${ }^{14,15}$ Another important contributory factor is the decoupling of the notification of death or testing for brain death and the request for donation. If the relatives considered the timing of the request as poorly chosen, the consent rate is lower. ${ }^{15}$ This is not supported by the results of our study. In the UD group, with a shorter period of time to take the donation decision and one conversation in which both death and donation were addressed, the consent rate was higher.

The approach and expertise of the person making the request is an important factor for obtaining consent. The optimal situation is when medical staff and the organ procurement organization coordinator approach the relatives together. ${ }^{16,17}$ This is not part of our routine practice in which the treating physician discusses the organ donation with the relatives. However, most of the physicians requesting organ donation in both UD group and the ED group received communication training, which included the request for organ donation. Physicians who requested donation in the ED group were more experienced as a smaller number of intensivists were possible engaged in a larger number of conversations. A recent study showed that guiding families by 'trained donation practitioners' during ICU admittance increased the consent rate with $20 \%{ }^{18}$

The DR was not consulted in almost $15 \%$ of the potential donors in both groups, although this is legally mandated in the Netherlands. Reasons mentioned for not consulting the DR included the known wish of the patient according to the relatives $(n=23)$, and refusal of the relatives despite the unknown outcome of the DR $(n=11)$. In the ED group, the relatives of three patients objected to donation despite consent in the DR. The decision of the deceased in the donor register is a will, which has to be respected. In the physicians' education regarding organ donation it should be underscored that the DR has to be consulted, before discussing organ donation with the relatives.

The overall family consent rate in our study was low; $49 \%$ of all families approached and $35 \%$ if potential donors with registered consent were excluded. Countries with an opting-out system have higher consent rates than countries with an opting- in system, but lack of a uniform way to compare the consent rates makes it difficult to compare countries. ${ }^{19}$ However, in Belgium and Spain donation rates have improved since an opting-out system has been implemented. 
There are some limitations to this study. First of all, it is unknown if the results of this single centre study can be generalized, although the differences between the setting of controlled and uncontrolled donation also exist in other hospitals. Furthermore, potential donors after brain death (DBD) and controlled DCD donors were combined in one group. Most studies that address the decision on organ donation 'only' include relatives of brain dead patients. In this study, the request for donation in both DBD and controlled DCD donors is made before brain death is confirmed with additional tests. The decision to discontinue treatment did not depend on the confirmation of brain death. Brain death was confirmed only if there was consent for organ donation. Therefore, separation of the ED group into DBD and controlled DCD donation would include an unacceptable bias in favour of DBD donors.

\section{Conclusion}

The consent for organ donation is higher after unexpected death in an uncontrolled setting, than in potential donors after expected death in a more controlled setting, despite the short period of time in which relatives of a potential uncontrolled donor have to take a decision about organ donation. 


\section{References}

1. Wolfe RA, Ashby VB, Milford EL, Ojo AO, Ettenger RE, Agodoa LY, Held PJ, Port FK. Comparison of mortality in all patients on dialysis, patients on dialysis awaiting transplantation, and recipients of a first cadaveric transplant. N Engl J Med 1999;341:1725-30.

2. Gevers S, Janssen A, Friele R. Consent systems for post mortem organ donation in Europe. Eur J Health Law 2004;11:175-86.

3. Coppen R, Friele RD, Marquet RL, Gevers SK. Opting-out systems: no guarantee for higher donation rates. Transpl Int 2005;18:1275-9.

4. van Leiden HA, Jansen NE, Haase-Kromwijk BJ, Hoitsma AJ. Higher refusal rates for organ donation among older potential donors in the Netherlands: impact of the donor register and relatives. Transplantation 2010;90:677-82.

5. Daemen JW, Oomen AP, Kelders WP, Kootstra G. The potential pool of non-heart-beating kidney donors. Clin Transplant 1997;11:149-54.

6. Terasaki PI, Cho YW, Cecka JM. Strategy for eliminating the kidney shortage. Clin Transpl. 1997:265-7.

7. Kootstra G, Daemen JH, Oomen AP. Categories of non-heart-beating donors. Transplant Proc 1995;27: 2893-4.

8. Jansen NE, van Leiden HA, Haase-Kromwijk BJ, Hoitsma AJ. Organ donation performance in the Netherlands 2005-08; medical record review in 64 hospitals. Nephrol Dial Transplant. 2010;25:1992-7.

9. Siminoff LA, Gordon N, Hewlett J, Arnold RM. Factors influencing families' consent for donation of solid organs for transplantation. JAMA 2001;286:71-7.

10. Simpkin AL, Robertson LC, Barber VS, Young JD. Modifiable factors influencing relatives' decision to offer organ donation: systematic review. BMJ 2009;338:b991.

11. DeJong W, Franz HG, Wolfe SM, Nathan H, Payne D, Reitsma W, Beasley C. Requesting organ donation: an interview study of donor and nondonor families. Am J Crit Care 1998;7:13-23.

12. Siminoff $\mathrm{LA}$, Lawrence $\mathrm{RH}$. Knowing patients' preferences about organ donation: does it make a difference? J Trauma 2002;53:754-60.

13. Siminoff L, Mercer MB, Graham G, Burant C. The reasons families donate organs for transplantation: implications for policy and practice. J Trauma 2007;62:969-78.

14. Niles PA, Mattice BJ. The timing factor in the consent process. J Transpl Coord 1996;6:84-7.

15. Rodrigue JR, Cornell DL, Howard RJ. Organ donation decision: comparison of donor and nondonor families. Am J Transplant 2006;6:190-8.

16. Evanisko MJ, Beasley CL, Brigham LE, Capossela C, Cosgrove GR, Light J, Mellor S, Poretsky A, McNamara P. Readiness of critical care physicians and nurses to handle requests for organ donation. Am J Crit Care 1998;7:4-12.

17. Gortmaker SL, Beasley CL, Sheehy E, Lucas BA, Brigham LE, Grenvik A, Patterson RH, Garrison N, McNamara P, Evanisko MJ. Improving the request process to increase family consent for organ donation. J Transpl Coord 1998;8:210-7.

18. Jansen NE, van Leiden HA, Haase-Kromwijk BJ, van der Meer NJ, Kruijff EV, van der Lely N, van Zon $H$, Meinders AJ, Mosselman M, Hoitsma AJ. Appointing 'trained donation practitioners' results in a higher family consent rate in the Netherlands: a multicenter study. Transpl Int 2011;24:1189-97.

19. Jansen NE, Haase-Kromwijk BJ, van Leiden HA, Weimar W, Hoitsma AJ. A plea for uniform European definitions for organ donor potential and family refusal rates. Transpl Int 2009;22:1064-72. 


\section{Chapter 3}

\section{Prediction of time of death after withdrawal of life sustaining treatment in potential donors after cardiac death}

J Wind, MGJ Snoeijs, CA Brugman, J Vervelde, J Zwaveling, WN van Mook, ELvan Heurn Critical Care Medicine 2012;40:766-769 


\section{Abstract}

\section{Objective}

Organ donation after cardiac death increases the number of donor organs. In controlled donation after cardiac death donors, the period between withdrawal of life-sustaining treatment and cardiac arrest is one of the parameters used to assess whether organs are suitable for transplantation. The objective of this study was to identify donation after cardiac death donor characteristics which affect the interval between withdrawal of life-sustaining treatment and cardiac death.

\section{Design}

Prospective multicentre study of observational data.

\section{Patients}

All potential donation after cardiac death donors in the Netherlands between May 2007 and June 2009 were identified.

\section{Measurements and main results}

Of the 242 potential donation after cardiac death donors, 211 entered analysis, $76 \%$ of them died within 60 minutes, and $83 \%$ died within 120 minutes after withdrawal of life-sustaining treatment. The median time to death was 20 minutes (range 1 minute to 3.8 days). Controlled mechanical ventilation, use of norepinephrine, absence of reflexes, neurologic deficit as cause of death, and absence of cardiovascular comorbidity were associated with death within 60 and 120 minutes. The use of analgesics, sedatives, or extubation did not significantly influence the moment of death. In the multivariable logistic regression analysis, controlled mechanical ventilation remained a risk factor for death within 60 minutes, and norepinephrine administration and absence of cardiovascular comorbidity remained risk factors for death within 120 minutes. The clinical judgement of the intensivist predicted death within 60 and 120 minutes with a sensitivity of $73 \%$ and $89 \%$, respectively, and a specificity of $56 \%$ and $25 \%$ respectively.

\section{Conclusion}

Despite the identification of risk factors for early death and the additional value of the clinical judgement by the intensivist, it is not possible to reliably identify potential donation after cardiac death donors who will die within 1 or 2 hours after life-sustaining treatment has been withdrawn. Consequently, a donation procedure should be initiated in every potential donor. 


\section{Introduction}

One way to expand the donor pool and decrease the persisting gap between patients waiting for an organ and the available organs, is by the use of organs from donation after cardiac death (DCD) donors for transplantation, also named non-heartbeating donors. ${ }^{1}$ In the Netherlands, DCD kidney transplantation has been popularized since 1981 and become well accepted. It has become an increasingly important source of donor organs for transplantation; in 2008, 41\% of the transplanted deceased donor kidneys in the Netherlands were from DCD donors. ${ }^{2}$

The vast majority of DCD donors are controlled donors, patients who die after withdrawal of life-sustaining treatment (WLST). Most potential controlled DCD donors are admitted to the intensive care unit (ICU), and usually suffer from irreversible neurologic injury. Once further medical intervention is considered unethical, an explicit decision to stop treatment is made by the treating intensivist, in close collaboration with other treating physicians and consented by the patients' relatives.

The period between WLST and death is one of the parameters used to decide whether donor organs are accepted for transplantation. The maximal interval depends on the DCD protocol and varies per organ (e.g. <60 minutes for liver, lung and pancreas donation, and $<120$ minutes for kidneys donation). These time intervals are used in all institutions in the Netherlands according to the National protocol and are based on transplantability of the donor organs.

If a patient does not die within this period of time, donation is abandoned and organs are not transplanted. This is associated with disappointment for the relatives and logistic and financial consequences, like the reservation of an operating theater and surgical staff. Therefore, there is increasing interest in the prediction of the interval between the WLST and death. Periods between withdrawal of treatment and death vary widely and range from minutes to hours. This time period is related to the degree of hemodynamic and respiratory support, and the patients' respiratory, neurologic, and circulatory condition. ${ }^{3-5}$ Available tools to predict the timing from WLST to death, including those from the University of Wisconsin and the United Network of Organ Sharing, have been based on limited number of potential donors or on a relatively small number of variables. ${ }^{6,7}$ Therefore, in a prospective study we aimed to identify patient and treatment characteristics that may accurately predict which potential DCD donors die within 60 or 120 minutes, in whom a donation procedure should be started.

\section{Materials and methods}

Between May 2007 and June 2009, all potential controlled DCD donors in the Netherlands were studied prospectively. Excluded from analysis were nonintubated 
patients and patients who were clinically brain dead but in whom relatives nevertheless specifically requested a DCD procedure. Patients with signs of brain death were evaluated according to the legally mandatory brain-death protocol, which includes clinical neurologic assessment, electroencephalogram, and apnea test. ${ }^{8}$

The decision to stop supportive treatment was made by the intensivist. Patient and treatment characteristics that might influence the interval between WLST and death were prospectively registered with the help of a study form. The characteristics are listed in Table 3.1 and have been identified from previous studies and chosen by 12 intensivists and 17 transplant coordinators as potential risk factors. Further content validity was improved by another group of intensivists $(n=18)$, resulting in a study form with 22 items. Next to the demographic variables, mode of ventilation, inotropic/ vasopressor support, analgesic/sedative use, the Glasgow Coma Scale score, absence or presence of brain stem reflexes (pupil, cough and swallowing reflex), reason for admission, cause of death and presence of cardiovascular (e.g. cardiac disease, cardiac failure, myocardial infarction, hypertension) and pulmonary comorbidity (e.g. chronic obstructive pulmonary disease, other lung diseases, severe thorax trauma) were recorded.

Table 3.1 Baseline characteristics and univariable logistic regression analysis for cardiac death within 60 minutes and within 120 minutes after withdrawal of life support.

\begin{tabular}{|c|c|c|c|c|c|}
\hline \multirow[t]{2}{*}{ Variable } & \multirow[b]{2}{*}{ Mean $\pm S D / \%$} & \multicolumn{2}{|c|}{$\begin{array}{c}\text { Cardiac Death } \\
<60 \text { minutes }(n=161)\end{array}$} & \multicolumn{2}{|c|}{$\begin{array}{c}\text { Cardiac Death } \\
<120 \text { minutes }(n=175)\end{array}$} \\
\hline & & $\begin{array}{l}\text { Odds ratio } \\
(95 \% \mathrm{Cl})\end{array}$ & $P$ & $\begin{array}{c}\text { Odds ratio } \\
(95 \% \mathrm{Cl})\end{array}$ & $P$ \\
\hline \multicolumn{6}{|l|}{ Demographics } \\
\hline Age & $52 \pm 13$ & $0.98(0.98-1.01)$ & .125 & $0.97(0.94-1.00)$ & .103 \\
\hline Gender (male) & $61 \%$ & $0.74(0.38-1.44)$ & .377 & $0.45(0.20-1.02)$ & .057 \\
\hline Body mass index & $25 \pm 6$ & $1.01(0.95-1.07)$ & .743 & 1.01 (0.94-1.07) & .862 \\
\hline \multicolumn{6}{|l|}{ Ventilator setting } \\
\hline Positive end-expiratory pressure & $7 \pm 3$ & $1.10(0.95-1.26)$ & .194 & $1.08(0.92-1.25)$ & .352 \\
\hline $\mathrm{FiO}_{2}$ & $47 \pm 18$ & $1.02(0.99-1.04)$ & .106 & $1.02(0.99-1.04)$ & .152 \\
\hline Controlled mechanical $^{\mathrm{a}}$ & $66 \%$ & $3.49(1.80-6.75)$ & $<0.001$ & $3.50(1.67-7.33)$ & .001 \\
\hline Extubation (yes) & $81 \%$ & $1.23(0.57-2.68)$ & .600 & $1.00(0.40-2.45)$ & .998 \\
\hline \multicolumn{6}{|l|}{ Medication } \\
\hline Norepinephrin & $41 \%$ & $3.17(1.52-6.63)$ & .002 & $5.47(2.03-14.71)$ & .001 \\
\hline Dopamine & $10 \%$ & $1.73(0.48-6.19)$ & .401 & $1.83(0.40-8.29)$ & .434 \\
\hline Dobutamine & $9 \%$ & $1.01(0.31-3.25)$ & .987 & $0.96(0.26-3.52)$ & .947 \\
\hline Sedatives & $42 \%$ & $1.49(0.72-3.05)$ & .281 & $0.90(0.44-1.38)$ & .281 \\
\hline Analgetics & $51 \%$ & $0.84(0.44-1.59)$ & .595 & $0.84(0.40-1.86)$ & .785 \\
\hline \multicolumn{6}{|l|}{ Neurologic examination } \\
\hline GCS score $3^{b}$ & $80 \%$ & $2.05(0.97-4.38)$ & .061 & $1.91(0.83-4.38)$ & .129 \\
\hline Brain reflexes $(0,1,2,3$, absent $)$ & $1 \pm 1$ & $1.57(1.18-2.09)$ & .002 & $1.61(1.17-2.21)$ & .003 \\
\hline Neurological deficit ${ }^{c}$ & $72 \%$ & $2.52(1.29-4.90)$ & .006 & $2.60(1.23-5.51)$ & .012 \\
\hline Cardiovasculaire co-morbidity (yes) & $33 \%$ & $0.37(0.19-0.71)$ & .003 & $0.29(0.14-0.61)$ & .001 \\
\hline Pulmonary co-morbidity (yes) & $17 \%$ & $1.15(0.49-2.72)$ & .744 & $1.08(0.41-2.81)$ & .880 \\
\hline
\end{tabular}


Patients who died within 2 hours after WLST were taken to the operation theater for procurement of the organs after a legal obligatory "no- touch" period of 5 minutes, and became organ donors.

\section{Data collection}

The donor and treatment characteristics were collected by the transplant coordinator before WLST, including a facultative "breathing test" following the treating intensivist's decision. For this test, the ventilator was temporarily (maximal 10 minutes) set on the continuous positive airway pressure mode and the respiratory frequency, tidal volume and oxygen saturation were registered. This test was used to test the ability of the potential, not brain-dead donor, to breathe without ventilatory support. The test was stopped if the oxygen saturation was $<75 \%$ and/or the systolic blood pressure $<80 \mathrm{mmHg}$. Also, the prediction of the intensivist whether the patient would die within 60 or 120 minutes or thereafter, was added to the dataset.

\section{Statistical methods}

Risk factors associated with death within 60 and 120 mins were identified with univariable and multivariable logistic regression analysis. In the analyses, patients who died within 60 minutes were included in the group who died within 120 minutes. Variables with a $P$-value $<0.05$ in the univariable analysis were included in a multivariable logistic regression model. Depending on the number of covariables allowed in the model, either enter or forward selection was performed. Predictive measurements were obtained by calculating a receiver operating characteristics curve for the prediction of the intensivist, the model of death within 60 minutes and the model of death within 120 minutes. For the regression models, the maximum combination of sensitivity and specificity, i.e. the point closest to the left- top corner of the receiver operating characteristics curve, was presented.

A $P$-value $\leq 0.05$ was considered statistically significant. SPSS version 16.0 for windows was used for the analysis (SPSS Inc., Chicago, IL). The study was performed in agreement with the code of conduct use of data in health research, put forward by the federation of Dutch medical scientific societies (http://www.federa.org). According to Dutch law, institutional review board approval is not mandatory for scientific analysis of anonymous data. 


\section{Results}

\section{Patient demographics}

In the 25- month period, life support was withdrawn in 242 potential controlled donors, of whom 211 entered analysis. Of the 31 potential donors excluded for analyses, six were clinically brain dead, and for 11 and 14 donors, the forms were missing or incomplete, respectively. The baseline characteristics of 211 potential donors are listed in Table 3.1. There were 128 (61\%) males and 83 (39\%) females; the mean age at death was 52 yrs. The ICU stay varied between 1 and 30 days. The reasons for admission included: neurotrauma (21\%), intracranial hemorrhage (33\%), occlusive cerebro-vascular accident (14\%), postanoxic encephalopathy after cardiopulmonary resuscitation (28\%) and other (4\%, e.g., pulmonary fibrosis, chronic obstructive pulmonary disease).

The majority of the patients were on controlled mechanical ventilation (66\%), meaning that ventilation was insufficient (leading to hypercapnia and/or hypoxia) when they were put on a supportive ventilation mode. The remaining $34 \%$ of the patients received a supportive ventilation mode, including pressure support and assisted spontaneous breathing; synchronized intermittent mandatory ventilation was never used in this group of patients.

In 78 (37\%) of the potential donors a "breathing test" was performed. Because of the expected additional risk of respiratory or hemodynamic instability, the intensivist decided to perform the test or not. In 23 patients (29\%), the test showed no spontaneous ventilation; 17 patients (73\%) of this group died within 60 minutes after WLST. In 48 of the 78 patients (61\%), the breathing test induced cardio respiratory instability, and was discontinued between 1 to 7 minutes after initiation of the test. From the effectuated donors with at least one organ transplanted, 342 kidneys, 22 lungs, and 57 livers were recovered.

\section{WLST}

The majority of patients, 171 (81\%) were extubated at WLST. The other patients were disconnected from the ventilator but the endotracheal tube remained in situ. Inotropic support, administered to $58 \%$ of the patients, was discontinued in all patients at the time of WLST. Analgesic drugs were continued in 51\% of the patients. Sedatives were continued or added as 'comfort medication' in 43\%, following the decision of the treating intensivist. The exact doses and initial time of medication administration were not documented in all patients (33\% missing). The most commonly used sedative was midazolam (64\%), with a mean doses of $9 \mathrm{mg} /$ hour. In $65 \%$ of the patients, the exact dose of administered analgetics was documented, most commonly morphine (45\%) with a mean doses of $5.8 \mathrm{mg} /$ hour, followed by fentanyl (12\%), with a mean doses of $192 \mu \mathrm{g} /$ hour. 


\section{Time to death}

Of the 211 potential donors, 134 (63\%) died within 30 minutes after WLST, 161 patients (76\%) died within 60 minutes and 175 (83\%) died within 2 hours and became organ donors. The remaining 36 patients (17\%) died more than two hours after withdrawal of treatment and were excluded from organ donation. The time to death of the total group ranged from 1 min to 3.8 days (median 20 minutes).

\section{Risk factors for death}

In the univariable logistic regression analyses, controlled mechanical ventilation, norepinephrine administration, absence of more brain reflexes, neurological injury as cause of death and absence of cardiovascular comorbidity were statistically significant risk factors for death within 60 and 120 minutes (Table 3.1). In the multivariable analysis, only controlled mechanical ventilation (odds ratio 2.50, 95\% confidence interval $[\mathrm{Cl}]: 1.18-5.28, P=0.016)$ remained a significant risk factor for death within 60 minutes (Table 3.2). In the multivariable analysis for death within 120 mins, controlled mechanical ventilation (odds ratio $2.59,95 \% \mathrm{Cl}: 1.17-5.73, P=0.019$ ), the use of norepinephrine (odds ratio 4.03, 95\% Cl: 1.43-11.32, $P=0.008$ ), and absence of cardiovascular co-morbidity (odds ratio $3.15,95 \% \mathrm{Cl}$ : $1.44-6.86, P=0.004$ ) were independent risk factors (Table 3.2). The area under the receiver operating curve (AUC) of the model for death within 60 minutes was fair $(0.738,95 \% \mathrm{Cl} 0.656$ to 0.819$)$ with a sensitivity and specificity of $70 \%$ and $74 \%$, respectively. For death within 120 minutes, the AUC was $0.775(95 \% \mathrm{Cl} 0.693$ to 0.857$)$ with a sensitivity of $84 \%$ and a specificity of $53 \%$. The treating intensivist's clinical judgement had a sensitivity and specificity of $73 \%$ and $56 \%$, respectively, for prediction of death within 60 minutes, with a poor AUC 0.646 (Cl 0.556 to 0.737 ). Prediction of death within 120 minutes by the intensivist had a sensitivity and specificity of $89 \%$ and $25 \%$ (AUC $0.571, \mathrm{Cl} 0.456$ to 0.686 ), respectively.

Table 3.2 Multivariable analysis of factors associated with time to death $<60$ minutes and $<120$ minutes after withdrawal of life support.

\begin{tabular}{|c|c|c|c|c|}
\hline \multirow[t]{2}{*}{ Variable } & \multicolumn{2}{|c|}{$\begin{array}{l}\text { Cardiac death }<60 \text { minutes } \\
\qquad(n=161)\end{array}$} & \multicolumn{2}{|c|}{$\begin{array}{l}\text { Cardiac death }<120 \text { minutes } \\
\qquad(n=175)\end{array}$} \\
\hline & $\begin{array}{c}\text { Odds ratio } \\
(95 \% \mathrm{Cl})\end{array}$ & $P$ & $\begin{array}{c}\text { Odds ratio } \\
(95 \% \mathrm{Cl})\end{array}$ & $P$ \\
\hline Controlled mechanical ventilation ${ }^{a}$ & $2.50(1.18-5.28)$ & .016 & $2.59(1.17-5.73)$ & .019 \\
\hline Norepinephrine (yes) & $1.97(0.87-4.45)$ & .104 & $4.03(1.43-11.32)$ & .008 \\
\hline Cardiovascular co-morbidity (yes) & $0.46(0.19-1.13)$ & .091 & $0.32(0.14-0.69)$ & .004 \\
\hline Brain reflexes ${ }^{b}$ & $1.21(0.87-1.70)$ & .258 & & \\
\hline Neurologic deficit ${ }^{c}$ & $1.30(0.51-3.29)$ & .580 & & \\
\hline $\begin{array}{l}\text { Area under the receiver operating } \\
\text { characteristic curve }\end{array}$ & $0.738(0.656-0.819)$ & $<.001$ & $0.775(0.693-0.857)$ & $<.001$ \\
\hline
\end{tabular}




\section{Discussion}

Transplantation of kidneys from donors after cardiac death has become an increasingly important source of deceased donor organs for transplantation and has proven to be successful $^{9-11}$. More recently, transplantation of DCD liver, pancreas and lung has further extended the number of donor organs. ${ }^{12,13}$ The period between WLST and death is often associated with hypotension and poor organ perfusion, resulting in warm ischemic injury to the organs. Therefore, it has become important to predict the interval between WLST and death. A DCD program inevitably includes a certain number of potential donors who do not die within the established period. It is desirable to minimize this number, since the necessary logistical preparations for controlled DCD and the surgical retrieval team and operating theater are on standby after treatment has been withdrawn. For the family, it is important to avoid false expectations of organ donation.

The present national study is the largest prospective study cohort of potential DCD donors until now. This study identified controlled mechanical ventilation as the most important variable associated with death within 60 minutes after WLST. Next to controlled mechanical ventilation, use of norepinephrine and absence of cardiovascular comorbidity were variables that increased the odds for dying within 120 minutes after WLST. However, in this group of patients, the variable cardiovascular comorbidity is closely associated with post anoxic encephalopathy patients, therefore the finding that cardiovascular comorbidity may delay the moment of death has to be interpreted with care.

There was a large variation in the interval between WLST and death, from 1 minute to 3.8 days, and most patients (76\%) died within the first hour after WLST. The predictive quality of the models for death within 60 minutes (AUC 0.738) and death within 120 minutes (AUC 0.776) were higher than the predictive quality of the intensivist (AUC 0.646 and 0.571 ), but still too low to be useful in clinical practise.

The treating intensivist performed a 'breathing' test in only a small number of patients because of expected respiratory or hemodynamic instability. This test was not conclusive; some patients showed no spontaneous breathing during the test, but started breathing within a few minutes after WLST.

The way life support is discontinued varies per country and sometimes even within ICUs. ${ }^{14}$ The use of sedatives and analgesics is topic of ongoing discussion but is considered part of good end-of-life care by many intensivists in doses to avoid discomfort or pain. End-of-life care is strictly separated from the donation procedure, since, according to the dead-donor rule, organ donation should not cause or hasten death. ${ }^{15}$ Although the proportion of the exact doses of the used sedation and analgesic drugs was not available for analysis, their use was not significantly associated with early 
death, which supports the opinion that their use does not interfere with the dead-donor rule per se. ${ }^{7,16-18}$ Also, in this study, extubation did not interfere with the moment of death. ${ }^{7}$ Therefore, it is very likely that the independent choice of the intensivist for a preferred WLST and associated end-of-life care for the dying patient is not compromised by the planned donation procedure, nor do these preferences accelerate the dying process.

There are a few studies on the prediction of death after WLST in potential DCD donors. In a small sample of 15 selected, successful DCD donors, the mean time to death after WLST was 22 minutes. ${ }^{6}$ In a cohort of mixed intensive care patients, the use of inotropes and high oxygen fraction were associated with a shorter time to death. ${ }^{7,19}$ A recent study identified young age, high inspiratory fraction of oxygen, and mode of ventilation as the most important variables associated with early death in potential DCD donors. ${ }^{20}$ In all studies, the majority of donors died within the first hour after WLST. The percentage in this nationwide study were comparable to the results from the United Kingdom. ${ }^{20,21}$ We performed a prospective analysis of risk factors and studied important treatment characteristics, such as extubation, analgesic and/or sedatives use, as well as the intensivist's prediction of the time of death, which had not been subject of previous studies.

\section{Conclusion}

This study shows that there are variables, including ventilation mode and use of norepinephrine, that increase the odds of dying within 60 or 120 minutes in potential DCD donors. However, in clinical practice, death can not be predicted within 60 or 120 minutes with acceptable certainty. Although the opinion of the intensivist was valuable, the sensitivity and specificity was too low to be useful in clinical practice. The persisting shortage of organs for transplantation forces us to maximize our efforts to retrieve every potentially viable organ. Therefore, a donation procedure should be initiated in every potential donor. 


\section{References}

1. Kootstra G, Daemen JH, Oomen AP. Categories of non-heart-beating donors. Transplant Proc. 1995;27: 2893-4.

2. Dutch Transplant Foundation annual report. 2008.

3. Cook D, Rocker G, Marshall J, Sjokvist P, Dodek P, Griffith L, et al. Withdrawal of mechanical ventilation in anticipation of death in the intensive care unit. N Engl J Med. 2003;349:1123-32.

4. Revelly JP, Imperatori L, Maravic P, Schaller MD, Chiolero R. Are terminally ill patients dying in the ICU suitable for non-heart beating organ donation? Intensive Care Med. 2006;32:708-12.

5. Keenan SP, Hoffmaster B, Rutledge F, Eberhard J, Chen LM, Sibbald WJ. Attitudes regarding organ donation from non-heart-beating donors. J Crit Care. 2002;17:29-36; discussion 7-8.

6. Lewis J, Peltier J, Nelson H, Snyder W, Schneider K, Steinberger D, et al. Development of the University of Wisconsin donation After Cardiac Death Evaluation Tool. Prog Transplant. 2003;13:265-73.

7. Devita MA, Brooks MM, Zawistowski C, Rudich S, Daly B, Chaitin E. Donors After Cardiac Death: Validation of Identification Criteria (DVIC) Study for Predictors of Rapid Death. Am J Transplant. 2008; 8:432-41.

8. Law on organ donation. Available at: http://wetten.overheid.nl/BWBR0008066. Accessed September 29, 2011.

9. Cooper JT, Chin LT, Krieger NR, Fernandez LA, Foley DP, Becker YT, et al. Donation after cardiac death: the university of wisconsin experience with renal transplantation. Am J Transplant. 2004;4:1490-4.

10. Weber M, Dindo D, Demartines N, Ambuhl PM, Clavien PA. Kidney transplantation from donors without a heartbeat. N Engl J Med. 2002;347:248-55.

11. Nicholson ML, Metcalfe MS, White SA, Waller JR, Doughman TM, Horsburgh T, et al. A comparison of the results of renal transplantation from non-heart-beating, conventional cadaveric, and living donors. Kidney Int. 2000;58:2585-91.

12. D'Alessandro A M, Hoffmann RM, Knechtle SJ, Odorico JS, Becker YT, Musat A, et al. Liver transplantation from controlled non-heart-beating donors. Surgery. 2000;128:579-88.

13. Oto T. Lung transplantation from donation after cardiac death (non-heart-beating) donors. Gen Thorac Cardiovasc Surg. 2008;56:533-8.

14. Sprung CL, Cohen SL, Sjokvist P, Baras M, Bulow HH, Hovilehto S, et al. End-of-life practices in European intensive care units: the Ethicus Study. JAMA. 2003;290:790-7.

15. Truog RD, Robinson WM. Role of brain death and the dead-donor rule in the ethics of organ transplantation. Crit Care Med. 2003;31:2391-6.

16. Bakker J, Jansen TC, Lima A, Kompanje EJ. Why opioids and sedatives may prolong life rather than hasten death after ventilator withdrawal in critically ill patients. Am J Hosp Palliat Care. 2008;25:152-4.

17. Kompanje EJ, van Zuylen L, van der Rijt CC. Morphine is not a sedative and does not shorten life. Arch Intern Med. 2006;166:2047; author reply -8.

18. Chan JD, Treece PD, Engelberg RA, Crowley L, Rubenfeld GD, Steinberg KP, et al. Narcotic and benzodiazepine use after withdrawal of life support: association with time to death? Chest. 2004;126: 286-93.

19. Coleman NL, Brieva JL, Crowfoot E. Prediction of death after withdrawal of life-sustaining treatments. Crit Care Resusc. 2008;10:278-84.

20. Suntharalingam C, Sharples L, Dudley C, Bradley JA, Watson CJ. Time to cardiac death after withdrawal of life-sustaining treatment in potential organ donors. Am J Transplant. 2009;9:2157-65.

21. Reid AW, Harper S, Jackson CH, Wells AC, Summers DM, Gjorgjimajkoska O, et al. Expansion of the kidney donor pool by using cardiac death donors with prolonged time to cardiorespiratory arrest. Am J Transplant. 2011;11:995-1005. 


\section{Chapter 4}

Determination of death after circulatory arrest by intensive care physicians A survey of current practise in the Netherlands

Jentina Wind, Walther NK van Mook, Sonny Dhanani, Ernest WL van Heurn Journal of Critical Care, in press 


\section{Abstract}

Purpose

Determination of death is an essential part of donation after circulatory death (DCD). We studied the current practices of determination of detah after circulatory arrest by intensive care physicians in the Netherlands, the availability of guidelines and the occurrence of the phenomenon of autoresuscitation

\section{Methods}

The Determination of Cardiac Death Practices in Intensive Care Survey (DDePICt) was send to all intensive care physicians.

\section{Results}

Fifty-five percent of 568 Dutch intensive care physicians responded. Most respondents learned death determination from clinical practise. The most commonly used tests for death determination were flat arterial line tracing, flat electrocardiogram (standard 3 leads ECG) and fixed and dilated pupils. Rarely used tests were absence pulse by echo Doppler, absent blood pressure by non-invasive monitoring and unresponsiveness to painful stimulus. No diagnostic test or procedure was uniformly performed, but $80 \%$ of respondents perceived a need for standardisation of death determination. Autoresuscitation was witnessed by $37 \%$, after withdrawal of treatment or after unsuccessful resuscitation. According to six respondents occurring more than 5 minutes after asystole after life support withdrawal.

\section{Conclusions}

Extensive variability in the practice of determining death after circulatory arrest exists, and a need for guidelines and standardization, especially if organ donation follows death is reported. Autoresuscitation is reported, this observation requires attention in further prospective observational studies. 


\section{Introduction}

The use of organs from donation after circulatory death (DCD) donors, is increasing in many countries. DCD, also known as donation after cardiac death or non-heartbeating donation, has become an established strategy to offer donation to more intensive care patients, expand the donor pool and to reduce the waiting list for transplantation. ${ }^{1}$ Most DCD donors are patients admitted to the intensive care unit (ICU) who die after withdrawal of life sustaining treatment (controlled DCD, CDCD). ${ }^{2}$ Organs from $c D C D$ donors are subjected to a period of warm ischemia; the period between the cessation of circulation and the initiation of preservation measures, which adversely affects transplant outcome. ${ }^{3}$ To minimize the warm ischemic damage, it is paramount to initiate organ preservation as soon as possible after the patient's death. A fundamental principle within the context of organ donation is the "dead-donor rule": organs cannot be removed until death has been declared. ${ }^{4}$ The determination of circulatory death and a subsequent obligatory no-touch period to ensure the permanent death are an essential part of $C D C D$ donation. ${ }^{5}$ However, in contrast to the criteria for brain death which are generally well defined and accepted with clear protocols, clearly defined criteria for determination of circulatory death are so far not available. ${ }^{6}$

A review of contemporary international guidelines shows the currently existing variability in the determination of death after cardiac arrest, ${ }^{7}$ resulting in an on-going discussion about the determination of cardiac death within the context of organ donation..$^{8-11}$ The main issues identified, relate to the irreversibility of the loss of cardiocirculatory function, the exact moment of death, and the concern about the possibility of spontaneous resumption of circulation, termed autoresuscitation (AR). ${ }^{12-14}$

The primary objective of this study was to describe the current practices of determination of death after cardiac arrest in adults in the Netherlands by intensive care physicians. Secondary objectives included to identify the policies and guidelines which are available to physicians, to determine the perceived need for standardization of practice and to determine the reported occurrence of AR.

\section{Materials and methods}

All intensive care physicians caring for adult patients in the Netherlands were approached by mail using information from the Dutch Intensive Care Society, combined with information retrieved from websites of the hospitals. The medical manager of each department was contacted by telephone or by e-mail, to explain the study and ask permission to send the questionnaire to all staff intensivists.

To assess determination of death practise, the Determination of Cardiac Death Practices in Intensive Care (DDePICt) Survey was used. ${ }^{15,16}$ Translations into Dutch language 
consisted of two independent forward translations, a reconciliation, a backward translation and then another reconciliation. The translated questionnaire was evaluated by four intensivists and four transplant coordinators, who were not involved in the study. Minor adjustments were made to individual questions and the questionnaire was again evaluated by four other independent intensivists. The final questionnaire consisted of six demographic questions, eight questions about the determination of death, one question about autoresuscitation and statements about standardization of practice. The physicians were asked which of 11 "tests" they used for the determination of death after cardiac arrest.

For seven questions, a multiple choice format for answers was used, to facilitate the surveyed, to minimize the time required for its completion and to simplify data collection. Ample space for narrative comments was provided for eight questions. Three questions were constructed using a 5-point Likert scale, ranging from never to always.

The survey was distributed between November 2012 and May 2013. The questionnaire was sent with a self-addressed return envelope. If the questionnaire was not returned within 6 weeks, a reminder was sent. Names were removed from the list when questionnaires were returned, when physicians proved to be retired, or when physicians had withdrawn from intensive care practice. The study was performed in agreement with the code of conduct on the use of data in health research, put forward by the Dutch Federation of Biomedical Scientific Societies. ${ }^{17}$

Ethical approval for the study was waived by the medical ethical examination committee (METC) of the Maastricht University Medical Center. The respondents consented to participate to the study by returning the completed questionnaire.

\section{Statistics}

Each questionnaire was numbered and linked with a respondent identifier to track the responses. Descriptive summaries of responses to each question were recorded. For categorical questions, frequencies and percentages were tabulated. For numeric questions, means, medians, ranges were tabulated. Narrative comments were transcribed verbatim and presented in groups. Analysis of these narrative comments was performed. The proportion of nonresponse for each question was recorded. SPSS version 16.0 for windows was used for the analysis (SPSS Inc., Chicago, IL, USA).

\section{Results}

\section{Demographics}

All approached medical managers agreed to sending the questionnaire to their staff intensivists, 582 staff ICU physicians were approached. 
The response rate was 55\% (311/568), 14 were excluded (not practicing as intensivist, retired or duplicated). The most frequent speciality training of participating intensivists included internal medicine and anaesthesia. Most respondents (72\%) were working in a University hospital, next to a large teaching hospital (41\%) and a district hospital (32\%). Fifty per cent of the respondents worked in a level 3 intensive care unit, the highest ICU level (range 1-3). Physicians had a median of 7 years' experience as an intensivist (range $0-40 \mathrm{yrs}$ ). The numbers of beds in the ICU's ranged from 3 to 51 with a median of 16 beds (Table 4.1.)

Table 4.1 Demographic characteristics of respondents ( $n=311)$.

\begin{tabular}{|c|c|}
\hline Characteristics & \% Respondents \\
\hline \multicolumn{2}{|l|}{ Background $(n=311)$} \\
\hline Internal medicine & 49.5 \\
\hline Anaesthesia & 39.5 \\
\hline Surgery & 4.5 \\
\hline Neurology & 2.3 \\
\hline Cardiology & 1.9 \\
\hline Other & 1.6 \\
\hline \multicolumn{2}{|c|}{ Number of years practicing in ICU $(n=309)$} \\
\hline Median & 7 \\
\hline Min & 0 \\
\hline Max & 40 \\
\hline \multicolumn{2}{|c|}{ Type of ICU patients $(n=311)$} \\
\hline Surgical & 98 \\
\hline Internal Medicine & 98 \\
\hline Cardiological & 92 \\
\hline Neurological & 92 \\
\hline Trauma & 77 \\
\hline Thoracic surgical & 55 \\
\hline Neurosurgical & 40 \\
\hline Paediatric & 11 \\
\hline Other & 11 \\
\hline \multicolumn{2}{|c|}{ Type of hospital $(n=310)$} \\
\hline Large teaching & 41 \\
\hline District & 32 \\
\hline University & 27 \\
\hline \multicolumn{2}{|c|}{ Level of intensive care $(n=310)$} \\
\hline 3 & 50 \\
\hline 2 & 28 \\
\hline 1 & 21 \\
\hline \multicolumn{2}{|c|}{ Number of beds $(n=310)$} \\
\hline Median & 16 \\
\hline Min-max & $3-51$ \\
\hline \multicolumn{2}{|c|}{ Number of times /year of determining death after cardiac death } \\
\hline Median & 10 \\
\hline Min-max & $0-52$ \\
\hline
\end{tabular}




\section{Determination of death practice}

The reported frequency of personally performing determination of death after circulatory arrest ranged from 0 to 52 times per year (median 10). Seventy-nine of 311 respondents reported a frequency of determining cardiac death more than 20 times per year. Many respondents (44\%) were not aware of any guideline or written policy for the determination of death after circulatory arrest in their hospital. There was a local guideline or written policy according to $28 \%$ of responses. Most of the time, the criteria were learned through clinical experience (learning by doing or experiential learning, 85\%), next to informal training (mentor/modelling) (67\%). Twenty-five per cent of the respondents used non-local guidelines or derived guidance on determination of death from the literature (19\%).

\section{Tests for determination of death}

Figure 4.1 lists the percentage of tests used, ranging from 'never' to 'always' used. Flat electrocardiogram tracing (standard 3 leads ECG) was the test most commonly used assessment to determine death, followed by flat arterial line tracing and the assessment of fixed and dilated pupils. Tests that were 'never'and 'rarely' used were absence of pulse by echo Doppler examination, absent blood pressure by non-invasive monitoring and unresponsiveness to painful stimulus. Combinations of methods most frequently used for determination of death are clustered in Table 4.2. Seventy-five percent of respondents reportedly 'always' performed 2 to 5 tests.

Table 4.2 The 5 most used combination of tests.

\begin{tabular}{lc}
\hline Test & $\%$ \\
flat arterial line tracing/ flat electrocardiogram & 60 \\
flat arterial line tracing/ fixed and dilated pupils & 44 \\
flat electrocardiogram/ fixed and dilated pupils & 37 \\
flat arterial line tracing/ flat electrocardiogram/ fixed and dilated pupils & 31 \\
\hline absence of heart sounds by auscultation/ absence of palpable pulse & 28 \\
\hline
\end{tabular}

Narrative feedback provided evidence for the use of other, not previously discussed, tests for the determination of death. These included measuring end tidal $\mathrm{CO}_{2}$, echo cardiography, control of cornea reflexes, signs of pupillary deformation, and inspection of the colour of patient's skin. The majority of respondents 'never' or 'rarely' repeated tests (78\%). If tests were repeated, then the median time until repetition was 5 minutes. Confirmation by a second physician was reportedly 'usually' or 'always' performed by $4 \%$. 


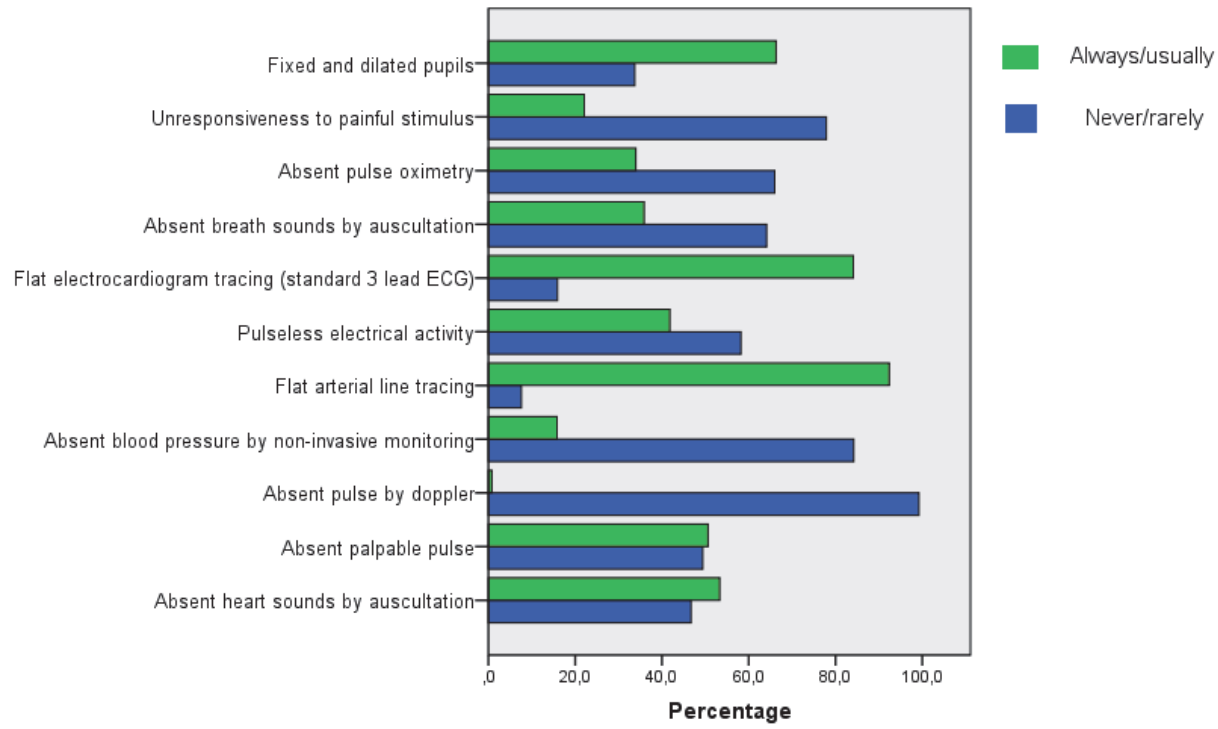

Figure 4.1 Diagnostic tests used to determine death after circulatory arrest. Percentage of physicians that used each diagnostic test by two grouped categories: "never and rarely" and 'always and usually'.

Physicians were asked which of 14 factors might influence their diagnostic criteria for determination of death. Respondents identified the following influences most commonly: hypothermia (74\%), the administration of sedatives (34\%), presence of a tension pneumothorax (34\%), pericardial tamponade (32\%), and pulmonary hyperinflation/auto positive end expiratory pressure PEEP (27\%).

\section{Death determination and donation after circulatory death}

The question to what extent the way of determining circulatory death would be changed if a subsequent CDCD procedure was planned was answered by 239 intensivists (67\%). No changes stated to the normally used tests were made according to 106 respondents. Narrative comments related to "invasive monitoring of the patient" the "time pressure after death", "the importance of the bedside presence of the intensivist", "the clear communication with the relatives about the necessary 'rapid' transportation to the operating room after death", "following the donation protocol" and a "close observation of the period between withdrawal of support and death". Sixteen intensivists (7\%) repeated the normally used tests themselves or had them repeated by a second intensivist. 


\section{Reported autoresuscitation}

In the questionnaire, AR was defined as the spontaneous resumption of a cardiac rhythm after asystole with circulatory output. Sixteen per cent of the physicians had never heard of AR. Forty-three per cent had knowledge of AR, but never witnessed it. According to 27 per cent, $A R$ is an important consideration in the determination of death. This percentage did not increase, if organ donation follows circulatory death. More than $50 \%$ did not response to the question. Thirty-seven per cent reported witnessing AR (116 intensivists), after withdrawal of treatment or after unsuccessful resuscitation.

Fifty-three per cent reported that autoresuscitation had occurred within two minutes after asystole. Thirteen of 116 respondents reported to have witnessed AR more than 5 minutes after asystole (6-20 minutes). Of those, six witnessed AR in a patient in whom life support had been withdrawn. Eight respondents reported that after AR the patients did not die, or at a much later moment. In six of these eight patients, the AR was reported to occur within two minutes after asystole, the other two after 10 and 12 minutes after the asystole.

In general, there were no reported differences between the tests used for determination of death between the intensivists who witnessed and those who did not witness AR. To the question if the AR had changed the way they subsequently determined death, 27 respondents answered that no changes were made, 20 respondents reported a longer observation time, 5 respondents now repeated tests and 4 had added echocardiography to their standard procedure(s), the remaining respondents described the use of various combinations of tests.

Many respondents commented on explanatory mechanisms underlying AR: the effect of an adrenaline bolus or the auto PEEP effect in patients after resuscitation.

According to $32 \%$ of the intensive care physicians, there is need for further studies on the incidence of AR, whereas $29 \%$ considered this not necessary. The other respondents scored neutral.

\section{Need for guidelines}

Almost $70 \%$ of the intensivists reported that a standardized method of the determination of death after circulatory arrest was required. This increased to $80 \%$ if organ donation after circulatory death would be involved. Accordingly, $65 \%$ of respondents 'agreed' or 'strongly agreed' that written guidelines are needed for the determination of death, which increased to $69 \%$ for death determination in case of a cDCD donation. Of the respondents, $42 \%$ agreed that education for the determination of death was needed. 


\section{Discussion}

This large national survey among all Dutch intensive care physicians caring for adult patients provides an in-depth insight in the practice of determination of death after circulatory arrest. The response rate was 55\% representing the opinions of 311 intensive care physicians, from different backgrounds and different intensive care units in the Netherlands, resulting in a reliable representation of common practice in the Netherlands.

The reported practice showed variability. No diagnostic test or procedure for death determination was uniformly performed. The majority of intensivists performed a combination of tests, of which the combination flat arterial line and iso-electrocardiogram was the most frequently used. Compared to a similar study among Canadian intensive care physicians, ${ }^{15}$ there were some similarities and differences in the reported used tests. Absence of palpable pulse, absence of heart sounds by auscultation and fixed and dilated pupils were the top three most used tests in Canada while in our study these were flat arterial line tracing, flat ECG, and fixed and dilated pupils. Both studies showed that absence of pulse by Doppler and absence of non- invasive blood pressure were rarely used, and in both studies many physicians chose a combination of tests for the determination of death. The criteria used for the determination of death were inconsistent.

Reviews of guidelines and statements and protocols in countries who practise donation after circulatory death, also shows variability in the determination of circulatory death. ${ }^{7,18}$ Peer-reviewed published guidelines are scarce.

Variation in determining death may be less important if the patient is not a potential organ donor. Without organ donation following death, there is sufficient time to determine the death and there is no risk of violating the dead donor rule. Therefore standardization of diagnostic tests to do a timely assessment of irreversible or permanent cessation of circulatory and respiratory function is less important. The need for uniform determination of death after circulatory arrest has been increased since the expansion of $C D C D$ donation. In these patients, it is important to have consensus on how death is determined. Within minutes after death, procurement of organs from the body of the deceased is initiated. To maintain professional and public trust, it is important to have clear and evidence-based guidelines for the determination of death. The lack of consensus about the determination of death is thus understandably a point of discussion and concern. $8,9,11$

Guidelines for the neurologic determination of death have also evolved to diagnose brain death. ${ }^{16}$ Although differences still exist between countries regarding the use of diagnostic procedures and guidelines to confirm brain death, protocols supporting physicians now exist. ${ }^{19,20}$ With the expansion of $c D C D$, it is also necessary to develop 
clear protocols and guidelines, which are only available in a limited number of countries. $^{21,22}$

A recently published article about international guideline development for the determination of death, described minimum acceptable standard clinical and additional tests to determine death after cessation of circulatory function in adults and children which take into account the subsequent cessation of neurologic function. ${ }^{23}$ Herein, the recommended minimum acceptable clinical standard included; absence of a palpable pulse, absence of breath sounds, absence of heart sounds, absence of respiratory effort or chest wall motion, loss of pulsatile arterial blood pressure by non-invasive measurement, coma and fixed and dilated pupils. Death is confirmed after continuous observation of these criteria over a time period of 2-10 minutes. The authors' recommended additional tests included the loss of pulsatile arterial blood pressure by arterial line monitoring, echocardiography (absence of anterograde blood flow through the aortic valve), isoelectric ECG, and absence of pulse by Doppler examination.

A review about the international perspectives on the diagnosis of death outlines that death can be diagnosed using three different sets of criteria: circulatory, somatic and neurological. Essential components for diagnosing death using circulatory criteria include no attempts to resuscitate is agreed, a minimum observation period and a prohibition against activities that might restore the cerebral circulation. To confirm circulatory arrest, monitoring is recommended such as intra-arterial pressure, electrocardiography, or echocardiography. ${ }^{24}$

In a prospective pilot observational study, arterial blood pressure and electrocardiogram activity were documented, after withdrawal of life support, until 30 minutes after declaration of death in 41 ICU patients. ${ }^{25}$ No return of circulation was observed after 89 seconds of cessation of arterial blood pressure activity, but electrocardiogram activity continued in a majority of patients after absence of arterial blood pressure activity. This suggests that electrocardiogram criteria in the declaration of death may have limited clinical relevance.

In our study, most respondents learned criteria for death determination from clinical practise, so called experiential learning, and only one third of the physicians were familiar with guidelines. The majority thought that standardization of the determination of circulatory death was needed, this increased if a DCD procedure would follow after death.

In June 2015, the Health Council of the Netherlands constructed a guideline for determination of death in various forms of postmortal organ donation. Besides a renewed brain death protocol, protocols for determination of death after circulatory arrest are described. After circulatory arrest assessed by the absence of circulation and 
respiration for an observation period of at least 5 minutes, death can be determined by the physician. Arterial line monitoring is recommended (observation of pulsatile arterial blood flow) as test. If not available, non-invasive blood measurement, auscultation of the heart, ECG or echocardiography (absence of anterograde blood flow through the aortic valve) can be used. ${ }^{26}$ The implementation of the guideline is expected later this year.

Almost half of the respondents were familiar with $A R$ and $37 \%$ reported having seen a case of AR themselves. There is a possibility that diagnostic pitfalls in the determination of death such as tamponade and hyperinflation could be responsible for reported AR. A comparable percentage of AR was reported in the Canadian study, ${ }^{15}$ although herein, no specification about AR after resuscitation or after withdrawal of treatment was made. In our study we reported cases of AR after resuscitation, but also after withdrawal of treatment. To the best of our knowledge, this finding has never been reported before. In the literature, AR has never been reported after withdrawal of life support, only following failed CPR. ${ }^{27}$ Publication bias is a possible explanation for this observation. .

Although most cases of AR in this study were reported to occur within 2 minutes after cardiac arrest, 13 respondents reported to have witnessed AR after 5 minutes or more. However, this survey reflects anecdotal retrospective cases with recall bias and where methods of monitoring were not documented. It is clear that generalization of these preliminary data regarding the possibility of $A R$ and its potential impact on the declaration of death is only possible after verification of its validity by gathering and analysing a large set of additional prospective observational data.

Most DCD protocols advise a minimal observation time after circulatory arrest of 5 minutes, before death can be determined, ${ }^{7,14,18}$ to ensure safety in the event of the occurrence of $A R$ in this period. There is a lack of scientific evidence concerning the pathophysiology underlying the phenomenon of AR; so far the underlying mechanisms which may lead to AR as well as the duration of time necessary to eliminate any change of $A R$ are yet to be determined. Further prospective observational research into the incidence of autoresuscitation following withdrawal of life support is necessary.

\section{Limitations of the study}

This study was based on retrospective data from a survey. Especially data on the observation of $A R$, the exact time after cardiac arrest could have been biased by recollection.

\section{Conclusion}

This large nationwide survey about the determination of death after cardiac arrest by intensive care physicians in the Netherlands, shows an extensive variability in the practice of determining death after circulatory arrest. There is a need for guidelines and 
standardisation of the determination of circulatory death, especially if organ donation follows death. The phenomenon of autoresuscitation is anecdotally reported, not only after unsuccessful resuscitation, but also after withdrawal of life support, which requires attention in further prospective observational studies. 


\section{References}

1. Daemen JW, Oomen AP, Kelders WP, Kootstra G. The potential pool of non-heart-beating kidney donors. Clin Transplant 1997;11:149-54.

2. Kootstra G, Daemen JH, Oomen AP. Categories of non-heart-beating donors. Transplant Proc 1995;27: 2893-4.

3. Shiroki R, Hoshinaga K, Higuchi T, Tsukiashi $Y$, Kubota $Y$, Maruyama T, Izumitani M, Horiba M, Naide $Y$, Kanno T. Prolonged warm ischemia affects long-term prognosis of kidney transplant allografts from nonheart-beating donors. Transplant Proc 1998;30:111-3.

4. Robertson JA. The dead donor rule. Hastings Cent Rep 1999;29:6-14.

5. Bernat JL, Capron AM, Bleck TP, Blosser S, Bratton SL, Childress JF, DeVita MA, Fulda GJ, Gries CJ, Mathur M, Nakagawa TA, Rushton CH, Shemie SD, White DB. The circulatory-respiratory determination of death in organ donation. Crit Care Med 2010;38:963-70.

6. Wijdicks EF, Varelas PN, Gronseth GS, Greer DM. Evidence-based guideline update: determining brain death in adults: report of the Quality Standards Subcommittee of the American Academy of Neurology. Neurology 2010;74:1911-8.

7. Dhanani S, Hornby L, Ward R, Shemie S. Variability in the determination of death after cardiac arrest: a review of guidelines and statements. J Intensive Care Med 2012;27:238-52.

8. Joffe AR. The ethics of donation and transplantation: are definitions of death being distorted for organ transplantation? Philos Ethics Humanit Med 2007;2:28

9. Rady MY, Verheijde JL, McGregor J. Organ donation after cardiac death: are we willing to abandon the dead-donor rule? Pediatr Crit Care Med 2007;8:507

10. Rady MY, Verheijde JL, McGregor J. Organ procurement after cardiocirculatory death: a critical analysis. J Intensive Care Med 2008;23:303-12.

11. Shemie SD. Clarifying the paradigm for the ethics of donation and transplantation: Was 'dead' really so clear before organ donation? Philos Ethics Humanit Med 2007;2:18

12. Potts M. Truthfulness in transplantation: non-heart-beating organ donation. Philos Ethics Humanit Med 2007;2:17

13. Verheijde JL, Rady MY, McGregor J. Recovery of transplantable organs after cardiac or circulatory death: the end justifying the means. Crit Care Med 2007;35:1439-40

14. Sheth KN, Nutter T, Stein DM, Scalea TM, Bernat JL. Autoresuscitation after asystole in patients being considered for organ donation. Crit Care Med 2012;40:158-61.

15. Dhanani S, Ward R, Hornby L, Barrowman NJ, Hornby K, Shemie SD. Survey of determination of death after cardiac arrest by intensive care physicians. Crit Care Med 2012;40:1449-55.

16. Burns KE, Duffett M, Kho ME, Meade MO, Adhikari NK, Sinuff T, Cook DJ; ACCADEMY Group. A guide for the design and conduct of self-administered surveys of clinicians. CMAJ 2008;179:245-52.

17. Dutch Federation of Biomedical Scientific Societies. (http://www.federa.org)

18. Wind J, Faut M, van Smaalen TC, van Heurn EL. Variability in protocols on donation after circulatory death in Europe. Crit Care 2013;17:R217.

19. Shemie SD. Variability of brain death practices. Critical care medicine 2004;32(12):2564-5.

20. Wijdicks EF. Brain death worldwide: accepted fact but no global consensus in diagnostic criteria. Neurology 2002;58:20-5.

21. Shemie SD, Baker AJ, Knoll G, Wall W, Rocker G, Howes D, Davidson J, Pagliarello J, Chambers-Evans J, Cockfield S, Farrell C, Glannon W, Gourlay W, Grant D, Langevin S, Wheelock B, Young K, Dossetor J. National recommendations for donation after cardiocirculatory death in Canada: Donation after cardiocirculatory death in Canada. CMAJ 2006;175:S1.

22. Academy of Medical Royal Colleges: A code of practise for the diagnosis and confirmation of death. London, 2008. Available from http://www.aomrc.org.uk/publications/reports-guidance.html

23. Shemie SD, Hornby L, Baker A, Teitelbaum J, Torrance S, Young K, Capron AM, Bernat JL, Noel L; The International Guidelines for Determination of Death phase 1 participants, in collaboration with the World Health Organization. International guideline development for the determination of death. Intensive Care Med 2014;40:788-97. 
24. Gardiner D, Shemie S, Manara A, Opdam H. International perspective on the diagnosis of death. Br J Anaesth 2012;108 Suppl 1:i14-28.

25. Dhanani S, Hornby L, Ward R, Baker A, Dodek P, Chamber-Evans J, Fowler R, Friedrich JO, Gow RM, Kutsogiannis DJ, Mcintyre L, Momoli F, Morin K, Ramsay T, Scales D, Writer H, Yildirim S, Young B, Shemie S; Canadian Critical Care Trials Group and in collaboration with the Bertram Loeb Chair and Research Consortium in Organ and Tissue Donation. Vital signs after cardiac arrest following withdrawal of lifesustaining therapy: a multicenter prospective observational study. Crit Care Med 2014;42: 2358-69.

26. Health Council of the Netherlands. determining death in postmortal organdonation. Protocols and criteria, including an updated Brain Death Protocol. The hague: health Council of the Netherlands, 2015; publication no.2015/13.

27. Hornby K, Hornby L, Shemie SD. A systematic review of autoresuscitation after cardiac arrest. Crit Care Med 2010;38:1246-53. 


\section{Chapter 5}

\section{Preservation of kidneys from controlled donors after cardiac death}

J Wind, MGJ Snoeijs, JA van der Vliet, B Winkens, MHL Christiaans, AJ Hoitsma, EL van Heurn 


\section{Abstract}

\section{Background}

Donation after cardiac death (DCD) expands the pool of donor kidneys, but is associated with warm ischaemic injury. Two methods are used to preserve kidneys from controlled DCD donors and reduce warm ischaemic injury: in situ preservation using a double-balloon triple-lumen catheter (DBTL) inserted via the femoral artery and direct cannulation of the aorta after rapid laparotomy. The aim of this study was to compare these two techniques.

\section{Methods}

This was a retrospective cohort study of 165 controlled DCD procedures in two regions in the Netherlands between 2000 and 2006.

\section{Results}

There were 102 donors in the DBTL group and 63 in the aortic group. In the aortic group the kidney discard rate was lower (4.8 versus 28.2\%; $P<0.001$ ), and the warm (22 versus 27 min; $P<0.001$ ) and the cold (19 versus $24 \mathrm{~h} ; P<0.001$ ) ischaemia times were shorter than in the DBTL group. Risk factors for discard included preservation with the DBTL catheter (odds ratio (OR) 5.19, 95\% confidence interval 1.88 to $14.36 ; P=0.001)$ and increasing donor age $(1.05,1.02$ to 1.07; $P<0.001$ ).Warm ischaemia time had a significant effect on graft failure (hazard ratio $1.04,1.01$ to 1.07; $P=0.009$ ), and consequently graft survival was higher in the aortic cannulation group $(86.2 \%$ versus $76.8 \%$ in the DBTL group at 1 year; $P=0.027$ ).

\section{Conclusion}

In this retrospective study, direct aortic cannulation appeared to be a better method to preserve controlled DCD kidneys. 


\section{Introduction}

The treatment of choice for many patients with end-stage renal failure is kidney transplantation. ${ }^{1}$ To reduce the shortage of organs for transplantation, there is increased reliance on the use of donation after cardiac death (DCD). ${ }^{2}$ Despite the higher incidence of primary non-function (PNF) and delayed graft function, compared with that in kidneys donated after brain death, DCD kidneys are used increasingly. The long-term survival of functioning grafts and the survival of recipients are similar in both groups. ${ }^{3-5}$

Of deceased donors in the Netherlands in 2008, 41\% were DCD donors. ${ }^{6}$

Organs from DCD donors are subjected to a period of warm ischaemia, which affects post-transplant graft function adversely. ${ }^{7}$ To minimize warm ischaemic damage during preservation, it is important to flush and cool the organs as quickly as possible after cardiac arrest.

Two in situ preservation methods are used in controlled donors (donors who die after withdrawal of treatment). One is that the kidneys are perfused with a double-balloon triple-lumen (DBTL) catheter introduced via the femoral artery into the aorta, and the other is in situ preservation, with direct cannulation of the aorta after a rapid laparotomy. ${ }^{8}$ Direct cannulation has gained popularity in recent years, stimulated by the development of the DCD liver and pancreas donation programme. ${ }^{9}$ In situ preservation with the DBTL catheter remains the preservation method of choice in uncontrolled donors (donors who die after failed resuscitation). It is relatively easy for an inexperienced surgeon to perform and can be done at the patient's bedside. It may be associated with a higher rate of complications owing to inaccessible femoral arteries, catheter malposition or balloon rupture, which may lead to unsuccessful donation. ${ }^{10}$ In the present study the results of the two preservation methods were compared retrospectively in a large cohort of controlled DCD donors.

\section{Methods}

This retrospective cohort study included all controlled DCD donors from two regions in the Netherlands from January 2000 to January 2006. ${ }^{11}$ Withdrawal of life sustaining treatment was usually performed in intensive care with the family present at the bedside. After the confirmation of patient death by an independent physician and the obligatory 'no-touch' period of at least 5 min after circulatory arrest, preservation measures were started. 


\section{Double-balloon triple-lumen catheter}

A DBTL catheter (Porges, Le Plessis-Robinson, France) was inserted into the aorta via the femoral artery. After introduction of the catheter, the abdominal balloon was inflated and positioned at the aortic bifurcation; thereafter the thoracic balloon was inflated, thereby isolating the entire abdominal aorta. Organs with the origin of their arterial supply in the isolated aortic segment were flushed with histidine-tryptophanketoglutarate (HTK) solution (Custodiol ${ }^{\circledR}$ HTK; Dr Franz Köhler Chemie, Alsbach, Germany). To allow outflow, a 22-Ch catheter was introduced through the femoral vein. $^{12}$ Donors were subsequently transported to the operating room and the organs retrieved by laparotomy.

\section{Aortic cannulation}

Direct cannulation of the aorta was performed in the operating room. After cardiac arrest, the donor was transported to the operating room where a surgical team was waiting. After rapid laparotomy, a cannula was inserted into the aorta or into one of the common iliac arteries, and the aorta was clamped below the diaphragm. Cold preservation fluid was infused through the cannula. HTK solution was the preservation method of choice for both groups, except for a small number of multiorgan donors in whom University of Wisconsin preservation fluid was used during a trial that compared both preservation fluids in DCD liver transplantation. Outflow was achieved with a 24-Ch catheter placed in the inferior vena cava. Additionally, the organs in the peritoneal cavity were cooled topically with cold saline. The organs were harvested immediately after flushing and cooling. Both DBTL catheter insertion and direct aortic cannulation were done by either an experienced consultant transplant surgeon or a supervised trainee.

\section{Kidney transplantation}

Kidneys were allocated through the Eurotransplant Kidney Allocation System and transplanted in one of the centres in the Eurotransplant region. ${ }^{5}$

\section{Data}

Donor, graft and recipient characteristics of all controlled DCD procedures in the study interval were analysed. Data on recipients of DCD kidneys were provided by the Dutch Organ Transplant Registry. Follow-up of serial glomerular filtration rate (GFR; estimated by the Modification of Diet in Renal Disease formula ${ }^{13}$ ), patient and graft survival was undertaken to 1 January 2007. Apart from donor and recipient characteristics, which are listed in Table 5.1, the following parameters were recorded: warm ischaemia time (time from circulatory arrest until the start of preservation), cold ischaemia time (time between preservation and the start of the vascular anastomosis) and the anastomosis time (time to complete both vascular anastomoses). Short-term graft function was 
classified as: immediate function (renal function without post-transplant dialysis); delayed graft function (renal function that required dialysis in the first week after transplantation but was ultimately sufficient without dialysis); or PNF (permanent inadequate renal function after transplantation).

The study was performed in agreement with the code of conduct on the use of data in health research, put forward by the Federation of Dutch Medical Scientific Societies (http://www.federa.org). According to Dutch law, institutional review board approval is not mandatory for scientific analysis of anonymous data.

Table 5.1 Donor, graft and recipient characteristics.

\begin{tabular}{|c|c|c|c|}
\hline & DBTL group & Aortic group & $P \ddagger$ \\
\hline \multicolumn{4}{|l|}{ Donor characteristics } \\
\hline All kidneys & $202(61.8)$ & $125(38.2)$ & \\
\hline Age (years)* & $48(16)$ & $44(17)$ & 0.035 \\
\hline Sex ratio(M:F) & $107: 95$ & $57: 68$ & $0.195 \S$ \\
\hline Cardiovascular cause of death & $52(25.7)$ & $65(52.0)$ & $<0.001 \S$ \\
\hline Serum creatinine $(\mu \mathrm{mol} / \mathrm{l})^{*}$ & $83(37)$ & $70(22)$ & $<0.001$ \\
\hline Donor region & & & $<0.001 \S$ \\
\hline 1 & $74(36.6)$ & $110(88.0)$ & \\
\hline 2 & $128(63.4)$ & $15(12.0)$ & \\
\hline Transplanted kidneys & $145(71.8)$ & $119(95.2)$ & $<0.001 \S$ \\
\hline Age (years)* & $44(16)$ & $44(17)$ & 0.985 \\
\hline Sex ratio(M:F) & $76: 69$ & $54: 65$ & $0.255 \S$ \\
\hline Cardiovascular cause of death & $32(22.1)$ & $61(51.3)$ & $<0.001 \S$ \\
\hline Serum creatinine $(\mu \mathrm{mol} / \mathrm{l})^{*}$ & $77(25)$ & $70(22)$ & 0.018 \\
\hline Donor region & & & $<0.001 \S$ \\
\hline 1 & $65(44.8)$ & $104(87.4)$ & \\
\hline 2 & $80(55.2)$ & $15(12.6)$ & \\
\hline \multicolumn{4}{|l|}{ Graft characteristics } \\
\hline Warm ischemia time (min)* & $27(8)$ & $22(9)$ & $<0.001$ \\
\hline Cold ischemia time $(h)^{*}$ & $24(6)$ & $19(5)$ & $<0.001$ \\
\hline Anastomosis time $(\mathrm{min})^{*}$ & $36(12)$ & $35(14)$ & 0.687 \\
\hline \multicolumn{4}{|l|}{ Recipient characteristics ${ }^{\dagger}$} \\
\hline Age (years)* & $50(13)$ & $50(13)$ & 0.945 \\
\hline Sex ratio(M:F) & $86: 58$ & $70: 46$ & $0.919 \S$ \\
\hline Kidney disease (renovascular) & 28 of $115(24.3)$ & 19 of $97(20)$ & $0.406 \S$ \\
\hline Dialysis time (years)* & $4.5(3.1)$ & $4.2(1.6)$ & 0.403 \\
\hline Dialysis type (haemodialysis) & $84(58.3)$ & $72(62.1)$ & $0.441 \S$ \\
\hline Retransplantation & 23 of $143(16.1)$ & 17 of $113(15.0)$ & $0.820 \S$ \\
\hline Total no. of HLA -ABDR mismatches* & $2.5(1.0)$ & $2.2(1.0)$ & 0.008 \\
\hline Length of follow-up (years)* & $3.4(1.9)$ & $2.7(1.4)$ & 0.001 \\
\hline
\end{tabular}

Values in parentheses are percentages unless indicated otherwise; * values are mean(s.d.). $\uparrow$ In the doubleballoon triple-lumen (DBTL) group 144 kidneys had follow-up, and 116 in the aortic group. HLA, human leucocyte antigen. $\$$ Independent-samples $t$ test, except $\S \chi_{2}$ test 


\section{Statistical analysis}

The outcome of the DCD kidneys preserved with DBTL catheter insertion was compared with that of kidneys preserved by direct aortic cannulation in the same interval. Differences in characteristics between these preservation methods were compared using the independent-samples $t$ test for continuous variables and Pearson's $\chi^{2}$ test for categorical variables. Graft and patient survival rates were calculated by the KaplanMeier method; survival curves were compared with the log rank test. Graft survival was censored for recipient death with a functioning graft. Differences in kidney discard rates between the preservation methods were analysed using multivariable logistic regression analysis with correction for donor characteristics that were considered potential confounders. The effects of the preservation method on graft failure were identified with Cox regression analysis, with correction for potential confounders. All statistical analyses were done using SPSS ${ }^{\circledR}$ version 16.0 for Windows software (SPSS, Chicago, Illinois, USA). $P \leq 0.050$ was considered statistically significant.

\section{Results}

In the study interval, 165 controlled DCD procedures were initiated in the two donor regions. There were 102 donors in the DBTL group and 63 in the aortic group. A potential 327 kidneys were recovered; one donor had a single kidney, and another had a horseshoe kidney. The kidneys from a paediatric donor were recovered en bloc. Some 202 kidneys were preserved by DBTL catheter insertion (DBTL group), and 125 kidneys with direct aortic cannulation (aortic group). In the aortic group, $14.4 \%$ of the procedures (18 donors) also included procurement of the liver. Of the 327 available kidneys, 264 (80.7\%) were transplanted. There were 260 recipients who had follow-up for a median of 3.4 (range $0-6.9$ ) years.

Donor, graft and recipient characteristics are presented in Table 5.1. The mean age of donors in the DBTL group was higher than in the aortic group (48 versus 44 years respectively; $P=0.035$ ), but the age of the donors whose kidneys were eventually transplanted was similar. Twelve donors were more than 65 years of age. The mean serum creatinine level of the donors of both preserved and transplanted kidneys was significantly higher in the DBTL group than in the aortic group: 83 versus $70 \mu \mathrm{mol} / \mathrm{I}$ $(P<0.001)$ and 77 versus $70 \mu \mathrm{mol} / \mathrm{l}(P=0.018)$ respectively; this was related to the older age of donors in the DBTL group. The cause of death was cardiovascular significantly more often in the aortic group than in the DBTL group (52.0 versus $25.7 \% ; P<0.001$ ).

\section{Kidney discard}

In the DBTL group, 57 kidneys (28,2\%) were not transplanted, compared with six (4.8\%) in the aortic group $(P<0.001)$. In seven donors (14 kidneys) this was caused directly by 
technical problems with the DBTL catheter: insertion of the catheter through the femoral artery was not possible in three donors (6 kidneys); wrong position of the catheter in three donors ( 6 kidneys); and accidental use of a paediatric catheter in one adult donor (2 kidneys). The main reason for kidney discard was their poor quality: 21 kidneys in the DBTL group were discarded because of marginal graft and poor flushout. In seven cases both kidneys were discarded at retrieval in the operating room because of poor flush-out, despite correct positioning of the DBTL catheter. In 26 kidneys (46\%) the discard was related to the DBTL catheter (difficulties with DBTL catheter insertion, 14; poor flush out, 12). Other reasons for discard are listed in Table 5.2. In the aortic group, four kidneys were of poor quality. From the 12 donors older than 65 years of age, 12 (50\%) of the 24 kidneys were discarded; in donors aged 65 years or less the discard rate was $16.8 \%$ (51 of 303 kidneys).

Table 5.2 Reasons for kidney discard.

\begin{tabular}{|c|c|c|}
\hline & $\begin{array}{l}\text { DBTL group } \\
\text { (57 kidneys) }\end{array}$ & $\begin{array}{c}\text { Aortic group } \\
\text { (6 kidneys) }\end{array}$ \\
\hline Difficulties with in situ preservation & 14 & \\
\hline DBTL catheter could not be inserted & 6 & \\
\hline Catheter malposition & 6 & \\
\hline Paediatric catheter used & 2 & \\
\hline Poor-quality kidney & 33 & 4 \\
\hline Anatomical & 4 & 2 \\
\hline Infection & 4 & \\
\hline Kidney damaged & 4 & 1 \\
\hline Marginal graft & 9 & \\
\hline Poor flush-out & 12 & 1 \\
\hline Medical contraindication & 6 & \\
\hline Kidney tumor & 4 & \\
\hline No suitable recipient & 2 & \\
\hline Wrong perfusion fluid used & & 2 \\
\hline Unknown reason & 4 & \\
\hline
\end{tabular}

DBTL, double-balloon triple-lumen

In multivariable analysis, increasing donor age, vascular cause of death, donor from region 2, and preservation with the DBTL catheter were independent risk factors for kidney discard, of which preservation with the DBTL catheter (odds ratio (OR) 5.19, 95\% confidence interval (c.i.) 1.88 to $14.36 ; P=0.001$ ) and increasing donor age (OR 1.05, 1.02 to $1.07 ; P<0.001$ ) were the most important (Table 5.3). 
Table 5.3 Multivariable logistic regression analysis of risk factors for discard.

\begin{tabular}{lcr}
\hline & Odds ratio & $P$ \\
Preservation (DBTL versus aortic*) & $5.19(1.88,14.36)$ & 0.001 \\
\hline Donor age (years) & $1.05(1.02,1.07)$ & $<0.001$ \\
Donor region (2 versus $\left.1^{*}\right)$ & $2.40(1.02,5.64)$ & 0.044 \\
Cause of death (cardiovascular versus other*) & $2.30(1.05,5.03)$ & 0.037 \\
Donor creatinine ( $\mu$ mol/l) & $1.01(1.00,1.01)$ & 0.023 \\
Donor sex (M versus $\left.\mathrm{F}^{*}\right)$ & $0.94(0.48,1.87)$ & 0.881 \\
\hline
\end{tabular}

Values in parentheses are 95 per cent confidence intervals. * Reference category. Four procedures were excluded owimh to missing values for creatinine. DBTL, double-balloon triple-lumen

\section{Results of kidney transplantation}

Both the warm and cold ischaemia times were significantly longer in the DBTL group (Table 5.1). The recipient characteristics in the two groups were similar, except for a higher total number of human leucocyte antigen (HLA)-ABDR mismatches in the DBTL group. The incidence of PNF was higher in the DBTL group (21.7 versus $12.9 \%$ ), but this did not reach statistical significance $(P=0.067)$. The rate of delayed graft function and the GFR of functioning grafts at 3 months, 1, 2 and 5 years after transplantation were similar in the two groups (Table 5.4). During follow-up, 29 patients died, 12with a functioning kidney. Recipient survival curves were similar in the two groups ( $P=0.142$, log rank test). In total, 58 patients lost their kidney grafts during follow-up: PNF (46 patients), chronic allograft nephropathy (3), chronic rejection (5), recurrent primary kidney disease (1), infection (2) and unknown (1). Graft survival, censored for recipient death, was better in the aortic than in the DBTL group: 86.2 versus $76.8 \%$ respectively at 1 year; 85.2 versus $76.0 \%$ at 2 years; and 85.2 versus $71.7 \%$ at 4 years ( $P=0.027$, log rank test).

The preservation method itself had no significant effect on graft failure (hazard ratio (HR) $0.90,95 \%$ c.i. 0.46 to $1.75 ; P=0.757)$; the only significant variable was warm ischaemia time (HR 1.04, 1.01 to 1.07; $P=0.009$ ) (Table 5.5).

Table 5.4 Function of kidneys from controlled donors after cardiac death.

\begin{tabular}{lccc}
\hline & DBTL group & Aortic group & $P \ddagger$ \\
Short-term function & & & \\
Primary non-function ${ }^{+}$ & 31 of $143(21.7)$ & 15 of $116(12.9)$ & $0.067 \S$ \\
Delayed graft function ${ }^{+}$ & 72 of $142(50.7)$ & 66 of $116(56.9)$ & $0.321 \S$ \\
Medium-term function & & & \\
GFR (ml/min)* & & & 0.174 \\
After 3 months & $40(19)$ & $43(22)$ & 0.555 \\
After 1 year & $47(22)$ & $48(20)$ & 0.870 \\
After 2 years & $28(21)$ & $49(21)$ & 0.583 \\
\hline After 5 years & $51(20)$ & $54(24)$ & \\
\hline
\end{tabular}

* Values are mean (s.d.); + values in parentheses are percentages. DBTL, double-balloon triple-lumen; GFR, glomerular filtration rate. $¥$ Independent-samples $t$ test, except $\S X^{2}$ test 
Table 5.5 Cox regression analysis of risk factors for graft failure.

\begin{tabular}{lcc}
\hline & Hazard ratio & $P$ \\
Preservation (aortic versus DBTL group*) & $0.90(0.46,1.75)$ & 0.757 \\
\hline Donor region (1 versus $\left.2^{*}\right)$ & $0.55(0.28,1.07)$ & 0.079 \\
Cold ischaemia time $(\mathrm{h})$ & $1.02(0.97,1.06)$ & 0.349 \\
Donor age (years) & $1.01(0.99,1.03)$ & 0.472 \\
Donor creatinine $(\mu \mathrm{mol} / \mathrm{l})$ & $0.99(0.98,1.01)$ & 0.472 \\
Warm ischaemia time $(\mathrm{min})$ & $1.04(1.01,1.07)$ & 0.009 \\
\hline
\end{tabular}

Values in parentheses are 95 per cent confidence intervals. * Reference category. DBTL, double-balloon triplelumen

\section{Discussion}

Kidneys from DCD donors are an important source of donor organs for kidney transplantation. In the Netherlands, more than $40 \%$ of the deceased donor kidneys are from DCD donors. Owing to the relatively liberal use of marginal DCD kidneys, the PNF rate is higher than that after brain-dead donor kidney transplantation. However, the long-term survival of functioning grafts and the survival of recipients are similar following transplantation of kidneys from DCD donors and brain-dead donors. ${ }^{14,15}$ In this study two methods of in situ preservation of controlled DCD kidneys were compared retrospectively in two donor regions in the Netherlands: insertion of the DBTL catheter and direct cannulation of the aorta after rapid laparotomy. Graft survival of transplanted kidneys was lower in the DBTL group, despite a significantly higher discard rate. Direct aortic cannulation was associated with a lower discard rate, shorter warm ischaemia and improved graft survival.

In controlled DCD procedures, there is sufficient time to prepare the necessary logistical and legal requirements before treatment is withdrawn. The authors prefer to withdraw treatment in intensive care rather than in the operating room, as this guarantees less interference with end-of-life care for patients and their relatives. This policy is not associated with inferior graft outcome. ${ }^{16}$ In the present study, direct aortic cannulation resulted in a shorter warm ischaemia time than DBTL catheter use, despite the time needed to transport the donor to the operating room. Direct access to the aorta was faster and more successful than inserting the DBTL catheter through the femoral artery. The shorter cold ischaemia time in the aortic group can be explained by the earlier acceptance of these kidneys after allocation in the Eurotransplant region.

One of the disadvantages of the DBTL catheter method is the potentially difficult insertion of the catheter into the femoral artery in patients with severe atherosclerosis. Moreover, although kidneys can eventually be flushed and cooled to $10-15^{\circ} \mathrm{C}^{8}$ with a DBTL catheter, the pressure with which the organs are perfused is higher with direct 
cannulation of the aorta. The aortic cannula is shorter and its inner diameter is almost twice that of the DBTL catheter. The slightly larger venous outflow catheter employed in the aortic group may have facilitated venous run-off, with improved organ perfusion. Additionally, with the direct aortic cannulation technique, topical intraperitoneal cooling using $4^{\circ} \mathrm{C}$ saline can be employed to cool the organs quickly. Finally, the delay between organ preservation and harvesting was shorter after direct aortic cannulation.

There may still be reasons to employ a DBTL catheter in the controlled DCD donor. It is relatively simple for a surgeon to use, and can be done at the bedside in every hospital with a DCD protocol. The method can be used if the operating room is not near intensive care, or if relatives explicitly request to be present at the moment of death, and for a period of time afterwards.

Donation in one of the two regions included was associated with an increased likelihood of kidney discard. In this region, the threshold to initiate a donor procedure was generally lower than in the other region. This resulted in a higher number of kidney donors, but also in a higher discard rate of recovered kidneys. In the multivariable risk analyses, the initial preservation technique remained the most important risk factor for kidney discard. The main reason for discard was poor kidney quality after preservation. In 12 of the kidneys from the DBTL group, the flush-out was poor, resulting in a blue congested kidney, as also described by others. ${ }^{17}$ This may have been due to insufficient flushing during perfusion through the catheter. Technical problems were not encountered with the aortic cannulation technique.

In the DBTL group, although more kidneys were discarded, $21.7 \%$ of patients had PNF, suggesting that the threshold to discard a kidney was relatively high. PNF leaves the recipient on dialysis, with a worse chance of subsequent transplant owing to immunological sensitization. The published rate of PNF after DCD kidney transplantation ranges from 4 to $20 \% .{ }^{14},{ }^{15}, 18$ Despite the high rate of PNF, recipients of DCD kidneys benefit overall from improved patient survival compared with patients who wait longer for a brain-dead donor kidney. ${ }^{19}$

The preservation method itself had no significant effect on the rate of graft failure. In the regression analysis, the only significant risk factor for graft failure was the warm ischaemia time, which was closely related to the preservation method and was significantly shorter in the aortic group.

There are some limitations of this study, mainly that it was not a randomized controlled trial. Direct aortic cannulation is the method of choice for controlled donors in many areas, supported by the findings of this retrospective study. A randomized comparison with the DBTL catheter method would be difficult. The reason for the regional variation was that organs were usually preserved and harvested by national procurement teams. In one region there was large experience with uncontrolled DCD donation, for which femoral artery cannulation was the commonly used technique. In this region, femoral 
artery cannulation was also used more often in controlled donors and direct aortic cannulation was introduced later. This did not appear to influence the results of the present study, as the risk factors for discard and graft failure showed equivalent results if corrected for epoch.

Finally, organ preservation in multiorgan donors was always done by direct aortic cannulation. In the present study the number of multiorgan donors in the direct aortic cannulation group was relatively small, and their exclusion did not affect the results, with equivalent effects of the preservation method on discard and graft failure. 


\section{References}

1 Wolfe RA, Ashby VB, Milford EL, Ojo AO, Ettenger RE, Agodoa LY, Held PJ, Port FK. Comparison of mortality in all patients on dialysis, patients on dialysis awaiting transplantation, and recipients of a first cadaveric transplant. N Engl J Med 1999;341:1725-30.

2 Kootstra G. Expanding the donor pool: the challenge of non-heart-beating donor kidneys. Transplant Proc 1997;29:3620.

3 Keizer KM, de Fijter JW, Haase-Kromwijk BJ,WeimarW. Non-heart-beating donor kidneys in the Netherlands: allocation and outcome of transplantation. Transplantation 2005;79:1195-9.

4 Nicholson ML, Metcalfe MS, White SA, Waller JR, Doughman TM, Horsburgh T, Feehally J, Carr SJ, Veitch PS. A comparison of the results of renal transplantation from non-heart-beating, conventional cadaveric, and living donors. Kidney Int 2000;58: 2585-91.

5 Gok MA, Buckley PE, Shenton BK, Balupuri S, El-Sheikh MA, Robertson H, Soomro N, Jaques BC, Manas DM, Talbot D. Long-term renal function in kidneys from non-heart-beating donors: a single-center experience. Transplantation 2002;74:664-9.

6 Dutch Transplant Foundation. Dutch Transplant Foundation Annual Report 2008. Dutch Transplant Foundation: Leiden, 2008.

7 Shiroki R, Hoshinaga K, Higuchi T, Tsukiashi Y, Kubota Y, Maruyama T, Izumitani M, Horiba M, Naide Y, Kanno T. Prolonged warm ischemia affects long-term prognosis of kidney transplant allografts from nonheart-beating donors. Transplant Proc 1998; 30:111-3.

8 Garcia-Rinaldi R, Lefrak EA, Defore WW, Feldman L, Noon GP, Jachimczyk JA et al. In situ preservation of cadaver kidneys for transplantation: laboratory observations and clinical application. Ann Surg 1975; 182:576-84.

9 Foley DP, Fernandez LA, Leverson G, Chin LT, Krieger N, Cooper JT, Shames BD, Becker YT, Odorico JS, Knechtle SJ, Sollinger HW, Kalayoglu M, D'Alessandro AM. Donation after cardiac death: the University of Wisconsin experience with liver transplantation. Ann Surg 2005;242:724-31.

10 Snoeijs MG, Dekkers AJ, Buurman WA, van den Akker L, Welten RJ, Schurink GW, van Heurn LW. In situ preservation of kidneys from donors after cardiac death: results and complications. Ann Surg 2007;246:844-52.

11 Kootstra G, Daemen JH, Oomen AP. Categories of non-heart-beating donors. Transplant Proc 1995;27: 2893-4.

12 Kootstra G, van Hooff JP. [In-situ preservation of kidneys of 'non-heart-beating' donors: a possible way to offset the shortage of donor kidneys.] Ned Tijdschr Geneeskd 1998;142:2838-43.

13 Pöge U, Gerhardt T, Palmedo H, Klehr HU, Sauerbruch T, Woitas RP. MDRD equations for estimation of GFR in renal transplant recipients. Am J Transplant 2005;5:1306-11.

14 Wijnen RM, Booster MH, Stubenitsky BM, de Boer J, Heineman E, Kootstra G. Outcome of transplantation of non-heart-beating donor kidneys. Lancet 1995;345:1067-70.

15 Weber M, Dindo D, Demartines N, Amb“ uhl PM, Clavien PA. Kidney transplantation from donors without a heartbeat. N Engl J Med 2002;347:248-55.

16 Johnson SR, Pavlakis M, Khwaja K, Karp SJ, Curry M, Curran CC, Monaco AP, Hanto DW. Intensive care unit extubation does not preclude extrarenal organ recovery from donors after cardiac death. Transplantation 2005;80:1244-50.

17 Gok MA, Bhatti AA, Asher J, Gupta A, Shenton BK, Robertson H, Soomro NA, Talbot D. The effect of inadequate in situ perfusion in the non heart-beating donor. Transpl Int 2005;18:1142-6.

18 Sánchez-Fructuoso Al1, Prats D, Torrente J, Pérez-Contín MJ, Fernández C, Alvarez J, Barrientos A. Renal transplantation from non-heart beating donors: a promising alternative to enlarge the donor pool. J Am Soc Nephrol 2000;11:350-8.

19 Snoeijs MG1, Schaubel DE, Hené R, Hoitsma AJ, Idu MM, Ijzermans JN, Ploeg RJ, Ringers J, Christiaans $\mathrm{MH}$, Buurman WA, van Heurn LW. Kidneys from donors after cardiac death provide survival benefit. J Am Soc Nephrol 2010;21:1015-21. 


\section{Chapter}

\section{Preservation techniques for donors after cardiac death kidneys}

J Wind, ERP Hoogland, LWE van Heurn 


\section{Abstract}

Purpose of review

The purpose of the present review is to describe the techniques currently used to preserve kidneys from donors after cardiac death.

\section{Recent findings}

Automated chest compression devices may be used to improve organ perfusion between cardiac death and preservation measures. Normothermic extracorporeal membrane oxygenation reduces warm ischemic injury and has the ability to improve organ viability in donors after cardiac death.

\section{Summary}

Kidneys from donors after cardiac death expand the donor pool but are inevitably subjected to a period of warm ischemia. Reduction of warm ischemic injury to the organs improves transplant outcome. To reduce this injury in organs from donors after cardiac death, different preservation techniques are used. Automated chest compression devices improve organ perfusion between cardiac death and the start of organ preservation. In-situ preservation with double-balloon triplelumen catheter is an easy technique to preserve organs in uncontrolled donors and is used in many centers to cool and flush the organs. In controlled donors, organs can also be flushed after laparotomy and direct cannulation of the aorta. Extracorporeal membrane oxygenation reduces warm ischemic injury and the use of normothermic perfusion seems promising.

Optimal preservation is essential to improve the viability of kidneys from donors after cardiac death, to fully utilize this large donor pool. 


\section{Introduction}

The donor pool of kidneys for transplantation can be expanded by the use of kidneys from donors after cardiac death (DCD). ${ }^{1,2}$ The graft survival of functioning DCD kidneys is similar to kidneys from donors after brain death, despite the higher incidence of primary nonfunction (PNF) and delayed graft function (DGF) after kidney transplantation. ${ }^{3-9}$ For patients on dialysis, transplantation with a DCD kidney results in a survival benefit compared with staying on dialysis and wait for a brain dead donor kidney. ${ }^{10^{* *}}$ The viability of DCD kidneys is limited by ischemic injury if the period of warm ischemia is long or if preservative measures are inadequate. Warm ischemic injury is inevitable in DCD organs and prolonged warm ischemia time is associated with reduced graft survival. ${ }^{11,12}$ There are several methods to reduce warm ischemic injury in both controlled and uncontrolled DCD kidneys.

\section{Categories of donors after cardiac death}

At the first international workshop on DCD donation in Maastricht in 1995, four categories of donors were established (Table 6.1) and were classified according to variations in warm ischemia duration. ${ }^{13}$. Uncontrolled donation (Maastricht categories I, II and IV) includes donors with unexpected cardiopulmonary arrest and/or unsuccessful resuscitation. In a short-time legal, logistical and medical requirements for donation must be met which requires a team of professionals familiar with DCD donation. In controlled donation (Maastricht category III), which is usually performed in the ICU, these requirements can be arranged before withdrawal of treatment. The moment of withdrawal of treatment can, within certain limits, be chosen. The methods to preserve DCD donor kidneys depend on the Maastricht category and vary per country and center. In most countries, preservation measures are started after a 'no touch' period of at least 5 min after declaration of death.

In this review we describe the different preservation techniques, currently used to preserve organs from DCD donors in order to reduce warm ischemia times.

Table 6.1 Maastricht classification of donors after cardiac death.

\begin{tabular}{lll}
\hline Category & Description & Procurement \\
I & Dead on arrival & Uncontrolled \\
II & Unsuccessful resuscitation & Uncontrolled \\
III & Awaiting cardiac arrest & Controlled \\
IV & Cardiac arrest while brain dead & Controlled/Uncontrolled \\
\hline
\end{tabular}




\section{Mechanical chest compression device}

In the uncontrolled category I and category II DCD donors, cardiopulmonary resuscitation (CPR) after cardiac death can be used as a bridge to organ preservation with the aim to improve kidney circulation and reduce warm ischemic injury to the kidneys of a potential donor.

Manual CPR primarily increases the coronary and cerebral perfusion with relatively little blood flow to the visceral organs. ${ }^{14}$ Automated chest compression devices, such as AutoPulse (ZOLL Circulation, Sunnyvale, California, USA; Figure 6.1), provide a higher peak aortic pressure with possibly superior perfusion of the visceral organs, resulting in less ischemic injury and better graft function after transplantation. ${ }^{15,16}$ Automated chest compression can be used until ISP is started. In Paris, by the use of the AutoPulse in uncontrolled DCD donors the number of transplanted kidneys increased with $10 \%$ with an excellent 6-month graft survival of $89 \%$ after kidney transplantation. ${ }^{17}{ }^{*}$ If the AutoPulse is used, it is important to position the chest band properly and check the position regularly to prevent injury to the abdominal organs. ${ }^{18}$

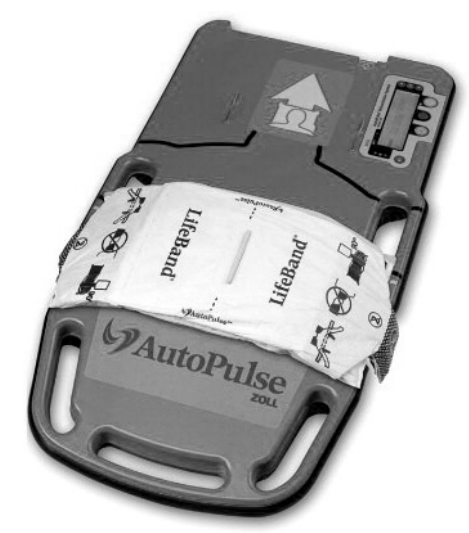

Figure 6.1 The AutoPulse (ZOLL Circulation) for delivery of chest compression during cardiopulmonary resuscitation. Reproduced with permission from ${ }^{16}$.

\section{Key points}

- Automated chest compression devices may improve organ perfusion between cardiac death and the start of organ preservation in uncontrolled donors.

- In-situ preservation with the double-balloon triple-lumen catheter is an easy technique to preserve kidneys in uncontrolled donors.

- Extracorporeal membrane oxygenation reduces warm ischemic injury in uncontrolled donors after cardiac death. 


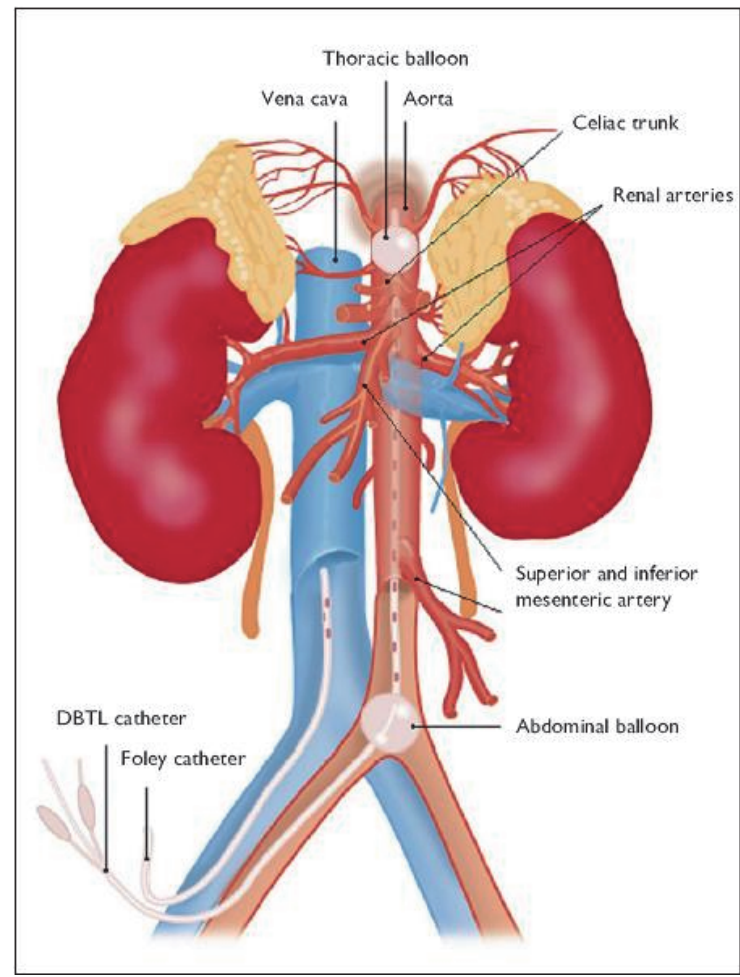

Figure 6.2 In situ preservation technique with the double-balloon triple-lumen catheter.

\section{In-situ preservation with the double-balloon triple-lumen catheter}

In many centers, the method of choice for uncontrolled Maastricht category I and category II DCD donors is in-situ preservation (ISP) with a double-balloon triple-lumen (DBTL) catheter (Figure 6.2). This minimally invasive technique is relatively simple and can be performed by surgeons with limited technical experience. ISP is usually performed in the Emergency Room after failed resuscitation. It preserves organ viability and gives the opportunity to meet the legal and logistical requirements before organ recovery. It also gives family the time to decide about organ donation. After declaration of death and a 'no touch' period, preservation measures are started. The DBTL catheter is inserted through the femoral artery into the aorta. After partial inflation of the abdominal balloon, the catheter is pulled back onto the aortic bifurcation and the balloon is fully inflated. 
Blood is taken for screening. After inflation of the thoracic balloon, which is positioned above the renal arteries, an infusion system is connected to the catheter and cold preservation solution is infused until donor nephrectomy. ${ }^{19}$ A total of $15-20$ । of preservation solution of $4{ }^{\circ} \mathrm{C}$ is flushed, resulting in cooling of the kidneys to $10-15^{\circ} \mathrm{C} .^{20}$ Before start of the perfusion, heparine and streptokinase are administered through the catheter to reduce the chance of capillary occlusion and warm ischemic damage. ${ }^{21}$ To allow outflow of the perfusate, a large Foley catheter is introduced into the femoral vein. After the catheters are fixed, the skin incision is closed and the relatives are offered the opportunity to visit the deceased patient. Donor nephrectomy is performed as soon as possible, but within $2 \mathrm{~h}$ after ISP.

A relatively small proportion of the initiated ISP procedures lead to transplantation. The procedure itself can be abandoned because of medical contra-indication of the patient or refusal to donation of the family. Technical complications of the procedure itself have been described, like an inaccessible femoral artery, malposition of the DBTL catheter and rupture of the abdominal balloon. Increasing donor age and uncontrolled DCD donation are associated with ISP complications. Prolonged DBTL catheter insertion time is an independent predictor of graft failure. ${ }^{22,23}$

\section{In-situ preservation and peritoneal cooling}

Additional peritoneal cooling next to ISP with a DBTL catheter in a model of uncontrolled DCD in animals showed a lower temperature of the kidneys with ischemia protection and improved viability. Organs were topically cooled with peritoneal dialysis via a laparoscopic port. The system was connected to a circuit with a roller pump and cooling unit. ${ }^{24}$ Outflow was secured with a pelvic catheter. There are no data in humans.

\section{Direct cannulation of the aorta after rapid laparotomy}

In Maastricht category III DCD donors, rapid laparotomy and direct cannulation of the aorta leads to superior graft survival compared with ISP with the DBTL catheter. ${ }^{22}$ Lifesustaining treatment can be withdrawn in the operating room or in the ICU, with the family present at the bedside. If treatment is withdrawn in the ICU, the operating room must be in the vicinity of the ICU. After declaration of death by an independent physician and the 'no touch' period, the patient is transferred to the operating room where prepared surgical staff is waiting. After rapid laparotomy, a cannula is inserted into the aorta or into one of the common iliac arteries and the aorta is clamped below the diaphragm. Cold preservation fluid is infused through the cannula. The inferior caval vein is vented to guarantee outflow. Additionally, the organs in the peritoneal cavity are topically cooled with cold saline and the organs are immediately procured. ${ }^{25}$ Depending 
on legal and ethical considerations, in some centers the potential donor is already prepared before withdrawal of treatment: the patients are cannulated and heparin is administered to reduce warm ischemic injury. ${ }^{26}$ After the declaration of death and the 'no touch' period, preservation starts. Withdrawal of treatment in the operating room may influence good end-of-life care. If the patient does not die within a certain period, the patient has to be transported back to the ICU, which may have a negative impact on the patients' relatives and involved medical staff.

\section{Extracorporeal membrane oxygenation}

Extracorporeal membrane oxygenation (ECMO) is a device which provides temporary circulatory support and systemic oxygenation for patients with reversible respiratory failure that cannot be adequately supported with conventional mechanical ventilation and inotropic support. ${ }^{27,28}$ It has become a standard therapy in many ICUs. ${ }^{29}$ ECMO used in organ preservation restores the warm and oxygenated blood flow through the organs in a donor after cardiac death to provide normal tissue perfusion between death and organ procurement. The femoral artery and vein are cannulated with an incision in the groin or inserted percutaneously. The cannulae are connected with a machine with a centrifugal pump and oxygenator. To adjust blood temperature, a heat exchanger can be included in the circuit (Figure 6.3). Cardiac and brain perfusion are prevented by occlusion of the thoracic aorta with a balloon catheter, which is inserted in the opposite femoral artery.

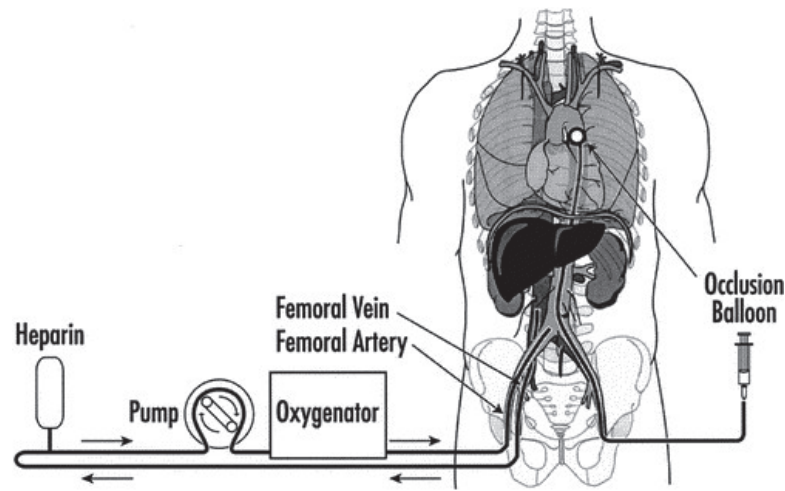

Figure 6.3 The extracorporeal membrane oxygenation configuration. Reporduced with permission from ${ }^{38}$. 


\section{Extracorporeal membrane oxygenation in uncontrolled donors after cardiac death}

In Spain, there is a relatively long experience with the use of ECMO in category I and category II DCD donors. ${ }^{30-35}$ The criteria for donation include: witnessed arrest, start of CPR within 15 min, age below 60 years, cause of death known or supposed, nonbleeding injuries in thorax and abdomen, and no external signs of possible intravenous drug abuse. After the declaration of death, the patient is heparinized, blood samples are taken and after the cannulae are in place, they are connected to the cardiopulmonary bypass machine with external oxygenation and hypothermia. ${ }^{35}$ At the same time juridical and family consent is obtained and evaluation of the donor is performed. The time limit from cardiac arrest until organ preservation has been set at 120 and 240 min from cardiac arrest until organ procurement. Using this technique, the results of DCD kidney transplantation are equivalent to DBD transplantation with 1-year and 5-year graft survival rates of 87.4 and $82.1 \%$, respectively. ${ }^{35}$ However, as a result of the stringent donor selection criteria and the limited time for thorough evaluation of the donor before starting the procedure, discard rates between 50 and $60 \%$ are reported. ${ }^{34}$

Normothermic ECMO with the donor's own blood at $37^{\circ} \mathrm{C}$ reduces the incidence of DGF and PNF compared with the ISP perfusion with the DBTL catheter and to total body cooling with a cardiopulmonary bypass. ${ }^{31}$ Normothermic ECMO also enables the use of other DCD organs than kidneys such as liver and lungs. ${ }^{32,36}$

\section{Extracorporeal membrane oxygenation in controlled donors}

Centres in the United States and Taiwan use ECMO in controlled donors. ${ }^{37-40}$ Before withdrawal of treatment and after consent of the patient's family, the patient is cannulated at the bedside in the ICU. Cannulae are placed in the common femoral artery and vein and, to avoid cardiac resuscitation, a balloon catheter is placed in the thoracic aorta. The catheters are heparinized and clamped. Life support is withdrawn and comfort measures continued. If death occurs, death is declared by the treating physician and after the 'no touch' period, ECMO perfusion starts. In the operating room, cold perfusate is connected to the arterial limb of the ECMO circuit and cold perfusion starts. The short-term results of ECMO assisted controlled DCD are comparable with kidneys from brain dead donors, and the percentage of patients with DGF after transplantation are decreased compared with conventionally preserved DCD kidney recipients. ${ }^{38,40}$

In animals, ECMO with normothermic venoarterial oxygenated blood is able to resuscitate controlled DCD kidneys after $30 \mathrm{~min}$ of warm ischemia. ${ }^{41}$. This finding 
suggests that normothermic ECMO is a valuable approach to preserve ischemically damaged kidneys, which can improve the viability of marginal grafts. ${ }^{42}$

\section{Conclusion}

Kidneys from DCD donors contribute substantionally to the donor pool. Preservation of the organs after the heart has stopped beating is one of the cornerstones to minimize warm ischemic injury to the organs and to ensure that organs can be used for transplantation. Several preservation techniques are currently used. Automated chest compression devices improve organ perfusion during resuscitation and can be used before preservation measures have been taken. ISP with the DBTL catheter is used in uncontrolled donors. The procedure is relatively easy to perform. In controlled DCD donors, laparotomy with direct cannulation of the aorta may be superior to ISP with the DBTL catheter. ECMO can be used both in uncontrolled and in controlled donors. It is a promising technique and minimizes ischemic injury in DCD kidneys, particularly with normothermic circulation. It may improve the viability of marginal donor kidneys, such as DCD kidneys. The method of choice to preserve DCD kidneys depends on logistic, ethical, financial and legal jurisdictional circumstances. 


\section{References}

Papers of particular interest, published within the annual period of review, have been highlighted as:

* of special interest

** of outstanding interest

1. Daemen JW, Oomen AP, Kelders WP, Kootstra G. The potential pool of non-heart-beating kidney donors. Clin Transplant 1997;11:149-54.

2. Terasaki PI, Cho YW, Cecka JM. Strategy for eliminating the kidney shortage. Clin Transpl. 1997:265-7.

3. Kootstra G, van Heurn E. Non-heartbeating donation of kidneys for transplantation. Nat Clin Pract Nephrol 2007;3:154-63.

4. Weber M, Dindo D, Demartines N, Ambuhl PM, Clavien PA. Kidney transplantation from donors without a heartbeat. N Engl J Med 2002;347:248-55.

5. Nicholson ML, Metcalfe MS, White SA, Waller JR, Doughman TM, Horsburgh T, Feehally J, Carr SJ, Veitch PS. A comparison of the results of renal transplantation from non-heart-beating, conventional cadaveric, and living donors. Kidney Int 2000;58:2585-91.

6. Cooper JT, Chin LT, Krieger NR, Fernandez LA, Foley DP, Becker YT, Odorico JS, Knechtle SJ, Kalayoglu M, Sollinger HW, D'Alessandro AM. Donation after cardiac death: the university of wisconsin experience with renal transplantation. Am J Transplant 2004;4:1490-4.

7. Barlow AD, Metcalfe MS, Johari Y, Elwell R, Veitch PS, Nicholson ML. Case-matched comparison of longterm results of non-heart beating and heart-beating donor renal transplants. Br J Surg 2009;96:685-91.

8. Hoogland ER, Snoeijs MG, van Heurn LW. DCD kidney transplantation: results and measures to improve outcome. Curr Opin Organ Transplant 2010;15:177-82.

9. Snoeijs MG, Winkens B, Heemskerk MB, Hoitsma AJ, Christiaans MH, Buurman WA, van Heurn LW. Kidney transplantation from donors after cardiac death: A 25-year experience. Transplantation. 2010;90:1106-12.

10.** Snoeijs MG, Schaubel DE, Hene R, Hoitsma AJ, Idu MM, Ijzermans JN, et al. Kidneys from donors after cardiac death provide survival benefit. J Am Soc Nephrol 2010;21:1015-21.

This study shows a survival benefit for patients transplanted with standard criteria DCD kidney compared with continuing on dialysis and awaiting a DBD kidney.

11. Shiroki R, Hoshinaga K, Higuchi T, Tsukiashi Y, Kubota Y, Maruyama T, et al. Prolonged warm ischemia affects long-term prognosis of kidney transplant allografts from non-heart-beating donors. Transplant Proc 1998;30:111-3.

12. Nishikido M, Noguchi M, Koga S, Kanetake H, Matsuya F, Hayashi M, Hori T, Shindo K. Kidney transplantation from non-heart-beating donors: analysis of organ procurement and outcome. Transplant Proc 2004;36:1888-90.

13. Kootstra G, Daemen JH, Oomen AP. Categories of non-heart-beating donors. Transplant Proc. 1995 Oct;27(5):2893-4.

14. Wigginton JG, Miller AH, Benitez FL, Pepe PE. Mechanical devices for cardiopulmonary resuscitation. Curr Opin Crit Care. 2005 Jun;11(3):219-23.

15. Timerman S, Cardoso LF, Ramires JA, Halperin H. Improved hemodynamic performance with a novel chest compression device during treatment of in-hospital cardiac arrest. Resuscitation 2004;61:273-80.

16. Risom M, Jorgensen $H$, Rasmussen LS, Sorensen AM. Resuscitation, prolonged cardiac arrest, and an automated chest compression device. J Emerg Med 2010;38:481-3.

17.* Fieux F, Losser MR, Bourgeois E, Bonnet F, Marie O, Gaudez F, Abboud I, Donay JL, Roussin F, Mourey F, Adnet F, Jacob L. Kidney retrieval after sudden out of hospital refractory cardiac arrest: a cohort of uncontrolled non heart beating donors. Crit Care 2009;13:R141.

This study shows that the donor pool can be succesfully expanded with Maastricht category I and II DCD donors after strict selection.

18. Wind J, Bekkers SC, van Hooren LJ, van Heurn LW. Extensive injury after use of a mechanical cardiopulmonary resuscitation device. Am J Emerg Med 2009;27:1017 e1-2.

19. Kootstra G, van Hooff JP. In-situ preservation of kidneys of 'non-heart-beating' donors: a possible way to offset the shortage of donor kidneys. Ned Tijdschr Geneeskd 1998;142:2838-43. 
20. Garcia-Rinaldi R, Lefrak EA, Defore WW, Feldman L, Noon GP, Jachimczyk JA, DeBakey ME. In situ preservation of cadaver kidneys for transplantation: laboratory observations and clinical application. Ann Surg 1975;182:576-84

21. Gok MA, Shenton BK, Buckley PE, Peaston R, Cornell C, Soomro N, Jaques BC, Manas DM, Talbot D. How to improve the quality of kidneys from non-heart-beating donors: a randomised controlled trial of thrombolysis in non-heart-beating donors. Transplantation 2003;76:1714-9.

22. Snoeijs MG, Dekkers AJ, Buurman WA, van den Akker L, Welten RJ, Schurink GW, van Heurn LW. In situ preservation of kidneys from donors after cardiac death: results and complications. Ann Surg 2007;246:844-52.

23. Gok MA, Bhatti AA, Asher J, Gupta A, Shenton BK, Robertson H, Soomro NA, Talbot D. The effect of inadequate in situ perfusion in the non heart-beating donor. Transpl Int 2005;18:1142-6.

24. Navarro AP, Asher J, Sohrabi S, Reddy M, Stamp S, Carter N, Talbot D. Peritoneal cooling may provide improved protection for uncontrolled donors after cardiac death: an exploratory porcine study. Am J Transplant 2009;9:1317-23.

25. de Vries EE, Snoeijs MG, van Heurn E. Kidney donation from children after cardiac death. Crit Care Med 2010;38:249-53.

26. Reich DJ, Mulligan DC, Abt PL, Pruett TL, Abecassis MM, D'Alessandro A, Pomfret EA, Freeman RB, Markmann JF, Hanto DW, Matas AJ, Roberts JP, Merion RM, Klintmalm GB; ASTS Standards on Organ Transplantation Committee. ASTS recommended practice guidelines for controlled donation after cardiac death organ procurement and transplantation. Am J Transplant 2009;9:2004-11.

27. Bartlett RH, Gazzaniga AB, Huxtable RF, Schippers HC, O'Connor MJ, Jefferies MR. Extracorporeal circulation (ECMO) in neonatal respiratory failure. J Thorac Cardiovasc Surg 1977;74:826-33.

28. Punch J. Extracorporeal circulatory-assisted nonheart-beating organ donation. In: Talbot D, D’Alessandro AM, editors. Organ donation and transplantation after cardiac death. 1st edn. Oxford University Press; 2009:153-159

29. McCunn M, Reed AJ. Critical care organ support: a focus on extracorporeal systems. Curr Opin Crit Care 2009;15:554-9.

30. Sánchez-Fructuoso Al, Prats D, Torrente J, Pérez-Contín MJ, Fernández C, Alvarez J, Barrientos A. Renal transplantation from non-heart beating donors: a promising alternative to enlarge the donor pool. J Am Soc Nephrol 2000;11:350-8.

31. Valero R, Cabrer C, Oppenheimer F, Trias E, Sánchez-Ibáñez J, De Cabo FM, Navarro A, Paredes D, Alcaraz A, Gutiérrez R, Manyalich M. Normothermic recirculation reduces primary graft dysfunction of kidneys obtained from non-heart-beating donors. Transpl Int 2000;13:303-10.

32. Nunez JR, Del Rio F, Lopez E, Moreno MA, Soria A, Parra D. Non-heart-beating donors: an excellent choice to increase the donor pool. Transplant Proc 2005;37:3651-4.

33. Alvarez J, del Barrio R, Arias J, Ruiz F, Iglesias J, de Elías R, Yébenes C, Matesanz J, Caniego C, Elvira J. Non-heart-beating donors from the streets: an increasing donor pool source. Transplantation 2000;70:314-7.

34. Alvarez J, del Barrio MR, Arias J, González M, Córdoba L, Moreno F, Corpas R, Nieto M, Iglesias J, Corral E, Barra C, Elvira J, Ibarguren C. Five years of experience with non-heart-beating donors coming from the streets. Transplant Proc 2002;34:2589-90.

35. Sánchez-Fructuoso Al, Marques M, Prats D, Conesa J, Calvo N, Pérez-Contín MJ, Blazquez J, Fernández C, Corral E, Del Río F, Núñez JR, Barrientos A. Victims of cardiac arrest occurring outside the hospital: a source of transplantable kidneys. Ann Intern Med 2006;145:157-64.

36. Fondevila C, Hessheimer AJ, Ruiz A, Calatayud D, Ferrer J, Charco R, Fuster J, Navasa M, Rimola A, Taurá P, Ginés P, Manyalich M, García-Valdecasas JC. Liver transplant using donors after unexpected cardiac death: novel preservation protocol and acceptance criteria. Am J Transplant 2007; 7:1849-55.

37. Gravel MT, Arenas JD, Chenault R 2nd, Magee JC, Rudich S, Maraschio M, DebRoy M, Miller W, Punch JD. Kidney transplantation from organ donors following cardiopulmonary death using extracorporeal membrane oxygenation support. Ann Transplant 2004;9:57-8.

38. Magliocca JF, Magee JC, Rowe SA, Gravel MT, Chenault RH 2nd, Merion RM, Punch JD, Bartlett RH, Hemmila MR. Extracorporeal support for organ donation after cardiac death effectively expands the donor pool. J Trauma 2005;58:1095-101. 
39. Lee CY, Tsai MK, Ko WJ, Chang CJ, Hu RH, Chueh SC, Lai MK, Lee PH. Expanding the donor pool: use of renal transplants from non-heart-beating donors supported with extracorporeal membrane oxygenation. Clin Transplant 2005;19:383-90.

40. Farney AC, Singh RP, Hines MH, Rogers J, Hartmann EL, Reeves-Daniel A, Gautreaux MD, Iskandar SS, Adams PL, Stratta RJ. Experience in renal and extrarenal transplantation with donation after cardiac death donors with selective use of extracorporeal support. J Am Coll Surg 2008;206:1028-37.

41.* Rojas-Pena A, Reoma JL, Krause E, Boothman EL, Padiyar NP, Cook KE, Bartlett RH, Punch JD. Extracorporeal support: improves donor renal graft function after cardiac death. Am J Transplant 2010;10:1365-74.

This study adds supporting physiologic data from a large animal model to the clinical data in human DCD donors that ECMO improves post transplant outcomes.

42. Fondevila C. Is extracorporeal support becoming the new standard for the preservation of DCD grafts? Am J Transplant 2010;10:1341-2. 


\section{Chapter}

Family satisfaction of organ donors versus non-donors in the Intensive Care Unit

J Wind, WKNA van Mook, AMM Muijtjens, LWE van Heurn 


\section{Abstract}

\section{Background}

It is unknown if organ donation influences end-of life care. Our aim was to compare family satisfaction of organ donors and non-donors of patients who died in the Intensive Care.

\section{Methods}

A cohort study was performed with family members of deceased ICU patients, in a 33-bed mixed ICU of a University Medical Centre, using a translated version of the validated Family Satisfaction in the Intensive Care Unit (FS-ICU) survey. Specific questions about the organ donation process were added.

\section{Results}

The response rate was $72 \%$ (114 of 158), 2 incomplete surveys were excluded form analysis. There were 32 donor and 80 non-donor families. Three scales were distinguished with factor analysis; care scale, decision-making scale and end-of life care scale. On all scales, the donor families were more satisfied than the non-donor families, which was significant for the end-of life care scale. On all scales prolonged length of stay was significantly associated with reduced family satisfaction. Negative comments concerned the communication with the family, the lack of privacy during the dying process, support for the family and the atmosphere of the waiting room.

\section{Conclusion}

Families of patients who became donor after death were generally more satisfied with the care for their family member, especially the care at the end of life, than families of patients who did not donate organs after death, suggesting that organ donation does not negatively influence the perception of end-of-life care. Increased length of stay of the patient had a negative impact on family satisfaction. More than $80 \%$ of the donor families were very satisfied about the organ donation process. 


\section{Introduction}

Scientific and technological development facilitates support and even temporarily replacement of organ functions in critically ill patients. Although such invasive support benefits many patients, the initial support may be ineffective in others so that it is decided to withdraw futile treatment in patients, in the Intensive Care Unit (ICU). Therefore, end-of-life care and the associated quality of end-of-life care has become an important issue in contemporary Intensive Care medicine. Increasing research into its measurement and improvement has been performed. ${ }^{1-4}$ In the ICU, patient-centred care includes family-centred care, and since many ICU patients cannot make decisions for themselves due to sedation, and severity of illness, families are often involved as surrogate decision makers. ${ }^{2}$ Seeing a loved one in an ICU surrounding is however stressful for many families. ${ }^{5}$ To assess family satisfaction and identify areas for potential improvement, the Family Satisfaction in the ICU survey (FS-ICU) was developed and validated. ${ }^{6-8}$ This instrument has been modified and validated in several cohorts of family members of ICU patients and has led to quality improvement in the ICU. ${ }^{9}$ The shortened, 24-item, FS-ICU measures two main conceptual domains: satisfaction with care and satisfaction with decision-making. There is a large variety in the practice of end-of life care in the ICU between countries including the frequency and timing of withdrawal of treatment, the nature of treatments withdrawn and the order and manner of their withdrawal. Reasons for these differences have not been clearly defined, but may be influenced by differences in religion, legislation, and culture. ${ }^{10-12}$ Furthermore, variability exists within countries and between ICU's in the same country, due to variation in organisation of care in the ICU in general and physicians' attitudes towards end-of-life care, and physicians' expectation of the patient's prognosis and future quality of life. ${ }^{13,14}$

Organ donation can be seen as an integral part of end-of-life care when the initial lifesaving support has become futile. ${ }^{3}$ Organ donation in the ICU is possible either after the determination of brain death; donation after brain death (DBD) or after the declaration of circulatory death, donation after circulatory death (DCD).

If death is followed by organ donation this obviously influences end-of-life care. Brain death tests and tests to assess organ quality before withdrawal of life sustaining treatment or after the determination of brain death may also influence the perception of the quality of end-of-life care. The timing of withdrawal and the actual organ procurement (depending on the availability of the surgical team and theatre) may likewise exert its influence. Concern about the quality of the end-of-life care in DCD patients has indeed been voiced. ${ }^{15}$ Specific studies about the influence of aspects of organ donation on the satisfaction of families regarding the end-of-life care are however lacking. In particular, the difference between the satisfaction of families of donors and non-donors about the end-of-life care and information how families of donors experience the donation procedure are lacking. 
The aim of this study was to compare the satisfaction of family members of patients who died in the ICU and became organ donor and the satisfaction of family members of patients who did not donate their organs.

\section{Materials and methods}

\section{Setting and study population}

A survey was conducted among family members of all patients aged less than 76 years who died in the ICU in 2008. The 33- bed mixed ICU is located in a 715-bed University Medical Centre staffed with intensivists 24/7. Age below 76 years at the time of death was the age limit for organ donation. To increase the number of donor families, the study period for organ donor families was increased from June 2007 until June 2009. The shortened 24-item Family Satisfaction in the Intensive Care Unit (FS-ICU) score was used. ${ }^{9}$ The original FS-ICU was state-of the-art translated into the Dutch language using forward and backward translation and subsequent comparison with the original FS-ICU. It consists of 27 questions and three open-end questions. Most questions could be answered using a 5-point Likert scale (poor to excellent), for some questions an answer that best matched the respondent's view could be picked. Eight questions about organ donation were added. These questions were developed by the authors and tested and corrected by three intensivists and four transplant coordinators.

The registered family representative of the patient was approached by telephone. The study was explained and consent was asked to send the questionnaire. An explanation about the confidentiality of information was added. If the family consented with study participation, the questionnaire and return envelope were sent. A reminder was sent after four weeks in case of no response. The study was performed with approval from the medical ethical reviewing committee of the Maastricht University Medical Centre. Formal additional written consent from respondents was considered not to be required since completion and return of the survey implied consent.

\section{Data analyses}

Data were analysed using SPSS 20.0. For the quantitative data descriptive statistics were computed. Individual items of the FS-ICU were transformed into a scale with values between 0-100. Items were oriented so that higher values indicate increased satisfaction ( $0=$ poor, 25=fair, 50=good, 75=very good, 100=excellent). A detailed explanation of item recoding is available on the FS-ICU website. ${ }^{16}$ Items with a high proportion of missing scores (>10\%) were deleted from analyses. Exploratory factor analysis (on the 27 FS-ICU items), with Varimax rotation with Kaiser normalization was performed for data reduction and to gain insight in the structure underlying the items and to provide a scoring method based on scales. All items with factor loadings $<0.5$ were not included, as 
considered not contributional. Internal consistency for the resulting (sub)scales was determined using Cronbach's $\alpha$. Per scale, differences between donor and non-donor groups were investigated in a linear regression analysis, including possible confounders as co-variates. A $P$-value $<0.05$ was considered evidence of a statistical significance. Narrative comments were analyzed to reveal possible aspects, which could be missed from the structured survey. ${ }^{17}$ Content analysis of the qualitative comments applying the principles of qualitative research was independently carried out by one of the investigators (JW). In an iterative process, consensus was reached by all investigators regarding the classification.

\section{Results}

\section{Demographic data}

158 family members were approached. Nine families were lost to follow up and 5 patients' relatives were not proficient in the Dutch language. A reminder letter was sent to 35 persons, of whom 50\% responded. One hundred fourteen family members completed the FS-ICU (Table 7.1), a response rate of 72\% (114/158).

Table 7.1 Characteristics of all patients and family respondents ( $N=112)$.

\begin{tabular}{|c|c|c|}
\hline Characteristics & Patients & Respondents \\
\hline Age, years, mean (SD) & $59(11.6)$ & $54(13.6)$ \\
\hline Female, n (\%) & $41(37)$ & $76(68)$ \\
\hline \multicolumn{3}{|l|}{ Primary diagnoses, $\mathrm{n}(\%)$} \\
\hline Cardiovascular & $22(19)$ & \\
\hline Respiratory & $11(10)$ & \\
\hline Neurological & $39(34)$ & \\
\hline Sepsis & $39(34)$ & \\
\hline Other & $3(3)$ & \\
\hline ICU LOS, median days (range) & $3.5(1-64)$ & \\
\hline \multicolumn{3}{|l|}{ Relationship to patient, $\mathrm{n}$} \\
\hline Spouse/partner & & $48(43)$ \\
\hline Child & & $33(29)$ \\
\hline Parent & & $9(8)$ \\
\hline Sister/brother & & $19(17)$ \\
\hline Other & & $3(3)$ \\
\hline Lives with patient, n (\%) & & $52(46)$ \\
\hline Time dead until response month, mean (sd) & $11(4.9)$ & \\
\hline \multicolumn{3}{|l|}{ Donors } \\
\hline $\mathrm{DBD}, \mathrm{n}(\%)$ & $15(13)$ & \\
\hline $\mathrm{DCD}, \mathrm{n}(\%)$ & $17(15)$ & \\
\hline
\end{tabular}

ICU: intensive care unit; LOS: length of stay; DBD: donation after brain death; DCD: donation after cardiac death 
Two questionnaires were excluded from analyses because of missing values. Mean patients' age was 59 years, most patients were male (64\%). The median length of stay was 3 days (range 1-64). There were 15 brain death donors (DBD) and 17 donors after circulatory death (DCD). The respondents' mean age was 54 and the majority were females (69\%), most of them spouses (47\%) (Table 7.2).

\section{Exploratory factor analysis}

Three items with a high number of missing scores (>10\%) were excluded from analysis; management of pain, of breathlessness and management of agitation (Table 7.1). With the remaining 24 items, factor analysis was performed. Three scales were distinguished: 'care' (16 items: item 1, 4 t/m 20 from Table 7.2), 'decision making' (4 items, 21 t/m 24) and 'end of life care' ( 3 items, item 25 t/m 27). The item 'atmosphere in the ICU waiting room' was deleted (factor loading 0.3). Internal consistencies measured by Cronbach's alpha of the scales were: care scale 0.97 , decision making scale 0.85 and end of life care scale 0.58 .

\section{Comparison between donor families and non-donor families}

On all three scales, the scores of the families of patients who became organ donor after death and the non-donor families were compared. The donor families scored higher compared to the non-donor families on every scale, reaching statistical significance on 'end of life care' $(P<0.001)$.

Patient age, sex and length of stay were included in the regression analysis as potential confounders of differences between the donor and non-donor group. The interaction between donor-nondonor and length of stay was also tested.

\section{Care scale}

All independent variables; patient age, patient sex, donor and length of stay did not explain much of the variance in satisfaction about the care of the patient; $R^{2}=0.092$. Only a moderate effect of 'length of stay' on 'satisfaction of the family' was observed (beta=-0.26, $P=0.005$ ). The satisfaction decreased, when the length of stay increased.

\section{Decision making scale}

A comparable effect is seen for the decision making scale; $R^{2}=0.043$ with a small to moderate effect of length of stay on satisfaction (beta=-0.18, $P=0.037$ ). 
Table 7.2 Descriptive statistics for individual FS-ICU items ( $\mathrm{N}=112$ respondents).

\begin{tabular}{|c|c|c|c|c|c|c|c|c|}
\hline Item & & Missing & Floor & Ceiling & Median & IQR & Mean & SD \\
\hline 1. & $\begin{array}{l}\text { Courtesy, respect and } \\
\text { compassion towards patient }\end{array}$ & 0,9 & 0,9 & 28.6 & 75 & $50-100$ & 72.5 & 22.6 \\
\hline 2. & Management of pain & 23.0 & 5.3 & 14.0 & 75 & $50-75$ & 63.0 & 24.4 \\
\hline 3 & Management of breathlessness & 33.0 & 2.7 & 11.6 & 50 & $50-75$ & 61.7 & 24.4 \\
\hline 4. & Management of agitation & 29.5 & 3.6 & 10.7 & 50 & $50-75$ & 61.7 & 24.9 \\
\hline 5. & $\begin{array}{l}\text { How well staff considered } \\
\text { Family needs }\end{array}$ & 0.9 & 4.5 & 21.4 & 75 & $50-75$ & 60.5 & 25.4 \\
\hline 6. & $\begin{array}{l}\text { How well staff provided } \\
\text { emotional support }\end{array}$ & 0 & 5.3 & 15.2 & 50 & $50-75$ & 60.5 & 25.4 \\
\hline 7. & $\begin{array}{l}\text { Coördination and teamwork by } \\
\text { staff }\end{array}$ & 2.7 & 3.6 & 21.4 & 50 & $50-75$ & 63.3 & 26.5 \\
\hline 8. & $\begin{array}{l}\text { Courtesy, respect and } \\
\text { compassion towards family }\end{array}$ & 0 & 0.9 & 22.3 & 75 & $50-75$ & 67.6 & 23.4 \\
\hline 9. & Skill and competence of nurses & 0 & 0 & 31.3 & 75 & $50-100$ & 74.1 & 20.9 \\
\hline 10. & Communication by nurses & 0 & 2.7 & 24.1 & 75 & $50-75$ & 66.7 & 25.4 \\
\hline 11. & Skill and competence of doctors & 0.9 & 1.8 & 20.5 & 75 & $50-75$ & 67.8 & 23.4 \\
\hline 12. & Atmosphere of the ICU & 2.7 & 1.8 & 12.5 & 50 & $50-75$ & 59.6 & 22.7 \\
\hline 13. & $\begin{array}{l}\text { Atmosphere of the ICU waiting } \\
\text { room }\end{array}$ & 5.4 & 16.1 & 3.6 & 50 & $25-50$ & 39.1 & 26.1 \\
\hline 14. & $\begin{array}{l}\text { Satisfaction with level or } \\
\text { amount of care for patient }\end{array}$ & 2.7 & 2.7 & 18.8 & 75 & $50-75$ & 65.1 & 24.7 \\
\hline 15. & $\begin{array}{l}\text { Frequency of communication } \\
\text { with doctors }\end{array}$ & 0.9 & 6.3 & 17.0 & 50 & $50-75$ & 57.8 & 28.6 \\
\hline 16. & $\begin{array}{l}\text { Willingness of staff to answer } \\
\text { questions }\end{array}$ & 0 & 1.8 & 25.0 & 75 & $50-75$ & 66.2 & 25.2 \\
\hline 17. & $\begin{array}{l}\text { Staff provided } \\
\text { understandableexplanations }\end{array}$ & 0 & 1.8 & 18.8 & 75 & $50-75$ & 65.4 & 23.5 \\
\hline 18. & Honesty of information & 0.9 & 5.4 & 25.9 & 75 & $50-100$ & 66.4 & 28.1 \\
\hline 19. & Completeness of information & 0.9 & 3.6 & 21.4 & 75 & $50-75$ & 64.1 & 25.8 \\
\hline 20. & Consistency of information & 2.7 & 3.6 & 15.2 & 50 & $50-75$ & 60.5 & 25.2 \\
\hline 21. & $\begin{array}{l}\text { Feel included in decision } \\
\text { making process }\end{array}$ & 0 & 9.8 & 52.7 & 100 & $50-100$ & 75.0 & 33.8 \\
\hline 22. & $\begin{array}{l}\text { Feel supported during decision } \\
\text { making process }\end{array}$ & 2.7 & 7.1 & 18.8 & 75 & $50-75$ & 66.1 & 28.1 \\
\hline 23. & $\begin{array}{l}\text { Feel control over the care of } \\
\text { the patient }\end{array}$ & 2.7 & 11.6 & 41.1 & 75 & $25-100$ & 64.8 & 36.8 \\
\hline 24. & $\begin{array}{l}\text { Adequate time to address } \\
\text { concerns \& answer questions }\end{array}$ & 2.7 & 18.8 & 78.6 & 100 & $75-100$ & 80.7 & 39.6 \\
\hline 25. & $\begin{array}{l}\text { Life unnecessarily } \\
\text { Prolonged/shortened }\end{array}$ & 3.6 & 7.1 & 70.5 & 100 & $50-100$ & 82.8 & 30.6 \\
\hline 26. & $\begin{array}{l}\text { During final hours } \\
\text { comfortable/uncomfortable }\end{array}$ & 0.9 & 4.5 & 24.1 & 50 & $50-75$ & 64.4 & 36.8 \\
\hline 27. & $\begin{array}{l}\text { Abandoned/supported during } \\
\text { last hours }\end{array}$ & 0.9 & 1.8 & 23.1 & 75 & $75-75$ & 75.4 & 18.7 \\
\hline
\end{tabular}




\section{End of life care scale}

This scale explains more variance, but the extent is still limited; $R^{2}=0.11$, a small to moderate effect of donation on the satisfaction of the end of life care was observed; the donor families were more satisfied about the care at the end of life; beta=0.20, $P=0.024$. Also a small to moderate effect of length of stay on satisfaction was noted (beta=-0.20, $P=0.020)$.

For none of the scales a significant contribution was found for the interaction donornondonor and length of stay

There were 3 items with significant higher scores for donor in the between group

differences: 1) 'Patients' comfort during the last hours' $\left(R^{2}=0.122\right.$, beta $\left.=0.21, P=0.011\right)$, 2) 'Support for the family during the last hours' $\left(R^{2}=0.173\right.$, beta=0.21, $\left.P=0.015\right)$, with also a small to moderate effect of length of stay (beta=-0.30, $P<0.01$ ), 3)'Courtesy, respect and compassion the family was given' $\left(R^{2}=0.29\right.$, beta $\left.=0.17, P=0.33\right)$, with also a small to moderate effect of length of stay (beta=-0.19, $P=0.02$ ).

\section{Analysis of written comments of families}

Narrative comments to the open-ended questions were provided. The question 'suggestions to improve the care in the ICU' was answered by 62 respondents; 18 donor families and 44 non-donor families. Comments on things the team did well were answered by 71 respondents; 50 non-donor and 21 donor families.

Three major themes with 9 subthemes were identified (Table 7.3). In Table 7.4 examples of typical quotes of the families are provided.

Table 7.3 Number of written comments.

\begin{tabular}{|c|c|c|c|c|}
\hline & $\begin{array}{l}\text { Positive } \\
\text { Donor }\end{array}$ & $\begin{array}{c}\text { Positive } \\
\text { Non-donor }\end{array}$ & $\begin{array}{c}\text { Negative } \\
\text { Donor }\end{array}$ & $\begin{array}{l}\text { Negative } \\
\text { Non-donor }\end{array}$ \\
\hline \multicolumn{5}{|l|}{ Care } \\
\hline Care for the family & 6 & 20 & 2 & 7 \\
\hline Care for the patient & 6 & 21 & 1 & 2 \\
\hline Organisation of care & 3 & 1 & 1 & 1 \\
\hline \multicolumn{5}{|l|}{ Communication } \\
\hline Clarity and completeness & 1 & 3 & 5 & 7 \\
\hline Decision making & 2 & & 3 & 2 \\
\hline \multicolumn{5}{|l|}{ End of life care } \\
\hline Privacy during dying process & & & 1 & 8 \\
\hline After care & 3 & 1 & & 2 \\
\hline Support for the family & & 3 & 2 & 8 \\
\hline \multicolumn{5}{|l|}{ Other } \\
\hline Atmosphere waiting room & & & 3 & 8 \\
\hline
\end{tabular}


Eighty per cent of the respondents were very satisfied about the way of paying the last respects to the patient, $11 \%$ moderately satisfied and $9 \%$ dissatisfied. Higher, but not significantly different scores were seen between the donor family and non-donor family.

Table 7.4 Some statements of the family.

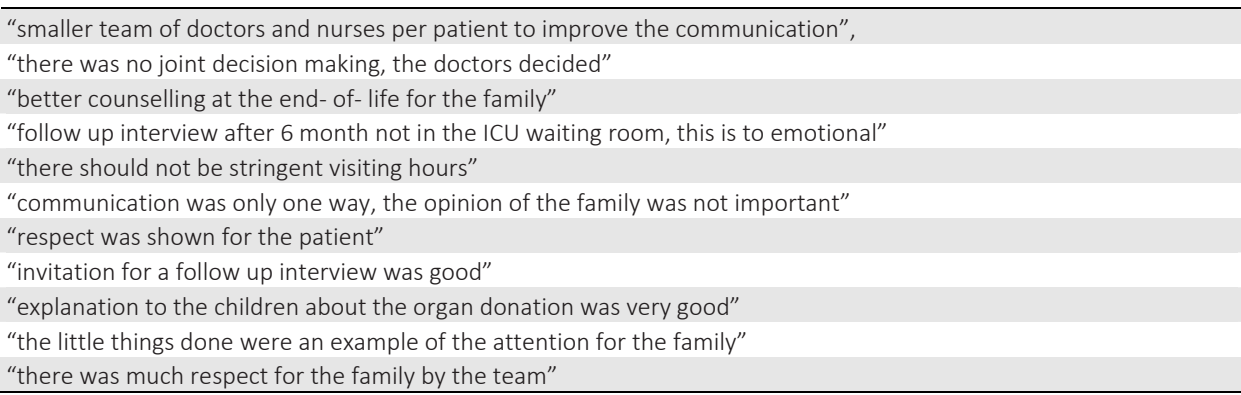

\section{Organ donation}

Organ donation was requested in $38 \%(n=43)$ of all patients, of these patients $52 \%$ was registered as a donor. Most of the families were aware of the patient's wishes (69\%). Eleven relatives of patients who were not registered refused donation. Explanations for this included: 'known wish of the patient' $(n=4)$, 'difficult for the children' $(n=1)$, 'patient had suffered enough' $(n=3)$; 'the dying process will be postponed' $(n=2)$, and 'the duration of the organ donation procedure' $(n=1)$. Eighty per cent of the respondents experienced the conversation with the physician and nurse about organ donation as 'good' to 'excellent'. In contrast, one respondent was dissatisfied.

\section{Donation process}

Sixteen per cent perceived the organ donation process as 'poor' (7\%) or 'reasonable' (9\%). Eighty-three per cent of the respondents, however, valued the organ donation process as 'good' to 'excellent'. The duration of the organ donation process was perceived to be 'short' or 'too short' for 7\%, and for 38\% 'long' or 'too long', the other respondents were satisfied about the duration. The majority of respondents (84\%) were 'satisfied' to 'very satisfied' about the information they received on the results of the transplantations. Three respondents regretted their decision regarding organ donation: one respondent was overwhelmed as the request was made and had refused, two respondents regretted their consent and felt that the dying process was postponed by the donation procedure. 


\section{Discussion}

This is the first study that compares satisfaction of donor and non-donor families. This survey of 112 relatives of patients, who died in the ICU, reveals that the families of patients, who became organ donor after death, were overall more satisfied than families of patients, who did not donate their organs after death. The main results from this study are discussed, and put in perspective of the literature.

Families of donors scored higher on all three scales that were identified by factor analysis. This reached significance on the 'end of life care' scale and a trend towards significance on the 'care' scale was notable. For all scales, regression analysis showed that length of stay was a confounder. With increased length of stay, the family satisfaction decreased. Not much variance was explained in the regression analyses, it is possible that there is a lot of random variance. No interaction was seen between the length of stay and being a donor. Three individual items scored significant higher in the donor group, especially items concerning end-of-life care.

\section{Narrative comments}

Families of donors as well as non-donor families provided mainly positive narrative comments on the care for the patient and the care for the family. Negative comments mainly concerned the communication with the family, the lack of privacy during the dying process, support for the family and the atmosphere of the waiting room. The families of non-donors provided more negative comments on these items. The atmosphere of the ICU's waiting room is an aspect that thus needs to be improved, likewise, quantitative data showed low satisfaction scores on 'ICU atmosphere' and 'ICU waiting room' (see Table 7.2).

\section{Comparison to the literature}

Other studies showed the same low satisfaction on ICU (waiting room) atmosphere as ours. ${ }^{17-19}$ This kind of facility is especially considered to be important in stressful situations. A quiet separate room for families to retreat in is valued then and its absence may contribute to anxiety and consequently dissatisfaction. ${ }^{20}$ Communication with and listening to family members also increases satisfaction especially in a stressful environment as the ICU and can likewise be very important for the family. ${ }^{21}$ Frequency of communication with doctors, consistency of information and emotional support of the staff are items with overall low scores in our study. Several studies report that contradicting information by caregivers this is associated with increased distress for the family. ${ }^{22}$ Empathy in the decision making process is also known to be of importance to the family. ${ }^{23}$ To our knowledge, there are no reports that the length of admission influences the satisfaction of relatives. This might be due to the reversed association 
between improved physicians communication with families and improved clinical outcomes, such as decreased length of stay of ICU survivors. ${ }^{24,25} \mathrm{~A}$ possible explanation for the association of decreasing family satisfaction with increased length of stay is the risk of communication inconsistencies due to the increasing number of different doctors and nurses caring for the patient.

\section{Organ donation}

More than $80 \%$ of organ donor families were very satisfied about the organ donation process, 38\% experience the length of the donation procedures as too long. For two respondents this was the basis of actual regrets of their consent for organ donation. Communication with the family about the expected duration and the underlying reasons can clarify the duration of the procedures to the family.

Significant differences between donor and non-donor families mainly concerned the satisfaction about items concerning the last hours of the patients life, not the organ donation itself. Organ donation does not seem to impact negatively on the quality of end of life care; on the contrary, families of donors were generally more satisfied. This effect could be influenced by providing more attention to the relatives, and more extensive conversations and explanations about the donation procedure by the intensive care staff and transplant coordinator. Increased family satisfaction during donation procedures is seen in previous studies, when a family support coordinator is brought in. ${ }^{26}$ A previous survey of families of patients who died in the ICU found also that key determinants of satisfaction were good communication, clear decision making, and respect and compassion shown to both the patient and family. ${ }^{27}$

\section{Limitations of the study}

Although the original FS-ICU was designed for a general ICU population, in this study it was used to study the perception of quality of care of relatives of patients who died in the ICU. However, the FS-ICU correlates well with the Family Quality Of Death and Dying (QODD), a previously validated instrument for measuring ICU quality at the end of life by relatives. ${ }^{9,28}$ Another limitation is the mean time between the patient's and study participation of the family of 11 months; this long period could have caused recollection bias. All families nevertheless stated on the telephone, that they had clear and persisting memories on the intensive care admission. Furthermore, an existing difference in the perceived quality of end of life care, would probably become smaller after a long period instead of larger. Finally, our study was a single center study, due to which the results may perhaps not be generalized to other centres or countries. 


\section{Conclusion}

Families of patients who became donor after death were generally more satisfied with the care for their family member, especially about end of life care, than families of patients who did not donate organs after death. This suggests that the donor procedure itself does not negatively influence the perception of end of life care of the intensive care patient. Increased length of stay of admission of the patient had a negative impact on the satisfaction of the family. More than $80 \%$ of the relatives of donors were very satisfied about the organ donation process. 


\section{References}

1. Nelson JE, Danis M. End-of-life care in the intensive care unit: where are we now? Crit Care Med 2001;29(2 Suppl):N2-9.

2. Clarke EB, Curtis JR, Luce JM, Levy M, Danis M, Nelson J, Solomon MZ; Robert Wood Johnson Foundation Critical Care End-Of-Life Peer Workgroup Members. Quality indicators for end-of-life care in the intensive care unit. Crit Care Med 2003;31:2255-62.

3. Truog RD, Campbell ML, Curtis JR, Haas CE, Luce JM, Rubenfeld GD, Rushton CH, Kaufman DC; American Academy of Critical Care Medicine. Recommendations for end-of-life care in the intensive care unit: a consensus statement by the American College [corrected] of Critical Care Medicine. Crit Care Med 2008;36:953-63.

4. Curtis JR, Nielsen EL, Treece PD, Downey L, Dotolo D, Shannon SE, Back AL, Rubenfeld GD, Engelberg RA. Effect of a quality-improvement intervention on end-of-life care in the intensive care unit: a randomized trial. Am J Respir Crit Care Med 2011;183:348-55.

5. Kentish-Barnes N, Lemiale V, Chaize M, Pochard F, Azoulay E. Assessing burden in families of critical care patients. Crit Care Med 2009;37(10 Suppl):S448-46.

6. Heyland DK, Tranmer JE. Measuring family satisfaction with care in the intensive care unit: the development of a questionnaire and preliminary results. J Crit Care 2001;16:142-9.

7. Heyland DK, Rocker GM, Dodek PM, Kutsogiannis DJ, Konopad E, Cook DJ, Peters S, Tranmer JE, O'Callaghan CJ. Family satisfaction with care in the intensive care unit: results of a multiple center study. Crit Care Med 2002;30:1413-8.

8. Heyland DK, Cook DJ, Rocker GM, Dodek PM, Kutsogiannis DJ, Peters S, Tranmer JE, O'Callaghan CJ. Decision-making in the ICU: perspectives of the substitute decision-maker. Intensive Care Med 2003; 29:75-82.

9. Wall RJ, Engelberg RA, Downey L, Heyland DK, Curtis JR. Refinement, scoring, and validation of the Family Satisfaction in the Intensive Care Unit (FS-ICU) survey. Crit Care Med 2007;35:271-9.

10. Sprung CL, Cohen SL, Sjokvist P, Baras M, Bulow HH, Hovilehto S, Ledoux D, Lippert A, Maia P, Phelan D, Schobersberger W, Wennberg E, Woodcock T; Ethicus Study Group. End-of-life practices in European intensive care units: the Ethicus Study. JAMA 2003;290:790-7.

11. Azoulay E, Metnitz B, Sprung CL, Timsit JF, Lemaire F, Bauer P, Schlemmer B, Moreno R, Metnitz P; SAPS 3 investigators. End-of-life practices in 282 intensive care units: data from the SAPS 3 database. Intensive Care Med 2009;35:623-30.

12. Yaguchi A, Truog RD, Curtis JR, Luce JM, Levy MM, Mélot C, Vincent JL. International differences in endof-life attitudes in the intensive care unit: results of a survey. Arch Intern Med 2005;165: 1970-5.

13. Curtis JR, Vincent JL. Ethics and end-of-life care for adults in the intensive care unit. Lancet 2010;376:1347-53.

14. Garland A, Connors AF. Physicians' influence over decisions to forego life support. J Palliat Med 2007;10:1298-305.

15. Rady MY, Verheijde JL, McGregor J. "Non-heart-beating," or "cardiac death," organ donation: why we should care. J Hosp Med 2007;2:324-34.

16. Survey. fsitlCuF-I. Available at: http://www.criticalcareconnections.com. Accessed January 1,2006.

17. Henrich NJ, Dodek P, Heyland D, Cook D, Rocker G, Kutsogiannis D, Dale C, Fowler R, Ayas N. Qualitative analysis of an intensive care unit family satisfaction survey. Crit Care Med 2011;39:1000-5.

18. Hunziker S, McHugh W, Sarnoff-Lee B, Cannistraro S, Ngo L, Marcantonio E, Howell MD. Predictors and correlates of dissatisfaction with intensive care. Crit Care Med 2012;40:1554-61.

19. Stricker $\mathrm{KH}$, Kimberger $\mathrm{O}$, Schmidlin $\mathrm{K}$, Zwahlen M, Mohr U, Rothen HU. Family satisfaction in the intensive care unit: what makes the difference? Intensive Care Med 2009;35:2051-9.

20. Pochard F, Azoulay E, Chevret S, Lemaire F, Hubert P, Canoui P, Grassin M, Zittoun R, le Gall JR, Dhainaut JF, Schlemmer B; French FAMIREA Group. Symptoms of anxiety and depression in family members of intensive care unit patients: ethical hypothesis regarding decision-making capacity. Crit Care Med 2001; 29:1893-7. 
21. McDonagh JR ET, Engelberg RA, Treece PD, Shannon SE, Rubenfeld GD, Patrick DL, Curtis JR. Family satisfaction with family conferences about end-of-life care in the intensive care unit: increased proportion of family speech is associated with increased satisfaction. Crit Care Med 2004;32: 1484-8.

22. Azoulay E, Pochard F, Chevret S, Lemaire F, Mokhtari M, Le Gall JR, Dhainaut JF, Schlemmer B; French FAMIREA Group. Meeting the needs of intensive care unit patient families: a multicenter study. Am J Respir Crit Care Med 2001;163:135-9.

23. Schwarzkopf D, Behrend S, Skupin H, Westermann I, Riedemann NC, Pfeifer R, Günther A, Witte OW, Reinhart K, Hartog CS. Family satisfaction in the intensive care unit: a quantitative and qualitative analysis. Intensive Care Med 2013;39: 1071-9.

24. Lilly CM, De Meo DL, Sonna LA, Haley KJ, Massaro AF, Wallace RF, Cody S. An intensive communication intervention for the critically ill. Am J Med 2000;109:469-75.

25. Norton SA, Hogan LA, Holloway RG, Temkin-Greener H, Buckley MJ, Quill TE. Proactive palliative care in the medical intensive care unit: effects on length of stay for selected high-risk patients. Crit Care Med 2007;35:1530-5.

26. Shelton W, Moore CD, Socaris S, Gao J, Dowling J. The effect of a family support intervention on family satisfaction, length-of-stay, and cost of care in the intensive care unit. Crit Care Med 2010;38:1315-20.

27. Heyland DK, Rocker GM, O'Callaghan CJ, Dodek PM, Cook DJ. Dying in the ICU: perspectives of family members. Chest 2003;124:392-7.

28. Curtis JR, Engelberg RA. Measuring success of interventions to improve the quality of end-of-life care in the intensive care unit. Crit Care Med 2006;34(11 Suppl):S341-7. 


\section{Chapter 8}

Variability in protocols on donation after circulatory death in Europe

J Wind, M Faut, TC van Smaalen, EL van Heurn 


\section{Abstract}

\section{Introduction}

Organ donation after circulatory death (DCD) has become an accepted strategy to reduce the shortage of organs for transplantation in many European countries. The use and number of DCD donors varies between countries. The purpose of this study was to evaluate the available protocols for DCD in Europe.

\section{Methods}

We contacted national transplant societies and responsible transplant co-ordinators in the countries that perform DCD to obtain DCD protocols. We compared information on the protocols and additional data including: inclusion and exclusion criteria for donation, legislation, determination of death and preservation methods.

\section{Results}

In ten European countries DCD is performed, eight of which describe the methods in protocols. There are large differences in used DCD categories, legislation and the way death is determined. Protocols differ in the detail in which DCD procedures are described and the way methods are supported by additional consensus statements and ethical frameworks.

\section{Conclusions}

Although DCD is an established strategy to enlarge the donor pool and to contribute to the reduction of the waiting list for transplantation, its potential has not been fully utilized yet. To further promote DCD transplantation, it is important to share expertise and obtain consensus, so that this can be translated into more uniform and solid protocols supported by the competent authorities, transplant and intensive care professionals, which may eventually result in a further promotion of DCD transplantation in Europe. 


\section{Introduction}

Kidney transplantation increases life expectancy and quality of life in patients with endstage renal disease compared with renal dialysis. ${ }^{1,2}$ However, there is an ongoing universal shortage of donor organs to meet the demand for transplantation, and organ donation and transplantation rates vary widely across countries. The World Health Organization published guiding principles on human cell, tissue and organ transplantation to support countries in taking responsibility for progression to selfsufficiency for the organ donation and transplantation needs of their people. ${ }^{3}$

One way to expand the organ donor pool is the use of organs from donors who die after circulatory death (DCD). These organs are inevitably subjected to a period of warm ischemia, which adversely affects transplant outcome. ${ }^{4}$ Despite the higher incidence of primary nonfunction and delayed graft function, transplantation of DCD kidneys is associated with increased recipient survival compared with staying on the transplant waiting list with the option of later receiving a conventional kidney from donation after brain death (DBD). ${ }^{5}$ Procurement of kidneys from DCD donors holds the potential to expand the donor pool 2.5 to 4 times. $^{6}$

Next to DCD kidney transplantation, which has been a generally accepted source of donor organs in many countries, DCD transplantation of the liver, lung and pancreas is possible and has been increasingly performed in the past decade. The results of DCD liver transplantation are comparable with DBD liver transplantation, with equivalent 1-year and 3-year graft survival and patient survival, although there is a higher risk of biliary strictures in DCD livers. ${ }^{7}$ The number of DCD lung transplantations is still relatively low; a number of transplant centers show equivalent outcomes for DCD and DBD lung transplantation. DCD lung transplantation offers a good opportunity to reduce the donor lung shortage. ${ }^{8}$ The DCD potential is still not fully used, despite the fact that DCD has proven to be effective to expand the donor pool. In contrast to DBD, DCD is not performed in every European country and the percentage of DCD donors out of the total number of deceased donors varies largely.

In 1995, at the First International Workshop on Nonheart Beating Donation in Maastricht, four categories of non-heart-beating donation were identified, which include controlled and uncontrolled donors (Table 8.1). ${ }^{9}$

Table 8.1 Maastricht classification of donors after circulatory death.

\begin{tabular}{lll}
\hline Category & Definition & Type \\
1 & Dead on arrival & Uncontrolled \\
2 & Unsuccessful resuscitation & Uncontrolled \\
3 & Awaiting circulatory arrest & Controlled \\
4 & Circulatory arrest while brain dead & Controlled/uncontrolled \\
\hline
\end{tabular}


Nomenclature has changed since then, from non-heart-beating donation to donation after cardiac death, to make a more clear difference between cardiac death and brain death. Recently, donation after circulatory death has been proposed as the nomenclature of choice.

Depending on the category, the donor procedure is carried out in the emergency room, in the ICU or in the operating room. The popularization of DCD has caused a growing demand for protocols that describe donor management and preservation strategies. Furthermore, ethical aspects of DCD are essential and have to be addressed. ${ }^{10,11}$

The aim of this study is to evaluate European DCD protocols, focusing on the inclusion and exclusion criteria for organ donation, legislation on DCD donation, determination of death and preservation methods for organ procurement. Although protocols do not always completely reflect the actual clinical practice and often small violations of the protocols are present, this evaluation may provide a general overview of the European attitude towards DCD. It is important to obtain an overall understanding of the different approaches to DCD in Europe and to evaluate whether there is room for improvement.

\section{Materials and methods}

There are currently 10 countries in Europe with an active DCD program. ${ }^{12}$ Between January 2011 and January 2012 we directly contacted national transplant societies in these countries and responsible transplant coordinators, and obtained their national and regional DCD protocols (Table 8.2). If the information was not complete, we were referred by the transplant societies to specific transplant centers and responsible representatives. Information of recent publications, the database from the Transplant Procurement Management organization and published national consensus meetings was used to further complete the information. From these data, we compared the national strategies in DCD donation, including inclusion and exclusion criteria for DCD donation, legislation, determination of death and preservation methods. The study was performed in agreement with the code of conduct on the use of data in health research, put forward by the Dutch Federation of Biomedical Scientific Societies. ${ }^{13}$

\section{Results}

Ten countries in Europe actively perform DCD, of which eight have specific protocols for DCD or describe DCD procedures in one general protocol for organ donation. Latvia and Czech Republic have no specific description of DCD donation mentioned in their protocol. In four countries (Italy, Austria, Latvia, Czech Republic), DCD activity is restricted to one or two hospitals. In the Netherlands and the UK, DCD donation is 
possible in almost every hospital. Ten other countries are planning to start a DCD program in the near future, including Cyprus, Estonia, Luxembourg, Norway, Poland, Portugal, Romania, Slovak Republic, Slovenia and Sweden. In seven countries (Finland, Germany, Greece, Bosnia-Herzegovina, Hungary, Lithuania, Turkey) there is no planned DCD activity, mainly because of legal restriction. The most important reason for not performing DCD next to legislation includes organizational difficulties. ${ }^{12}$

Table 8.3 summarizes the donor registration system, the DCD categories used for donation and the organs procured from DCD donors in different European countries.

Reasons to explain the absence of controlled DCD donation (Maastricht category III) were ethical and juridical restraints (France, Spain, Latvia); uncontrolled DCD (Maastricht category I and II) was often not performed because of organizational difficulties.

Table 8.2 National authorities for organ donation and responsible organisations for organ allocation.in different countries.

\begin{tabular}{|c|c|c|}
\hline Country & National authority for organ donation & $\begin{array}{l}\text { Responsible organization for } \\
\text { organ allocation }\end{array}$ \\
\hline Austria & $\begin{array}{l}\text { Österreichisches Bundesinstitut für Gesundheitswesen (ÖBIG) } \\
\text { http://www.goeg.at }\end{array}$ & Eurotransplant \\
\hline Belgium & $\begin{array}{l}\text { Belgische Transplantatie Vereniging / Société Belge de } \\
\text { Transplantation / Belgian Transplant Society (BTS) } \\
\text { http://www.transplant.be }\end{array}$ & Eurotransplant \\
\hline Czech Republic & $\begin{array}{l}\text { Koordinační Středisko Transplantací (KST) } \\
\text { http://www.kst.cz }\end{array}$ & $\begin{array}{l}\text { Koordinační Středisko } \\
\text { Transplantací }\end{array}$ \\
\hline France & $\begin{array}{l}\text { Agence de la Biomédecine } \\
\text { http://www.agence-biomedecine.fr }\end{array}$ & Agence de la Biomédecine \\
\hline Italy & $\begin{array}{l}\text { Centro Nazionale Trapianti (CNT) } \\
\text { http://www.trapianti.salute.gov.it }\end{array}$ & Centro Nazionale Trapianti \\
\hline Latvia & $\begin{array}{l}\text { BaltTransplant - Latvian subdivision } \\
\text { http://www.stradini.lv }\end{array}$ & BaltTransplant \\
\hline The Netherlands & $\begin{array}{l}\text { Nederlandse Transplantatie Stichting (NTS) } \\
\text { http://www.transplantatiestichting.nl }\end{array}$ & Eurotransplant \\
\hline United Kingdom & $\begin{array}{l}\text { National Health Service Blood and Transplant (NHSBT) } \\
\text { http://www.nhsbt.nhs.uk }\end{array}$ & $\begin{array}{l}\text { National Health Service } \\
\text { Blood and Transplant }\end{array}$ \\
\hline Spain & $\begin{array}{l}\text { Organización National de Trasplantes (ONT) } \\
\text { http://www.ont.es }\end{array}$ & $\begin{array}{l}\text { Organización National de } \\
\text { Trasplantes }\end{array}$ \\
\hline Switzerland & $\begin{array}{l}\text { Swiss Transplant } \\
\text { http://www.swisstransplant.org }\end{array}$ & Swiss Transplant \\
\hline
\end{tabular}

\section{Inclusion and exclusion criteria}

Out of the 10 countries with DCD, seven countries (70\%) described inclusion and exclusion criteria of controlled and/or uncontrolled donation. Seven countries actively performed controlled as well as uncontrolled DCD (Spain, France and Latvia only uncontrolled DCD), of which four separated inclusion and exclusion criteria for controlled and uncontrolled donation in their protocols, which mainly included 
differences in donor age limits. Inclusion criteria for donation generally included positive registration as a donor or permission of the next of kin if a donor had not been registered with a donor registry, witnessed arrest (in uncontrolled DCD) and age limits. The most commonly used exclusion criteria were hypothermia, intoxication, malignancy, sepsis (untreated) and organ-specific contra-indications such as renal failure and liver cirrhosis. Next to the internationally used Maastricht DCD categories, Spain and Italy describe additional categories that include donation after sudden irreversible cardiac arrest in the ICU (Spain) and death during extracorporeal membrane oxygenation (Italy). In most countries DCD donors are predominantly Maastricht category III donors - that is, donors who die after withdrawal of treatment - which results in a high percentage of DCD donors in the UK, the Netherlands and Belgium (Table 8.4). France performs only uncontrolled DCD.

Spain recently performed its first controlled DCD, after many years of successful uncontrolled DCD.

Table 8.3 Registration system, DCD categories, and retrieved organs in different countries.

\begin{tabular}{llll}
\hline Country & Registration system & DCD Categories & Organs retrieved \\
Austria & Opt out & II, III & Kidneys \\
Belgium & Opt out & II, III, IV * & Kidney, liver, pancreas, lungs* \\
Czech republic & Opt out & I, II, III, IV & Kidneys \\
France & Opt out & I, II, IV & Kidneys \\
Italy & Opt out & II, III, IV & Kidneys \\
Latvia & Opt out & II, IV & Kidneys \\
The Netherlands & Opt in & II, III, IV & Kidneys, liver, pancreas, lungs \\
United Kingdom & Opt in & II, III, IV & Kidneys, liver, pancreas, lungs* \\
Spain & Opt out & I,II,IV * & Kidney, liver, lungs \\
Switzerland & Opt in & I,II,III,IV & Kidney, liver, lungs \\
\hline
\end{tabular}

*variation in regional protocols

\section{Legislation}

In all countries with a donor protocol, there was an organ donation law. Although the actual donation act was often not included in the protocol, a reference was always available. Three out of 10 countries (30\%) performing DCD in Europe have an opt-in registration system; this means that explicit consent for donation is necessary by donor card or registration in a national registry (Table 8.3). In the other seven countries (70\%) with a DCD program, presumed consent is used; explicit consent for donation is not required but is presumed if the person has not objected during life.

\section{Opt-in registration}

There are three countries with a DCD program and an opt-in registration system (the UK, the Netherlands and Switzerland). In the Netherlands and Switzerland, registration as a donor is sufficient to proceed to organ procurement, and the relatives are informed. In 
the UK, the opt-in registration system requires additional consent by the next of kin. A registered objection to donation always excludes organ donation.

All three protocols allow use of in situ preservation (ISP) in uncontrolled DCD donors to preserve organs if a person has not objected to donation. ISP is a minimally invasive technique to preserve the organs after determination of death and a no-touch period. A special catheter with proximal and distal occlusion balloons is inserted through the femoral artery into the aorta, which enables selective flushing of the kidneys. ISP preserves organ viability and provides the opportunity to meet legal and logistical requirements before organ procurement. ISP also gives relatives time to decide about organ donation.

\section{Opt-out registration}

Seven countries use the system of presumed consent for donation. Six out of seven protocols require additional permission from the next of kin; Spain requires written permission. Austria does not specify informed consent of the relatives in its protocol. In clinical practice, in most countries with an opt-out system, the relatives are consulted to confirm the consent for donation. In Latvia, the next of kin has to submit their objection in writing if there is no information in the donor registry. In uncontrolled donors, most protocols allow ISP awaiting the relatives' consent. In Spain, approval has to be requested from the local court. In most countries, it is allowed or otherwise not specifically mentioned in the protocol for controlled donors, to maintain or optimise the condition of the potential donor after the decision has been made to withdraw treatment if this does not harm the patient or cause discomfort. In Switzerland, (opt-in) consent of the next of kin is required before starting any medical treatment to improve the condition of the donor.

\section{Determination of death}

The description of how death is determined varied in the protocols; from no description at all, or referring to standard criteria (the so-called lege artis), to more specific guidelines and tests that have to be performed (Table 8.5). Some protocols refer to guidelines or protocols for the determination of death. ${ }^{14,15}$ The standard criteria to determine death after cessation of medical treatment of a DCD donor refer to cardiocirculatory criteria: irreversible cessation of circulatory and respiratory function. Diagnostic procedures used to confirm death differ among protocols; absent intraarterial pressure, isoelectric electrocardiogram, absent cardiac function on echocardiogram (Table 8.4). 
Table 8.4 Absolute numbers of DCD donors and percentage of DCD donors in 2011 and 2012 in different countries.

\begin{tabular}{lcccccccc}
\hline Country & Actual DCD donors & $\begin{array}{c}\text { Percentage DCD donors of the } \\
\text { total deceased donors }\end{array}$ & $\begin{array}{c}\text { Number of deceased } \\
\text { donor (PMP) }\end{array}$ & $\begin{array}{c}\text { DCD since } \\
\text { (year) }\end{array}$ \\
\cline { 2 - 3 } & 2011 & 2012 & 2011 & 2012 & 2011 & 2012 & \\
Austria & 6 & 4 & $3 \%$ & $2 \%$ & 23.2 & 22.5 & 1994 \\
Belgium & 61 & 70 & $19 \%$ & $19 \%$ & 29.3 & 32.9 & 1994 \\
Czech republic & 1 & 2 & $<1 \%$ & $1 \%$ & 17.6 & 19.8 & 2002 \\
France & 58 & $\mathrm{n} / \mathrm{a}$ & $4 \%$ & $\mathrm{n} / \mathrm{a}$ & 25.0 & $\mathrm{n} / \mathrm{a}$ & 2006 \\
Italy & 6 & 5 & $<1 \%$ & $1 \%$ & 21.9 & 22.4 & 2005 \\
Latvia & 13 & 23 & 32 & $60 \%$ & 17.9 & 19.0 & 1992 \\
The Netherlands & 111 & 124 & $50 \%$ & $49 \%$ & 13.2 & 15.0 & 1981 \\
United Kingdom & 405 & $\mathrm{n} / \mathrm{a}$ & $38 \%$ & $\mathrm{n} / \mathrm{a}$ & 17.0 & $\mathrm{n} / \mathrm{a}$ & 1989 \\
Spain & 117 & 161 & $7 \%$ & $10 \%$ & 35.3 & 34.8 & 1989 \\
\hline Switzerland & 3 & 7 & $3 \%$ & $7 \%$ & 12.8 & 12.0 & 1993 \\
\hline
\end{tabular}

Absolute numbers and percentage of DCD donors of the total numbers of deceased donors in 2011 and 2012 in different countries. DCD, donation after circulatory death; PMP, percentage per million population

All protocols describe an observation period after circulatory arrest - the no-touch time, the period of time during which no interventions are performed in the donor. However, this period is described differently: as the observation period between the circulatory arrest and the determination of death, or as the time period between determination of death and initiation of organ procurement. The no-touch time differs from 5 to 20 minutes (Table 8.5). In Italy, 20 minutes of an isoelectric elektrocardiogram registration is necessary before organ procurement is allowed, which makes DCD practically very difficult.

Separation of the team responsible for the treatment of the patient and the organ procurement team is mentioned in all protocols. In Spain and France, the potential uncontrolled donor is recognized by the ambulance service and, after unsuccessful resuscitation, treated as a potential donor with continuation of chest compressions, ventilation and fluid perfusion. Only after arrival at the hospital does the attending physician determine death of the patient and the procurement team starts the donor procedure.

\section{Preservation methods}

The most commonly used preservation method for controlled DCD donation is rapid laparotomy with cannulation of the abdominal aorta. ${ }^{16}$ After death in the ICU, the deceased is taken to the operating room. In uncontrolled donors, ISP with the doubleballoon, triple-lumen catheter or the Gillot catheter is used. In the two countries with the largest numbers of uncontrolled donors (Spain and France), extracorporeal membrane oxygenation with either hypothermic or normothermic perfusion is used as the preservation method of choice. 
Table $8.5 \quad$ Items described in the protocols.

\begin{tabular}{|c|c|c|c|c|}
\hline Country & $\begin{array}{l}\text { Criteria for determination of death } \\
\text { and diagnostic procedures }\end{array}$ & Death determined by & $\begin{array}{l}\text { No touch } \\
\text { time } \\
\text { (min) }\end{array}$ & Preservation method \\
\hline Austria & Asystole, not specified & $\begin{array}{l}\text { Treating physician with } \\
\text { "jus practicandi" }\end{array}$ & 10 & $\begin{array}{l}\text { Laparotomy with } \\
\text { direct cannulation }\end{array}$ \\
\hline Belgium & $\begin{array}{l}\text { Cardiorespiratory criteria, according } \\
\text { to most recent standard.* }\end{array}$ & Three independent physicians & 5 & $\begin{array}{l}\text { Laparotomy with } \\
\text { direct cannulation }\end{array}$ \\
\hline $\begin{array}{l}\text { Czech } \\
\text { republic }\end{array}$ & Not described & $\begin{array}{l}\text { Independent physician, not } \\
\text { involved in donation }\end{array}$ & 10 & DBTL catheter \\
\hline France & $\begin{array}{l}\text { Cardio respiratory criteria, } \\
\text { unconsciousness, absence brainstem } \\
\text { reflexes. ECG }\end{array}$ & $\begin{array}{l}\text { Independent physician, not } \\
\text { involved in donation }\end{array}$ & 5 & $\begin{array}{l}\text { nECMO, DBTL } \\
\text { catheter }\end{array}$ \\
\hline Italy & $\begin{array}{l}\text { Asystole, Iso- electrical ECG to } \\
\text { confirm }\end{array}$ & Treating physician & 20 & nECMO \\
\hline Latvia $^{\text {b }}$ & Not described & Intensivist & 15 & $\begin{array}{l}\text { Laparotomy with } \\
\text { direct cannulation } \\
\text { DBTL catheter }\end{array}$ \\
\hline $\begin{array}{l}\text { The } \\
\text { Netherlands }\end{array}$ & $\begin{array}{l}\text { Cardiocirculatory arrest, not } \\
\text { specified }\end{array}$ & Treating physician & 5 & $\begin{array}{l}\text { Laparotomy with } \\
\text { direct cannulation, } \\
\text { DBTL catheter }\end{array}$ \\
\hline $\begin{array}{l}\text { United } \\
\text { Kingdom }\end{array}$ & $\begin{array}{l}\text { Cardiocirculatory arrest, } \\
\text { unconsciousness. Intra-arterial } \\
\text { pressure monitoring, echo } \\
\text { cardiogram or ECG during } 5 \text { minutes. } \\
\text { After } 5 \text { min. absence of brainstem } \\
\text { reflexes confirmed }\end{array}$ & Treating physician & 5 & $\begin{array}{l}\text { Laparotomy with } \\
\text { direct cannulation } \\
\text { DBTL catheter }\end{array}$ \\
\hline Spain & $\begin{array}{l}\text { Asystole, apnoea, no response to } \\
\text { stimuli. ECG to confirm }\end{array}$ & Treating physician & 5 & $\begin{array}{l}\text { ECMO, nECMO, DBTL } \\
\text { catheter }\end{array}$ \\
\hline Switzerland & $\begin{array}{l}\text { "lege artis", referred to specific } \\
\text { guidelines, TTE to confirm asystole }\end{array}$ & Two independent physicians & 10 & $\begin{array}{l}\text { Laparotomy with } \\
\text { direct cannulation }\end{array}$ \\
\hline
\end{tabular}

DBTL: double balloon. triple lumen; ECG: electrocardiogram; ECMO: extra corporeal membrane oxygenation; nECMO: normothermic extra corporeal membrane oxygenation; TTE: transthoracic echocardiogram. a Variation in regional protocols. ${ }^{b}$ Donation after circulatory death not described in a protocol.

\section{Discussion}

There is a relatively large variability in European DCD protocols. This can be expected, because legislation, expertise, experience and organizational factors differ. Especially uncontrolled DCD requires specific organization, because the donation procedure is always unexpected.

The time between the determination of death and preservation of the organs is important, to minimize warm ischemic time and organ injury. The way in which DCD procedures are described varies, from no specific protocol (two countries) to detailed protocols with complementary consensus statements and ethical frameworks, as in the UK. ${ }^{17}$ 
Reasons for not performing DCD at all include conflicts with national law or difficulties with the infrastructure to initiate a DCD program. ${ }^{12}$ Also, reluctance to explore the possibilities within the law to perform DCD can play a role. Countries that perform DCD differ in the percentage of DCD transplantations compared with the total numbers of deceased donors, and the use of different Maastricht categories. Some countries focus on uncontrolled DCD (Spain, France), and others focus on controlled DCD (the Netherlands, the UK) or perform both. The difference can be explained by practice in ICUs to withdraw life-sustaining treatment or not. In northern European countries, withdrawal of treatment, if treatment is considered futile, is a more accepted practice than in southern European countries. ${ }^{18}$ These differences may partly be caused by the availability of intensive care capacity, which may force doctors towards less expectative approach to discontinue useless medical treatment.

A notable difference between protocols is the way in which death of the patient is determined. When a deceased patient is an eligible organ donor, both the accurate determination of death and a fast transition from treating a patient to preserving a donor is essential to enable organ preservation with minimized ischemic injury to the organs.

Definitions of the criteria to determine death and the no-touch period, to ensure irreversibility of cardiocirculatory arrest, are therefore crucial. Determination of death varies in the different protocols, but also between ICUs. There is a lack of uniformity. ${ }^{19-21}$ This includes the definition of death, the tests used to determine death and the period of time between death and the moment organs can be procured. Different definitions have important implications for donor treatment and end-of-life care, but also for the ischemic period of the organs and organ viability.

With the expansion of DCD programs, the lack of consensus about determination of death is a point of discussion and concern. ${ }^{22-24}$ It is important to have clear, uniform and consistent evidence-based guidelines to determine death, in order to fulfill medical, ethical and legal obligations and to ensure public trust. ${ }^{19}$

Donor procurement strategies differ throughout Europe, and the implementation of protocols differs even more.

Strategies to procure organs each have their advantages and disadvantages and depend on consent systems, legal opportunities, in-hospital and out-of-hospital institution and financial possibilities. Protocols can be helpful to obtain and maintain support for DCD programs and to help other institutes or countries to develop, implement and continue DCD. The protocols also provide answers to important ethical questions concerning endof-life management and care. ${ }^{25}$ 


\section{Conclusion}

DCD is an established strategy to enlarge the donor pool and to contribute to the reduction of the waiting list for transplantation. The DCD potential in Europe is not yet fully utilized. DCD protocols in European countries and even in individual hospitals are heterogeneous. Restrictions by national laws, organizational problems or ethical struggles are important factors for this. Following these conclusions, we feel it is important that experiences with DCD are shared and consensus is obtained, so these can be translated into more uniform and solid protocols supported by the competent authorities, transplant and intensive care professionals, which may eventually result in a further promotion of DCD transplantation in Europe.

\section{Key messages}

- Transplantation of organs from donors after circulatory death (DCD) contributes to the reduction of the waiting list for transplantation, but the DCD potential in Europe is not yet fully utilized.

- There is a large variability within European countries to perform DCD and existing DCD protocols are heterogeneous.

- Protocols can be helpful to develop, implement and improve DCD performance and answer ethical questions. 


\section{References}

1. Wolfe RA, Ashby VB, Milford EL, Ojo AO, Ettenger RE, Agodoa LY, Held PJ, Port FK. Comparison of mortality in all patients on dialysis, patients on dialysis awaiting transplantation, and recipients of a first cadaveric transplant. N Engl J Med 1999;341:1725-30.

2. Evans RW, Manninen DL, Garrison LP Jr, Hart LG, Blagg CR, Gutman RA, Hull AR, Lowrie EG. The quality of life of patients with end-stage renal disease. N Engl J Med 1985;312:553-9.

3. Delmonico FL, Dominguez-Gil B, Matesanz R, Noel L. A call for government accountability to achieve national self-sufficiency in organ donation and transplantation. Lancet 2011;378:1414-8.

4. Shiroki R, Hoshinaga K, Higuchi T, Tsukiashi Y, Kubota Y, Maruyama T, Izumitani M, Horiba M, Naide Y, Kanno T. Prolonged warm ischemia affects long-term prognosis of kidney transplant allografts from nonheart-beating donors. Transplant Proc 1998, 30:111-3.

5. Snoeijs MG, Schaubel DE, Hene R, Hoitsma AJ, Idu MM, Ijzermans JN, Ploeg RJ, Ringers J, Christiaans MH, Buurman WA, van Heurn LW. Kidneys from donors after cardiac death provide survival benefit. J Am Soc Nephrol 2010;21:1015-21.

6. Daemen JW, Oomen AP, Kelders WP, Kootstra G. The potential pool of non-heart-beating kidney donors. Clin Transplant 1997;11:149-54.

7. Dubbeld J, Hoekstra H, Farid W, Ringers J, Porte RJ, Metselaar HJ, Baranski AG, Kazemier G, van den Berg $A P$, van Hoek B. Similar liver transplantation survival with selected cardiac death donors and brain death donors. Br J Surg 2010;97:744-53.

8. Erasmus ME, Verschuuren EA, Nijkamp DM, Vermeyden JW, van der Bij W. Lung transplantation from nonheparinized category III non-heart-beating donors. A single-centre report. Transplantation 2010, 89:452-7.

9. Kootstra G, Daemen JH, Oomen AP. Categories of non-heart-beating donors. Transplant Proc 1995;27: 2893-4.

10. Bernat JL. The boundaries of organ donation after circulatory death. N Engl J Med 2008, 359:669-71.

11. Bos MA. Ethical and legal issues in non-heart-beating organ donation. Transplantation 2005, 79:1143-7.

12. Dominguez-Gil B, Haase-Kromwijk B, Van Leiden H, Neuberger J, Coene L, Morel P, Corinne A, Muehlbacher F, Brezovsky P, Costa AN, Rozental R, Matesanz R, European Committee (Partial Agreement) on Organ Transplantation. Council of Europe (CD-P-TO). Current situation of donation after circulatory death in European countries. Transpl Int 2011;24:676-86.

13. Dutch Federation of Biomedical Scientific Societies. [http://www.federa.org] 14. Academy of Medical Royal Colleges. A Code of Practice for the Diagnosis and Confirmation of Death. London: PPG Design and Print Ltd; 2008.

15. Wissenschaften SAM. Feststellung des Todes mit Bezug auf Organtransplantationen. Muttenz: Schwabe; 2011.

16. Wind J, Snoeijs MG, van der Vliet JA, Winkens B, Christiaans MH, Hoitsma AJ, van Heurn LW. Preservation of kidneys from controlled donors after cardiac death. Br J Surg 2011;98:1260-6.

17. Donation Ethics Committee UK. An Ethical Framework for Controlled Donation After Circulatory Death. London: Academy of Medical Royal Colleges; 2011.

18. Thompson BT, Cox PN, Antonelli M, Carlet JM, Cassell J, Hill NS, Hinds CJ, Pimentel JM, Reinhart K, Thijs LG, American Thoracic Society; European Respiratory Society; European Society of Intensive Care Medicine; Society of Critical Care Medicine; Sociètède Rèanimation de Langue Française. Challenges in end-of-life care in the ICU: statement of the $5^{\text {th }}$ international consensus conference in critical care: Brussels, Belgium, April 2003: executive summary. Crit Care Med 2004;32:1781-4.

19. Dhanani S, Hornby L, Ward R, Shemie S. Variability in the determination of death after cardiac arrest: a review of guidelines and statements. J Intensive Care Med 2012;29:238-52.

20. Fugate JE, Stadtler M, Rabinstein AA, Wijdicks EF. Variability in donation after cardiac death protocols: a national survey. Transplantation 2011;91:386-9.

21. Gardiner D, Shemie S, Manara A, Opdam H. International perspective on the diagnosis of death. $\mathrm{Br} J$ Anaesth 2012;108:i14-28.

22. Joffe AR. The ethics of donation and transplantation: are definitions of death being distorted for organ transplantation? Philosophy, ethics, and humanities in medicine. Philos Ethics Humanit Med 2007;2:28. 
23. Rady MY, Verheijde JL, McGregor J. Organ donation after cardiac death: are we willing to abandon the dead-donor rule? Pediatr Crit Care Med 2007;8:507. author reply 507-9.

24. Shemie SD. Clarifying the paradigm for the ethics of donation and transplantation: was 'dead' really so clear before organ donation. Philos Ethics Humanit Med 2007;2:18.

25. Carlet J, Thijs LG, Antonelli M, Cassell J, Cox P, Hill N, Hinds C, Pimentel JM, Reinhart K, Thompson BT. Challenges in end-of-life care in the ICU. Statement of the 5th international consensus conference in critica care: Brussel Belgium. Intensive Care Med 2004;30:770-84. 



\section{Chapter}

Ethical, legal and societal issues and recommendations for controlled and uncontrolled DCD

B Haase, M Bos, C Boffa, P Lewis, V Rudge, R Valero, T Wind, L Wright Transplant International, accepted for publication 


\section{Abstract}

This report deals with organ retrieval procedures in both controlled and uncontrolled DCD, looking at the ethical, legal and psychosocial aspects during the different phases of the process. A recently published report by the UK Donation Ethics Committee (UKDEC) has served as an important reference document to outline the steps in the controlled DCD patient-donor pathway. For uncontrolled DCD the UKDEC pathway description was adapted. At the ${ }^{\text {tth }}$ International Conference in Organ Donation held in Paris in 2013, an established expert European Working Group reviewed the UKDEC reports, which were then considered along with the available published literature. Along this pathway the crucial ethical, legal and psychosocial aspects have been flagged, and relevant recommendations have been formulated based on a consensus of the working group. 


\section{The overall DCD process and context (see Figure 9.1)}

Although DCD donation is not available in all countries, in those where it is allowed, in order for hospitals, to implement an ethically acceptable DCD program, a number of preconditions should be met. A key prerequisite is the availability of a national protocol or set of (inter)national best practice guidelines for DCD, on which a local program can be based. A second important prerequisite is that all decisions concerning the treatment of the patient, including the decision to withdraw or limit life-sustaining treatment in a controlled DCD setting, or the cessation of cardiopulmonary resuscitation (CPR) in an uncontrolled DCD procedure, should be based on the patient's best interests. ${ }^{1}$

\section{Avoiding conflicts of interest}

Conflicts of interest may arise if a medical professional involved in treating a potential uncontrolled DCD donor (cardiac arrest donor) has a vested interest in this person becoming a donor, since this may (intentionally or unintentionally) influence his actions and decisions to focus on securing a successful donation rather than performing adequate resuscitation, and facilitating a comfortable and peaceful end-of-life care of the patient. On the other hand - considering that donation could be the last will of a patient - the treating professional should offer this possibility to their patient.

Consulting the Donor Register during the CPR procedure and before death has been declared, may be seen by some to constitute a conflict of interest, since it means that one is considering the possibility of organ donation while the patient is still being treated. However, no actual steps towards donation will be performed until the treating team has declared the patient dead, and valid consent for donation has been obtained. The decision to stop the treatment (CPR) must be made strictly on medical judgement and be independent of the possibility of donation. If there is no evidence available of what the patient wanted, the option to perform organ donation will be open to the family to decide. 
Pathway

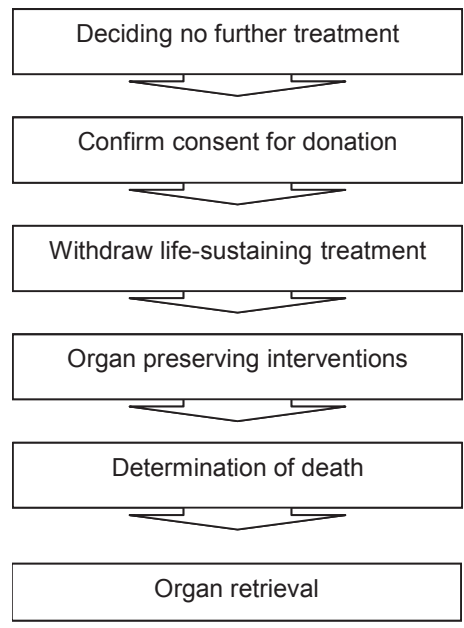

\section{Actions}

Decision on withdrawal or cessation of further treatment; make end-of-life care plan

Check donor registry, consult with family, ask for consent; check donor suitability

Plan withdrawal of treatment, place of withdrawal; arrange for family goodbyes

Donor management, pre-mortem interventions to preserve organs

Monitor dying process, observe no-touch interval, determination of death by treating physician

Organ retrieval by retrieval team, organ preservation

Figure 9.1 DCD pathway (controlled).

Further conflicts may arise as a result of staffing or other logistical issues. The Working Group has considered the position of three professional groups involved, and distinguishes the following division of roles and responsibilities:

a) The treatment team in the Intensive Care Unit or Emergency Department (intensivist, anaesthetist, nurse, or cardiologist resp.). The treatment team is fully responsible for the treatment of the patient, including the decision to withdraw or withhold treatment or to end CPR, and for the determination of death.

b) The donor team (e.g. transplant coordinator, specialist nurse - SNOD). Their task is to coordinate the donation process, to communicate with the potential donor's family, and - once consent for donation is obtained - for liaising between the treatment team, the retrieval team and with the organ transplant centre. The Working Group considers there would be a conflict of interest if the transplant coordinator or SNOD were to be involved in providing medical care to the patient whilst he/she is still alive and being treated.

c) The retrieval team is the surgical team that - with the help of the donor team carries out the preservation of the organs after death has been confirmed and retrieves the organs. The potential donor is handed over into the care of the retrieval team after death has been determined by the treating team. The Working Group considers there would be a conflict of interest if the retrieval team were to play any part in the care of the patient before death has been confirmed. 
Once the death of the patient has been officially determined and declared, the donor team, as well as members of the Emergency Department/ICU team, may assist in caring for the donor if their particular skills are required (e.g. re-intubation to facilitate lung retrieval may be carried out by a member of the treatment team if necessary).

In certain situations staffing problems may compromise the DCD donation procedure. It is advised that hospitals should have protocols setting out solutions for managing staff shortages in order to achieve a potential donor's wish, and for identifying circumstances when such difficulties render donation inappropriate. The Working Group is of the opinion that the treating physician and nurse in charge are responsible for ensuring that staffing arrangements are sufficient to provide appropriately skilled care that meets the necessary ethical standards to the potential donor.

Taking into account the above considerations, the following recommendations are relevant when implementing a DCD program:

\section{Recommendation 1:}

Hospitals, planning to implement a DCD program (controlled and/or uncontrolled) should develop a clear and approved protocol, preferably based on (inter)national guidance, describing the roles and responsibilities of all staff and teams involved, as well as the range of possible outcomes in a (potential) DCD case.

\section{Recommendation 2:}

As the basis of any DCD program, there should be a clear medical, ethical and legal framework outlining when and how to decide on withdrawing or withholding lifesustaining treatment, or on the cessation of CPR. This should be based on the patient's best interests. In making these decisions each action involving that patient is justified by balancing the potential benefits and harms to that patient, also taking into account his or her wish to donate.

\section{End-of-life care}

The decision to start a DCD procedure evolves from the fact that the patient is approaching the end of life. In the context of the provision of end-of-life care, decisions have to be taken concerning the different pathways for that particular patient (controlled or uncontrolled DCD). ${ }^{2}$ The roles and responsibilities of those treating the patient, and those performing the retrieval procedure, should be clearly defined and separated. ${ }^{3}$ Consideration should be given to the possibility of carrying out interventions to optimize donation, prior to death. These considerations lead to the following recommendations: 


\section{Recommendation 3:}

In order to avoid any conflict of interest, there must be a clear separation between the team treating the patient, including taking care of donor management, and the team responsible for retrieving the organs. Responsibility for deciding to withdraw, limit or end further treatment in a patient, as well as determining and declaring his death, lies solely with the treatment team.

\section{Recommendation 4:}

In all patients (including children) approaching the end of life, the option to donate organs should be considered and discussed with the next-of-kin, depending on the known will of the patient, the existence of medical contra-indications, and the possibility of obtaining consent for donation. It is acceptable to consult a National Donor Registry (or similar source), at the time when withdrawal, limitation of treatment, or cessation of CPR in a patient is considered (and before death is declared), in order to know the registered will of the patient concerning organ donation. For each patient a plan for end-of-life care should be made that addresses these issues.

\section{Determination of death}

In organ donation, death should be diagnosed and confirmed by the treatment team, by strictly following the schedule laid out in a national protocol for the determination of death that is approved by the medical profession (and in some countries prescribed by legislation). ${ }^{4}$ Most countries already have such a protocol for determining death on neurological criteria (brain death), but protocols based on cardio-circulatory criteria (circulatory death) are often lacking. The onset of death in a potential DCD donor is to be determined by the irreversible loss of the capacity for consciousness, and the irreversible loss of the capacity for spontaneous respiration in that patient, in order to comply with the Dead Donor Rule. ${ }^{5}$ These considerations lead to the following recommendations: 


\section{Recommendation 5:}

A hospital implementing a DCD program should have a clear and approved local protocol- consistent with national protocol - for determining and declaring death in a DCD context (controlled/uncontrolled).

\section{Recommendation 6:}

After the onset of circulatory arrest or the cessation of CPR, an observation period (notouch interval) of at least 5 minutes must be observed before death shall be declared. In controlled DCD (withdrawal or limitation of life-sustaining treatment) the requirement of 'irreversibility' of respiratory-circulatory function is (ethically) met because a deliberate decision has been taken not to take any action to resuscitate the patient, in his or her best interests.

\section{Pre (ante) -mortem and post-mortem interventions}

In controlled DCD, transplantation of the organs is facilitated, and the outcome of the transplantation improved, if certain measures are taken in the period after withdrawal of treatment and before the death of the patient is declared. ${ }^{6}$ These pre-mortem measures are intended to optimize the viability of the organs, and should be consistent with the wish of the patient to become a donor. Interventions to preserve and improve organ quality in-situ can be taken after death has been declared, thereby facilitating the wish of the patient to be a donor, but care should be taken not to compromise the determination of death (e.g. the risk of re-starting cerebral or cardiac circulation when applying normothermic regional perfusion. ${ }^{7}$

\section{A strategy for implementing pre-mortem interventions}

When preparing pre (ante)-mortem interventions in controlled DCD, with the aim to improve the quality of transplantable organs, the following considerations and ethical framework should be taken into account.

a) The question whether interventions to improve donation are acceptable and relevant, will arise at the end of a three-stage decision making process:

- It should have been decided that the continuation of life-sustaining treatment is no longer in the best interests of the patient;

- It should have been decided that organ donation would be in the best interests of the patient;

- A balancing process for deciding whether particular interventions to optimise donor organ quality and improve transplant outcomes would be in the best interests of the patient, should be undertaken in a manner that is both ethical, and lawful. 
b) Before the balancing process is undertaken in relation to a particular intervention, a clear justification for the intervention in terms of its potential to improve the transplant outcomes from the patient's donation(s) should be identified. If an intervention is routinely undertaken but the evidence for its potential to improve transplant outcomes is weak, then the potential for the patient to benefit from the intervention will be proportionately reduced. The absolute minimum level of intervention should be used consistent with facilitating the success of the transplant.

c) In order to assess whether an intervention designed to optimise donor organ quality and improve transplant outcomes would be in the best interests of the patient, the potential benefits to the patient must be balanced against the potential harm or distress (or risk of harm and distress) that may be caused by the intervention.

d) In the assessment of the balance of benefits and harms for any such intervention, the patient's wishes and feelings, beliefs and values must all be considered. A person's interests are wider than simply their clinical interests. A person's social, emotional, cultural and religious interests should be considered in determining what course of action may be in his or her best interests.

e) The strength of the patient's decision or wish to donate will play an important role in assessing the balance of benefits and harms for any such intervention. Further information from the patient's family and friends about their wishes, feelings, beliefs and values about organ donation and (if available) any procedures designed to optimise donor organ quality and improve transplant outcomes may also be valuable in building up a picture of the strength of the patient's wishes.

\section{Potential benefits}

Not being able to fulfil the patient's wish to be an organ donor may potentially harm the patient's best interests. This concept can be made more positive by considering the potential benefits, which may accrue to the patient by facilitating their wish to be an organ donor. These encompass both the prospective benefit of knowing their wishes will be facilitated, as well as the future benefit it will attach to their legacy. In most cases the patients will have an interest in the well being of their family and so may also be benefitted indirectly if the donation helps family and friends to come to terms with their loss and promotes positive memories of the patient after death.

\section{Potential harm}

An intervention designed to optimise donor organ quality and improve transplant outcomes may potentially cause harm or distress (or risk causing harm or distress) to the patient. Examples of potential harm include pain or discomfort; examples of potential distress include anxiety or gasping. 
Thought should be given to the extent to which symptoms of pain, discomfort or distress might be caused so they can be alleviated using appropriate symptom control.

The risk of causing distress to the patient's family should also be considered a potential risk of harm to the patient. Ways of avoiding this should be explored through careful explanation of both the need for particular interventions in order to facilitate the patient's wish to be a donor and what is involved in those interventions. Those caring for the patient must also ensure that interventions are carried out in a way that is as respectful as possible of the patient and their family and friends.

For each patient and each proposed intervention, the clinical team will need to assess whether the potential benefits of the intervention outweigh any potential harm that cannot be prevented by using appropriate symptom control. If so, the proposed intervention may not be in the best interests of the patient. A wide range of relatively minor interventions are likely to meet this threshold for all patients who want to become organ donors. A few interventions carry risks of serious harm, and very strong evidence of potential benefits would be needed in order for them to be in the best interests of the patient. The evidence relating to the risk of harm associated with particular interventions is likely to change over time and should be regularly revisited by a suitable body in order to ensure that clinicians are able to make evidence-based assessments of those risks, if they exist.

The above considerations lead to the following recommendations:

\section{Recommendation 7:}

When it has been established that a) further treatment is no longer in the best interests of the patient, and b) organ donation is in accordance with the will of the patient and/or the next-of-kin, it is medically and ethically appropriate to take certain measures before the death of the patient is declared, to ensure the best possible quality of organs to improve the outcome of the transplanted organ. For each specific intervention the potential to optimize the organ quality, and thereby facilitate the patient's wish to be a donor, should be balanced against the potential for harm and distress in that patient (and also his next-of-kin).

\section{Recommendation 8:}

Interventions in the donor, that are carried out (or continued) after the death of the patient has been declared, should be applied in such a way that the determination of death is not compromised in any way. 


\section{Family communication and guidance}

Good communication with and guidance of the family throughout the end-of-life care and donation procedure is of utmost importance for their acceptance of donation and bereavement care. ${ }^{8}$ Following the wishes of the next-of-kin is of paramount importance for a good outcome of a DCD procedure and this may have a bearing on the way the procedure is arranged and implemented. These considerations lead to the following recommendations:

\section{Recommendation 9:}

The option of organ donation should not be discussed with the next-of-kin before the decision to withdraw or limit treatment or cease CPR has been made, and the family has been informed and consulted on this issue. Consent from the next-of-kin should be sought after efforts have been made to establish the own will of the patient. If the family objects to donation, or if donation is abandoned in case of a contra-indication, the family should still receive full support and bereavement care.

\section{Recommendation 10:}

Communication with the family should preferably be the responsibility of a single designated liaison (member of treatment staff or trained nurse) throughout the DCD procedure. At an early stage in the donation process, this communication should address any particular religious observances that need to be fulfilled or cultural traditions to be taken into account during the dying phase and period following the death of the patient.

\section{Allocation of DCD organs}

The allocation of retrieved DCD organs should follow the current national allocation system, taking into account the characteristics of both the donor and the potential recipient, and the potential for a good outcome of the transplant, as well as equity of access. DCD organs can also be offered for cross-border exchange, between countries where DCD is accepted. These considerations lead to the following recommendation:

\section{Recommendation 11:}

At the time of being waitlisted, potential recipients of DCD organs should be informed about the possibility of receiving and accepting such an organ. Allocation of DCD organs should be based on the agreed national allocation policy. 


\section{General policy for implementing DCD}

When considering starting a DCD program, hospitals should make efforts to inform the general public and other stakeholders involved, by setting up and implementing an outreach education program., 90 This should focus on preparing all parties for the occurrence of DCD, and growing and maintaining trust and confidence. This leads to the following recommendation.

\section{Recommendation 12:}

There is a need for information, education and guidance to the general public, as well as stakeholders involved, on the issue of DCD.

Timelines and responsibilities

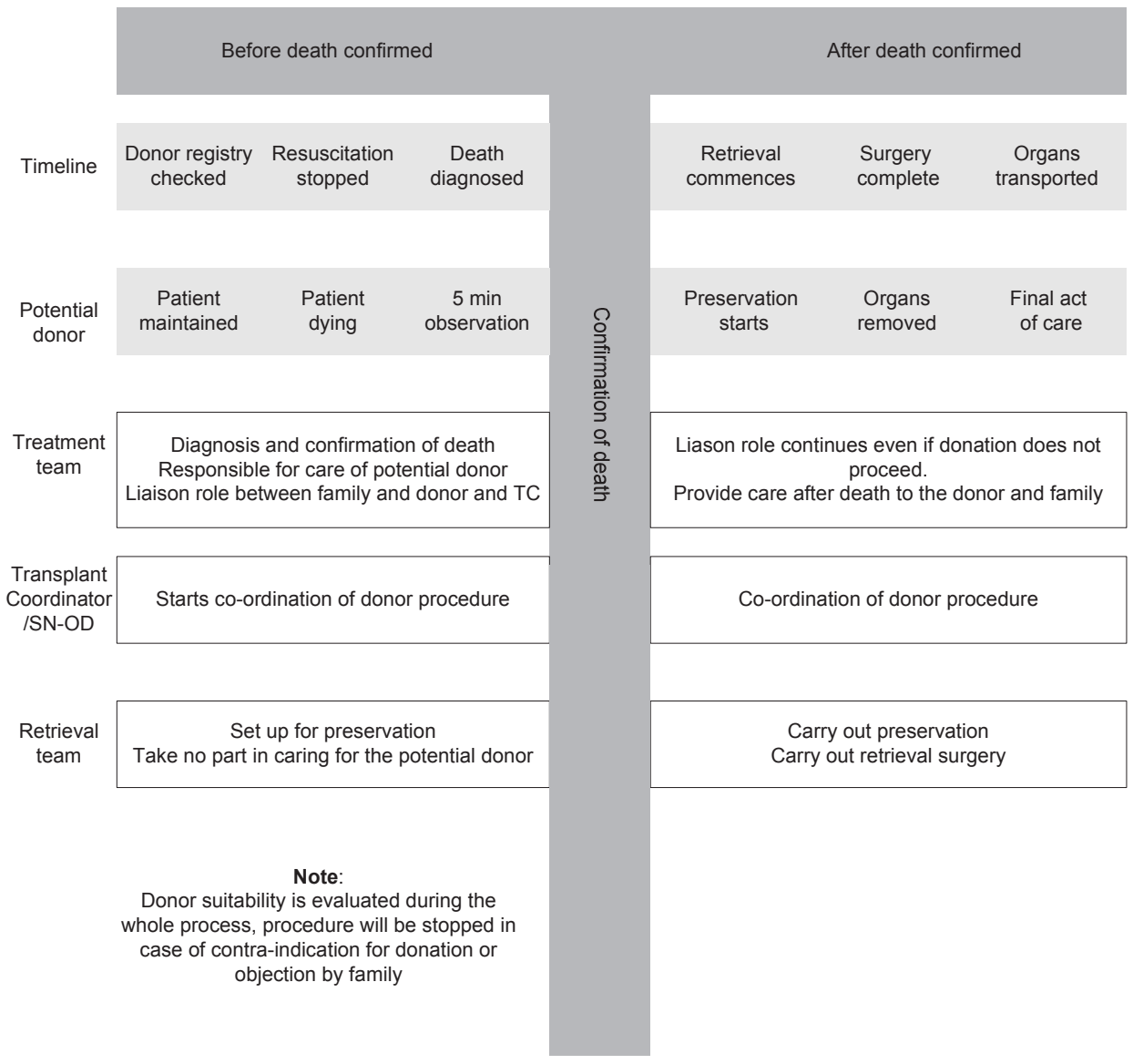

Figure 9.2 Time line and responsibilities in Uncontrolled DCD. 
Decision making tree in uncontrolled donation

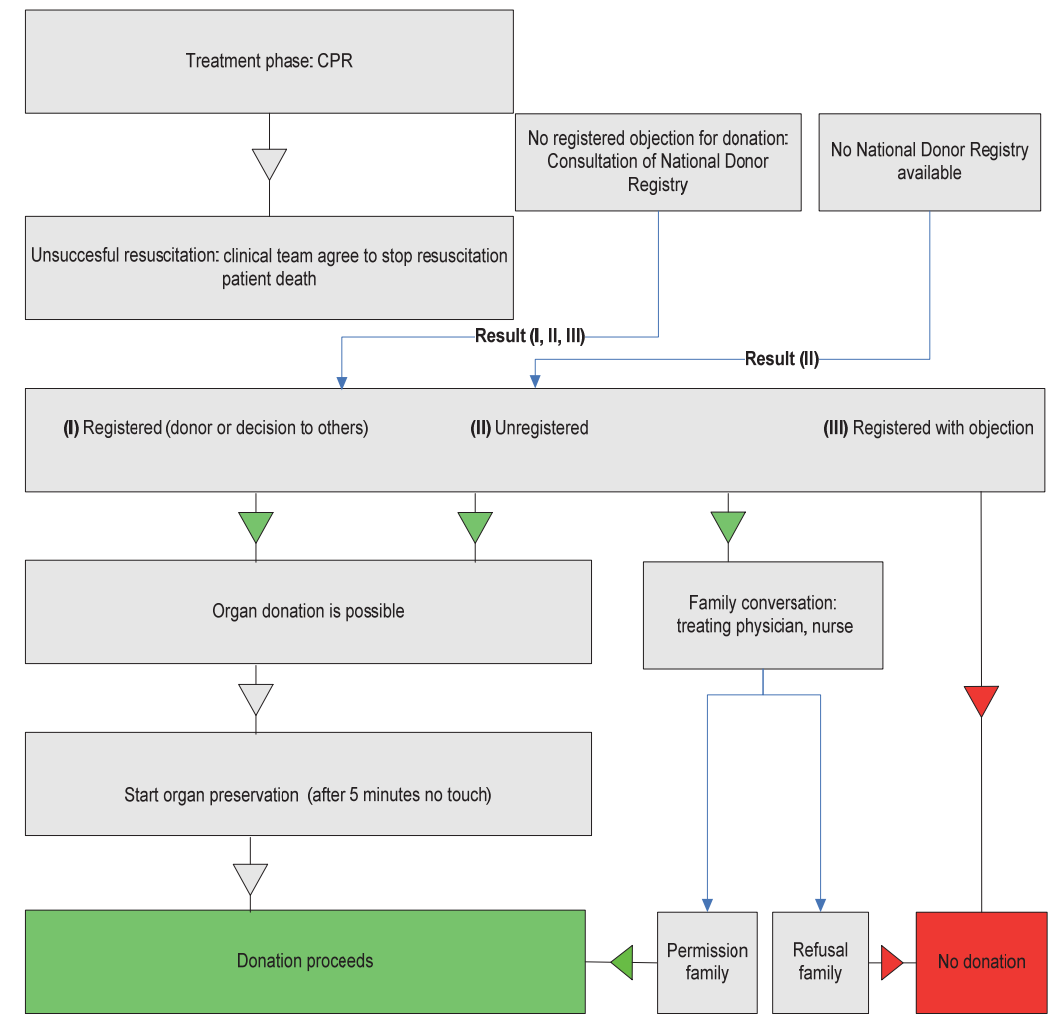

Figure 9.3 Decision making tree in uncontrolled DCD. 


\begin{tabular}{|c|c|c|}
\hline Issue & Uncontrolled DCD & Controlled DCD \\
\hline CPR & $\begin{array}{l}\text { CPR attempted following standard criteria } \\
\text { and algorithms, is unsuccessful, death is } \\
\text { declared }\end{array}$ & $\begin{array}{l}\text { CPR is not attempted, life-sustaining } \\
\text { treatment is withdrawn, cardiac arrest } \\
\text { awaited }\end{array}$ \\
\hline Irreversibility & $\begin{array}{l}\text { Irreversibility is demonstrated: all attempts } \\
\text { at resuscitation, under established medical } \\
\text { standard, have failed }\end{array}$ & $\begin{array}{l}\text { Permanent absence of circulation ultimately } \\
\text { leads to irreversible circulatory arrest: there } \\
\text { is no intention to attempt CPR to recover } \\
\text { cardiac function }\end{array}$ \\
\hline Auto-resuscitation & Evidence of auto-resuscitation at 7 minutes & $\begin{array}{l}\text { No reported auto-resuscitation after } 1 \\
\text { minute following cardiac arrest }\end{array}$ \\
\hline $\begin{array}{l}\text { Demonstrating cardio- } \\
\text { circulatory arrest }\end{array}$ & Asystole on ECG must be confirmed & $\begin{array}{l}\text { In general, absence of pulse (by arterial } \\
\text { blood pressure monitoring) will be } \\
\text { confirmed }\end{array}$ \\
\hline $\begin{array}{l}\text { No-touch time (standard } \\
\text { observation time) }\end{array}$ & $\begin{array}{l}\text { Time elapsed between demonstration of } \\
\text { unsuccessful CPR until declaration of death, } \\
\text { and beginning of preservation measures }\end{array}$ & $\begin{array}{l}\text { Time elapsed between demonstration of } \\
\text { circulatory arrest until declaration of death, } \\
\text { and beginning of preservation measures }\end{array}$ \\
\hline $\begin{array}{l}\text { Pre-mortem } \\
\text { interventions }\end{array}$ & $\begin{array}{l}\text { No interventions to optimize organ quality } \\
\text { during attempts to recover cardiac function. }\end{array}$ & $\begin{array}{l}\text { According to protocols, ethical consideration } \\
\text { etc. }\end{array}$ \\
\hline $\begin{array}{l}\text { Post-mortem } \\
\text { interventions }\end{array}$ & $\begin{array}{l}\text { According to protocols, ethical } \\
\text { considerations etc. }\end{array}$ & $\begin{array}{l}\text { According to protocols, ethical } \\
\text { considerations etc. }\end{array}$ \\
\hline Preservation techniques & $\begin{array}{l}\text { Irreversible circulatory arrest after failed CPR } \\
\text { (irreversible brain damage) and no risk of } \\
\text { recovery of brain perfusion. } \\
\text { Circulation isolation during normothermic } \\
\text { recirculation may be done to improve } \\
\text { splanchnic perfusion. }\end{array}$ & $\begin{array}{l}\text { Potential recovery of circulation to the brain } \\
\text { and heart must be prevented (CPR, } \\
\text { normothermic regional perfusion without } \\
\text { circulation isolation). }\end{array}$ \\
\hline
\end{tabular}

Figure 9.4 Key differences between uncontrolled and controlled DCD. 


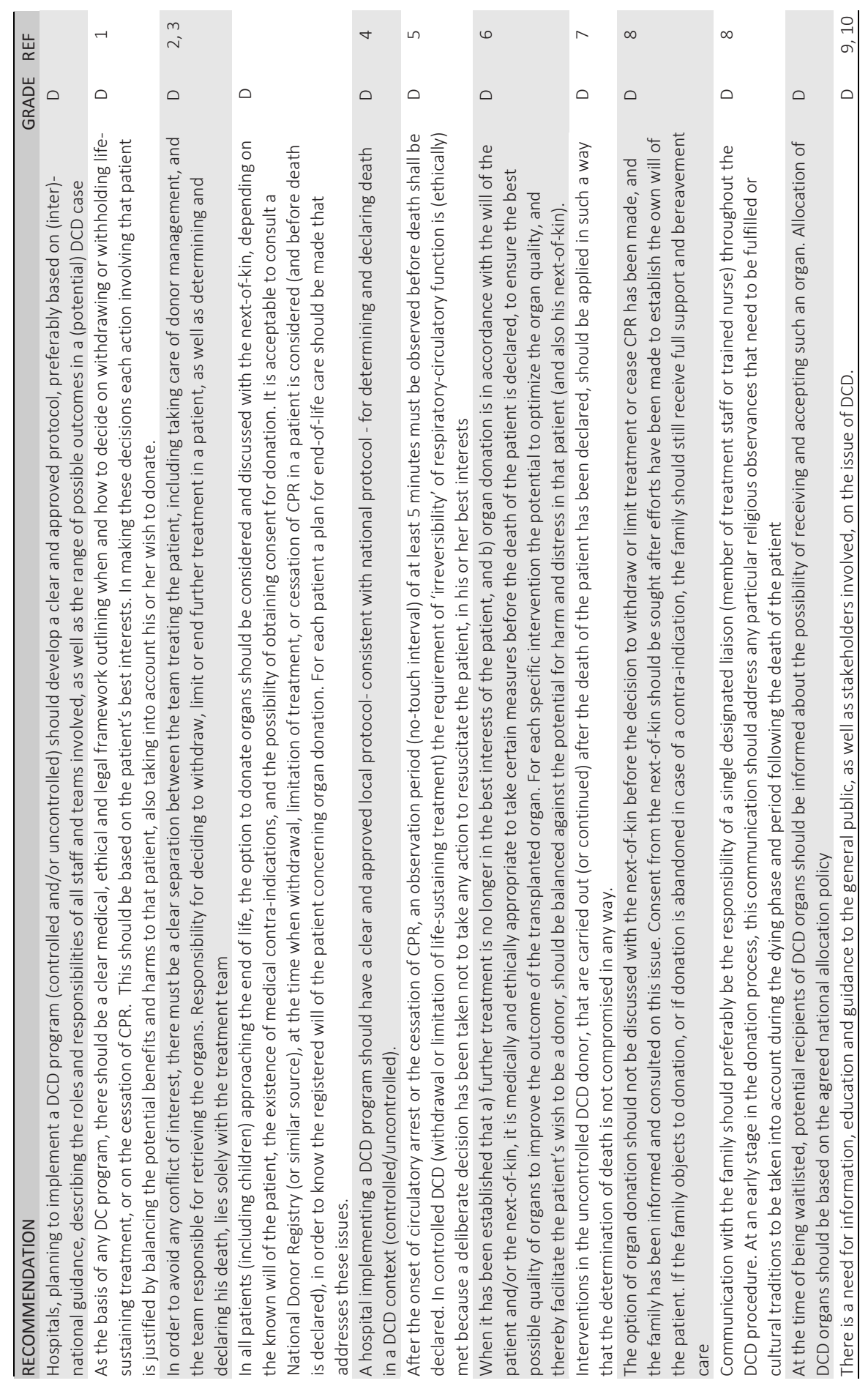




\section{References}

1. Academy of Medical Royal Colleges. UK Donation Ethics Committee. An ethical framework for controlled donation after circulatory death. December 2011.

2. Pellegrino ED. Decisions to withdraw life-sustaining treatment: a moral algorithm. JAMA 2000;283: 1065-7.

3. Beckstrand RL, Kirchhoff KT. Providing end-of-life care to patients: critical care nurses' perceived obstacles and supportive behaviors. Am J Crit Care 2005;14:395-403.

4. Academy of Medical Royal Colleges. A code of practice for the diagnosis and confirmation of death UK, October 2008.

5. Bernat JL. How the distinction between "irreversible" and "permanent" illuminates circulatoryrespiratory death determination. J Med Philos 2010;35:242-55.

6. Richards B, Rogers WA. Organ donation after cardiac death: legal and ethical justifications for antemortem interventions. Med J Aust 2007;187:168-70.

7. Bernat JL, Capron AM, Bleck TP, Blosser S, Bratton SL, Childress JF, et al. The circulatory-respiratory determination of death in organ donation. Crit Care Medi 2010;38:963-70.

8. Youngner SJ, Arnold RM. Ethical, psychosocial, and public policy implications of procuring organs from non-heart-beating cadaver donors. JAMA 1993;269:2769-74.

9. Bos MA. Ethical and legal issues in non-heart-beating organ donation. Transplantation 2005;79:1143-7.

10. Randhawa G. Death and organ donation: meeting the needs of multiethnic and multifaith populations. $\mathrm{Br}$ J Anaesth 2012;108 Suppl 1:i88-91.

\section{Other recommended reading}

- Bonnie RJ, Wright S, Dineen KK. Legal authority to preserve organs in cases of uncontrolled cardiac death: Preserving family choice. J Law Med Ethics 2008: 36: 741-51.

- Daar AS. Non-heartbeating donation: ten evidence-based ethical recommendations. Transplant Proc 2004; 11: 202.

- $\quad$ Department of Health. Legal issues relevant to non-heartbeating organ donation. UK, November 2009.

- Ethics Committee American College of Critical Care medicine, Society of Critical Care Medicine: Recommendations for non-heartbeating organ donation. A position paper by the Ethics Committee, American College of Critical Care Medicine, Society of Critical Care Medicine. Crit Care Med 2001; 29: 1826-31.

- $\quad$ Glannon W. A review of the ethical isses surrounding donation after cardiocirculatory determination of deah. A working document. Universiry of british Columbia, 2005.

- $\quad$ Papalois V, et al. Ethical issues in non-heart beating donation. Bull Med Eth 2004:

- $\quad$ President's Council on Bioethics. Controvesies in the determination of death. 2008, Washington DC. 



\section{Chapter 10}

General discussion and summary 



\section{Introduction}

Organ transplantation is an accepted medical treatment for organ failure; however, the number of available organs cannot meet the demand for patients on the waiting lists. Next to living donor kidney transplantation ${ }^{1,2}$ and the liberal use of brain dead donors with expanded donor criteria, ${ }^{3}$ donation after circulatory death (DCD) has become an accepted strategy to expand the donor pool, which contributes to reduce the waiting lists for transplantation. ${ }^{4}$ It's use is expanding rapidly throughout the world. In the Netherlands, the number of DCD donors exceeded the number of donation after brain death (DBD) donors in 2013. ${ }^{5}$ The DCD process differs from the conventional DBD process; the main difference is the period of warm ischemia from circulatory arrest until initiation of organ preservation, which can cause early complications after transplantation due to acute ischemic organ injury. ${ }^{6}$ As a consequence, a number of initiated DCD procedures fail to lead to transplantation at all, due to prolonged warm ischemia time.

The aim of this thesis was to increase the insight into critical aspects of the processes involved in organ donation after circulatory death, and potentially contribute to its optimization. Several critical issues in the DCD process were therefore studied, to see whether and where optimization is possible. In this chapter, these studies are summarized and its main findings are discussed.

\section{The moment of death and consent for donation}

The first issue in the DCD process studied was the impact of the setting and the moment of death on consent for organ donation. A donation procedure can only start, after consent for donation. The large number of families who refuse donation is one of the bottlenecks in the organ donation process. In the Netherlands, the refusal rate is high; around $60 \%$ of the relatives object to donation when a potential donor is not registered in the 'Donor Registry' and the decision has to be made by the relatives. ${ }^{7}$ In Chapter 2 we compared the consent rates for donation of relatives in two different settings: patients in whom death was unexpected after unsuccessful resuscitation and in patients where death was expected, because brain death was suspected or the decision was made to withdraw the treatment of the patient.

In the Maastricht University Medical Center (MUMC) the donor pool has been expanded with DCD donors since the early 1980's. ${ }^{6,8}$ The MUMC is one of the few centers in the Netherlands, which also performs uncontrolled DCD (after unsuccessful resuscitation) in addition to controlled DCD (after withdrawal of treatment). Kidneys from uncontrolled DCD can be a valuable expansion of the donor pool, provided that a careful selection of 
donor kidneys and recipients is made. ${ }^{9}$ It should be acknowledged that the uncontrolled DCD is a complicated and demanding procedure with a higher chance of failure. For the relatives, the circumstances in which the decision for donation is made in an uncontrolled donation setting are also different; death is unexpected and consequently the time to decide on organ donation is short.

Therefore we studied whether the consent rate in uncontrolled DCD was lower than the consent rate of controlled DCD. If so, this finding would necessitate re-evaluation of the uncontrolled DCD programme. Over a period of eight years, all identified 523 potential organ donors were retrospectively analyzed. Two different groups of donors were compared, based on the moment of death and the time available to discuss donation with the relatives: potential donors where death was expected (ED), including the potential of controlled DCD and DBD donors, and the unexpected death (UD) group; the potential donor after failed resuscitation. No differences in registration in the Donor Registry between the two groups (around 40\%) were seen, or in the outcome of the registration. The consent rate of the relatives was significantly higher in the UD group $(52 \%)$ compared to the ED group (29\%) ( $p<0.001)$. In the univariable and multivariable regression analyses, donation in a controlled setting (ED group) and older donor age were independent risk factors for objection to donation. This study showed that the relatives of the potential donors who died unexpectedly consented more often to donation than those in whom death was expected. This preliminary evidence suggests that the refusal rate of relatives is not a valid argument to restrict the initiation and implementation of an uncontrolled donor programme to expand the donor pool.

\section{Factors associated with consent}

Although the process of consent is complex and not easy to analyze, several important factors associated with consent to donation have been identified. These include the appropriate timing of the request according to the family, the expertise, approach and skills of the requestor, the decoupling of the notification of death and request for donation, the amount of information given to the family and the perceived quality of care for the donor. ${ }^{10-12}$ Almost all studies have studied relatives of potential brain death donors, in contrast to our study. The higher consent rate in uncontrolled donation suggests that the actual witnessed death is an understandable situation for the relatives, which provides insight and clarity about the medical treatment efforts, thereby preventing doubts that donation may influence either the moment of death or end-oflife care. 


\section{Prediction and determination of death}

One of the main issues in the controlled DCD process is the uncertainty if a donation procedure can be effectuated. This is, among others, determined by the moment of death after withdrawal of life sustaining treatment in the ICU. If the time period between withdrawal and death is too long, this will affect organ viability, and as a result the organs are not suitable for transplantation. The prospective multicentre study in Chapter 3, aimed to identify donor characteristics that affect the interval between withdrawal of treatment and death. In a 25-month period, 242 potential DCD donors were identified, of whom 211 were included in the analysis. Within the first hour after withdrawal of treatment, when liver, pancreas and lung donation is possible, $76 \%$ of donors died and $83 \%$ of donors died within two hours, the time limit for kidney donation. The median time to death was 20 minutes. The following factors associated with early death were identified: controlled mechanical ventilation, the administration of norepinephrine, absence of reflexes, neurologic cause of death, and absence of cardiovascular comorbidity. In the multivariable logistic regression analysis, controlled ventilation remained a risk factor for death within 60 minutes, with a fair area under the receiver operating characteristic curve $(A \cup C)(0.738,95 \% \mathrm{Cl} 0.656$ to 0.819$)$. For death within 120 minutes, norepinephrine and absence of cardiovascular comorbidity remained risk factors, $A \cup C 0.775$ (95\% $\mathrm{Cl} 0.693$ to 0.857). Before withdrawal, the clinical judgement of the intensivist about the expected time of death was noted; they predicted death with a sensitivity of $73 \%$ and $89 \%$ for 60 and 120 minutes respectively, but the specificity was low; $56 \%$ and $25 \%$, respectively.

From this study it was concluded that in clinical practice, death of a potential DCD donor cannot be predicted with acceptable certainty, although variables have been identified that increase the odds of dying within 60 or 120 minutes after withdrawal of treatment. The opinion of the intensivist about time of death was valuable, but the sensitivity and specificity of their prediction too low to decide whether to initiate an organ donation procedure or not. Because of the persisting shortage of organs for transplantation, it is necessary to initiate a donation procedure in every potential donor irrespective of the estimated time of death.

Over the last years, several studies worldwide have tried to construct a model to predict the probability of death. A recently published review of those studies by Mushi et al. concluded that consistent predictors of time to death included controlled ventilation, higher oxygenation need, vasopressor use, lower Glasgow Coma Scale Score, and absence of brain stem reflexes. Only moderate sensitivity in the currently existing prediction tools was revealed. The opinion of the physician and simultaneous withdrawal of all support demonstrated promising predictor capabilities according to Mushi. ${ }^{13}$ 


\section{Death determination after circulatory arrest}

An important step in the DCD process is the determination of death after circulatory arrest by the physician. Organs from DCD donors are subjected to a period of warm ischemia, the period between the cessation of circulation and the initiation of preservation measures, which adversely affects transplant outcome. Therefore, there is time pressure to determine death at the earliest possible time after circulatory arrest that is scientifically, ethically, and professionally acceptable to minimize warm ischaemic time. ${ }^{14}$ In Chapter 4 the results of a study of the current practice of the determination of death after circulatory arrest by Dutch intensive care physicians is described. A validated survey; the Determination of Cardiac Death Practices (DDePICt) was sent to all intensive care physicians and returned by 311 (response rate 55\%).

The results showed that local or national guidelines or written policy for the determination of death after circulatory arrest were lacking, therefore most respondents learned death determination from clinical practice. The most commonly used tests for the determination of death were observation of a flat arterial line curve, flat electrocardiogram (standard 3 leads ECG) tracing and presence of fixed and dilated pupils. Tests that were rarely used included absence pulse by echo Doppler, absent blood pressure by non-invasive monitoring and unresponsiveness to painful stimulus. No diagnostic test or procedure was uniformly performed, but $80 \%$ of respondents perceived a need for standardisation of death determination. Most of the intensivists would not change the practice of death determination if an organ procedure followed after death. Nevertheless, in the narrative comments, the time pressure after death, close observation of the patient and bedside presence of the intensivist were mentioned as differences. The occurrence of autoresuscitation (AR: spontaneous resumption of a perfusing rhythm after cardiac arrest) was reported to occur, by the responding intensivists. So far, this phenomenon is only reported in the literature in patients after resuscitation. Thirty-seven per cent of the responding intensivists reported having witnessed AR, not only after unsuccessful resuscitation, but also after withdrawal of treatment. According to six respondents the observed auto resuscitation occurred more than 5 minutes after asystole after life support withdrawal.

In conclusion, extensive variability in the practice of determining death after circulatory arrest exists. A need for guidelines and standardization of practice to determine death after circulatory arrest is reported, especially if a DCD procedure follows death. Although anecdotally reported, autoresuscitation, both after unsuccessful resuscitation, as well as after withdrawal of life support, requires attention in prospective observational studies.

In the setting of organ donation following circulatory death, it is important to have clear defined uniform criteria for determination of circulatory death, like there are clearly defined protocols for the determination of brain death. ${ }^{15}$ In the Netherlands, the 
National Health Council recently published a national protocol for the establishment of death in organ donors both in brain death and death after circulatory arrest. ${ }^{16}$ According to this protocol: determining death in DCD has two crucial components: 1) determination of circulatory arrest ('mechanical asystole'); 2) respecting an observation period after circulatory arrest without intervention: the no-touch time. Circulatory death is ascertained by recording the absence of an intra-arterial pressure wave or based on another current method of monitoring circulation. A no-touch period of five minutes is then observed. This time is required to rule out spontaneous recovery of circulation and breathing. After this time has elapsed, irreversible circulatory and respiratory arrest exists and death may be declared.

\section{Preservation methods for DCD kidneys}

Kidneys from DCD donors are inevitably associated with warm ischemic damage due to the period of circulatory arrest. Therefore, rapid cooling is indicated to reduce this damage. In the retrospective study of a large cohort of 165 controlled DCD donors described in Chapter 5, two in situ preservation methods in two donor regions in the Netherlands were studied. One method is to perfuse the kidneys with a double-balloon triple-lumen (DBTL) catheter introduced via the femoral artery into the aorta, and the other is in situ preservation with direct cannulation of the aorta after a rapid laparotomy. ${ }^{17}$ The first method is a minimally invasive surgical technique that can be performed at the bedsite, whereas direct cannulation is performed in the operating room. A previous study from our organ procurement region, showed that complicated in situ perfusion with the DBTL catheter was the cause for failure to proceed to organ recovery in a large proportion of the potential DCD donors. ${ }^{18}$ In situ preservation by use of the DBTL catheter is a useable technique for uncontrolled donation, because it provides the time to meet the legal and logistical requirements for organ recovery, and the procedure can be performed at the bed site.

In the study, 102 donors in the DBTL group and 63 in the aortic group were included. The discard rate was higher in the DBTL group; $28,2 \%$ of the kidneys were not transplanted, compared with six $(4.8 \%)$ in the group in which direct cannulation was performed (aortic group) $(P<0.001)$. In 26 kidneys, the discard was related to the DBTL catheter (difficulties with DBTL catheter insertion and poor flush out). In the multivariable analysis, most important independent risk factors for kidney discard were preservation with the DBTL catheter (odds ratio (OR) 5.19, 95\% confidence interval (c.i.) 1.88 to $14.36 ; P=0.001$ ) and increasing donor age (OR 1.05, c.i. 1.02 to $1.07 ; P<0.001$ ). Recipient survival was similar in both groups, but the graft survival was better in the Aortic group. From this study it was concluded that direct aortic cannulation is the preferred preservation method for controlled DCD. 
In Chapter 6 the currently used techniques in the world to preserve kidneys from DCD donors were reviewed. Beside the techniques studied in Chapter 5, the in situ preservation with the DBTL catheter, mainly used in uncontrolled DCD procedures, and the rapid laparotomy with direct aortic cannulation for the controlled DCD, several other techniques are used. In the uncontrolled DCD donors, cardiopulmonary resuscitation (CPR) with automated chest compression device can be used as a bridge to organ preservation with the aim to improve kidney circulation and reduce warm ischemic injury to the kidneys of a potential donor. In Paris and Madrid this technique is used to transport potential DCD donors to the hospital for organ recovery, after lifesaving resuscitation has failed. ${ }^{19}$ Extracorporeal membrane oxygenation (ECMO), a technique used in ICU patients for temporary circulatory support and systemic oxygenation can be used in DCD donors. It restores the warm and oxygenated blood flow through the organs to provide normal tissue perfusion between death and organ procurement. Cardiac and brain perfusion are prevented by occlusion of the thoracic aorta with a balloon catheter, which is inserted in the opposite femoral artery. To distinguish the use of the ECMO technique in donors and ICU patients, the terminology for ECMO in donors has been changed to normothermic regional perfusion, because only the (abdominal) organs are perfused. Although only a few clinical studies in renal transplantation are published, they all reach consistent conclusions and describe better kidney transplant outcome with normothermic regional perfusion, in both uncontrolled and controlled DCD. ${ }^{20}$

Normothermic regional perfusion seems a promising technique and may improve the viability of marginal donor kidneys. Nevertheless, in contemporary practice the method of choice to preserve DCD kidneys still depends on logistic, ethical, financial and jurisdictional circumstances.

\section{Family satisfaction of end-of life care}

An organ procedure following after death of a ICU patient, has impact on the end of life care. In Chapter 7 the satisfaction of the family of ICU patients who became donor after death and the family of ICU patients who did not donate their organs was compared. A cohort of 158 family members of deceased ICU patients from our University Medical Centre, a mixed 33- beds ICU were asked to complete a translated version of the Family Satisfaction in the Intensive Care Unit (FS-ICU) survey. The response rate was $72 \%$; 32 donor and 80 non-donor families. Families of donors scored higher on all three scales that were identified by factor analyses; the care scale, the decision making scale and on the end-of life care scale. Only the latter difference was statistically significant $(P=0.024)$. Length of stay was identified as confounder by regression analyses. Correction for length of stay showed only a small to moderate effect of donation on the satisfaction on the end of life care scale. Length of stay exerted a small to moderate effect on the family 
satisfaction on all scales. Increased length of stay, decreased the satisfaction. Over $80 \%$ of the donor families were very satisfied regarding the organ donation process.

Non-donor families provided more negative comments; the main items concerned the communication with the family, the lack of privacy during the dying process, support for the family and the atmosphere of the waiting room. Although only a small to moderate effect of donation on the satisfaction of the family was observed, the donor procedure itself does not negatively influence the perception of the family about the end of life care of the intensive care patient.

Families are often involved in the ICU as surrogate decision makers; due to sedation and severity of illness, many ICU patients cannot make their own decisions. The focus of research the last years was on measurement and improvement of end-of-life care in the ICU. ${ }^{21,22}$ Key determinants of family satisfaction after patients' death in the ICU, from previous studies were found to be good communication, good decision making and respect and compassion shown to patient and family. ${ }^{23,24}$

\section{European perspective}

In Chapter 8 and Chapter 9, the DCD process was studied from a European perspective. In Chapter 8; to provide a general overview of the European attitude towards DCD, the available protocols for DCD in Europe were evaluated. Focus was on the inclusion and exclusion criteria for organ donation, legislation on DCD donation, and the determination of death and preservation methods for organ procurement within the protocols. From the 10 European countries, which actively perform DCD, eight have specific protocols for DCD or describe DCD procedures in one general protocol for organ donation. Legal restrictions, ethical considerations and organizational difficulties are reasons for not performing DCD. In most countries (70\%) presumed consent is used to obtain permission for organ donation, the way it is executed varies in the protocols. The use of the different Maastricht categories varies per country, as is the percentage of DCD of the total number of deceased donors. In the Netherlands, the United Kingdom and Latvia the percentage DCD is high. There was extensive variation in the protocols ranging from small differences concerning in-and exclusion criteria, to major differences in the description of the determination of death. Some more detailed protocols are supported by ethical frameworks and consensus statements, like DCD protocols in the UK. ${ }^{25}$

From Chapter 8 it was concluded that DCD procurement strategies differ throughout Europe, and the implementation of protocols differs even more. DCD is not fully utilized yet in Europe, within the countries and hospitals, therefore solid protocols, supported by 
the responsible authorities, and transplant and intensive care professionals, may eventually result in a further increase of DCD transplantation in Europe.

Finally, in Chapter 9, important topics within the DCD process, thereby focussing on ethical, legal and psychological aspects of the controlled and uncontrolled DCD procedure were explored with DCD experts from different countries with an active DCD programme were explored. To outline the steps in the DCD pathway, the UK Donation Ethics Committee (UKDEC) report served as an important reference document. ${ }^{25}$

Recommendations in the study were formulated on the following aspects: the overall DCD process and context, the end-of life care of the potential donor, the determination of death, pre-and post mortem interventions, family communication and guidance, allocation of DCD organs, and the general policy for implementing a DCD program. A clinical pathway for uncontrolled and controlled DCD was developed. To implement an ethically acceptable DCD programme, a number of preconditions should be met. A key prerequisite is the availability of a national protocol or best practice guidelines for $D C D$, on which a local programme can be based. A second important prerequisite is that all decisions concerning the treatment of the patient, including the decision to withdraw life-sustaining treatment in a controlled DCD setting, or the cessation of cardiopulmonary resuscitation (CPR) in an uncontrolled DCD procedure, should be based on the patient's best interests and be made independently of any consideration of donation.

\section{Conclusions}

This thesis provides insight in important critical issues of the donation after circulatory death process. It showed that the consent rate of relatives of potential donors who died unexpectedly is higher than when death is expected. Variables that increase the odds of dying within 60 or 120 minutes after withdrawal of treatment were identified, although in clinical practice, the death of a potential DCD donor cannot be predicted with acceptable certainty based on these findings.

It is identified that there is variability in the determination of death after circulatory arrest, as well as a need for guidelines and standardization in the practice of death determination after circulatory death as voiced by Dutch intensive care physicians. The reported occurrence of autoresuscitation requires attention in prospective observational studies.

The best preservation method for controlled DCD is direct cannulation of the aorta after rapid laparotomy, for uncontrolled DCD preservation the double balloon triple lumen catheter can be used, since direct cannulation is not readily available. Normothermic 
regional perfusion seems a promising technique in uncontrolled $D C D$, as well as in controlled DCD.

The DCD donor procedure itself does not negatively influence the perception of the family about end of life care of the intensive care patient. Within Europe, the DCD donor pool is so far not used to its full potential; carefully constructed multidisciplinary protocols supported by the national medical organisations can contribute to a further expansion of this potentially large donor pool. To implement an ethically acceptable DCD programme, recommendations on key aspects of the DCD process were formulated.

On all these and other critical aspects of the DCD process, attempts to continuously check and further improve should be made to optimize the quality and further expansion of the potential donor pool and thereby realize an increase in the organ donor rate. 


\section{References}

1. Roodnat JI, Kal-van Gestel JA, Zuidema W, van Noord MA, van de Wetering J, IJzermans JN, Weimar W. Successful expansion of the living donor pool by alternative living donation programs. Am J Transplant 2009;9:2150-6.

2. Terasaki PI, Cecka JM, Gjertson DW, Takemoto S. High survival rates of kidney transplants from spousal and living unrelated donors. N Engl J Med 1995;333:333-6.

3. Merion RM, Ashby VB, Wolfe RA, Distant DA, Hulbert-Shearon TE, Metzger RA, Ojo AO, Port FK. Deceased-donor characteristics and the survival benefit of kidney transplantation. JAMA 2005;294: 2726-33.

4. Daemen JW, Oomen AP, Kelders WP, Kootstra G. The potential pool of non-heart-beating kidney donors. Clin Transplant 1997;11:149-54.

5. Dutch Transplant Foundation. Annual report 2011 of the Dutch Transplant Foundation. The Netherlands. 2012.

6. Wijnen RM, Booster MH, Stubenitsky BM, de Boer J, Heineman E, Kootstra G. Outcome of transplantation of non-heart-beating donor kidneys. Lancet 1995;345:1067-70.

7. Jansen NE, van Leiden HA, Haase-Kromwijk BJ, Hoitsma AJ. Organ donation performance in the Netherlands 2005-08; medical record review in 64 hospitals. Nephrol Dial Transplant 2010;25: 1992-7.

8. Kootstra G, Daemen JH, Oomen AP. Categories of non-heart-beating donors. Transplant Proc 1995;27: 2893-4.

9. Hoogland ER, Snoeijs MG, Winkens B, Christaans MH, van Heurn LW. Kidney transplantation from donors after cardiac death: uncontrolled versus controlled donation. Am J Transplant 2011;11: 1427-34.

10. Rodrigue JR, Cornell DL, Howard RJ. Organ donation decision: comparison of donor and nondonor families. Am J Transplant 2006;6:190-8.

11. Siminoff LA, Gordon N, Hewlett J, Arnold RM. Factors influencing families' consent for donation of solid organs for transplantation. JAMA 2001;286:71-7.

12. Simpkin AL, Robertson LC, Barber VS, Young JD. Modifiable factors influencing relatives' decision to offer organ donation: systematic review. BMJ 2009;338:b991.

13. Munshi L, Dhanani S, Shemie SD, Hornby L, Gore G, Shahin J. Predicting time to death after withdrawal of life-sustaining therapy. Intensive Care Med 2015;41:1014-28.

14. Manara AR, Murphy PG, O'Callaghan G. Donation after circulatory death. Br J Anaesth 2012;108 Suppl 1:i108-21.

15. Wijdicks EF, Varelas PN, Gronseth GS, Greer DM. Evidence-based guideline update: determining brain death in adults: report of the Quality Standards Subcommittee of the American Academy of Neurology. Neurology 2010;74:1911-8.

16. Netherlands Health Council. Determining death in postmortal organ donation - Protocols and criteria, including an updated Brain Death Protocol. The Hague: Health Council of the Netherlands. 2015; publication no.2015/13(ISBN 978-94-6281-040-2).

17. Garcia-Rinaldi R, Lefrak EA, Defore WW, Feldman L, Noon GP, Jachimczyk JA, et al. In situ preservation of cadaver kidneys for transplantation: laboratory observations and clinical application. Ann Surg 1975;182: 576-84.

18. Snoeijs MG, Dekkers AJ, Buurman WA, van den Akker L, Welten RJ, Schurink GW, et al. In situ preservation of kidneys from donors after cardiac death: results and complications. Ann Surg 2007; 246:844-52.

19. Fieux F, Losser MR, Bourgeois E, Bonnet F, Marie O, Gaudez F, Abboud I, Donay JL, Roussin F, Mourey F, Adnet F, Jacob L. Kidney retrieval after sudden out of hospital refractory cardiac arrest: a cohort of uncontrolled non heart beating donors. Crit Care 2009;13:R141.

20. Barrou B, Billault C, Nicolas-Robin A. The use of extracorporeal membranous oxygenation in donors after cardiac death. Curr Opin Organ Transplant 2013;18:148-53.

21. Clarke EB(1), Curtis JR, Luce JM, Levy M, Danis M, Nelson J, Solomon MZ; Robert Wood Johnson Foundation Critical Care End-Of-Life Peer Workgroup Members. Quality indicators for end-of-life care in the intensive care unit. Crit Care Med 2003;31:2255-62. 
22. Truog RD(1), Campbell ML, Curtis JR, Haas CE, Luce JM, Rubenfeld GD, Rushton CH, Kaufman DC; American Academy of Critical Care Medicine. Recommendations for end-of-life care in the intensive care unit: a consensus statement by the American College [corrected] of Critical Care Medicine. Crit Care Med 2008;36:953-63.

23. Heyland DK, Rocker GM, O'Callaghan CJ, Dodek PM, Cook DJ. Dying in the ICU: perspectives of family members. Chest 2003;124:392-7.

24. Hunziker S(1), McHugh W, Sarnoff-Lee B, Cannistraro S, Ngo L, Marcantonio E, Howell MD. Predictors and correlates of dissatisfaction with intensive care. Crit Care Med 2012;40:1554-61.

25. Academy of Medical Royal Colleges. UK Donation Ethics Committee. An ethical framework for controlled donation after circulatory death. December 2011. 



\section{Samenvatting}
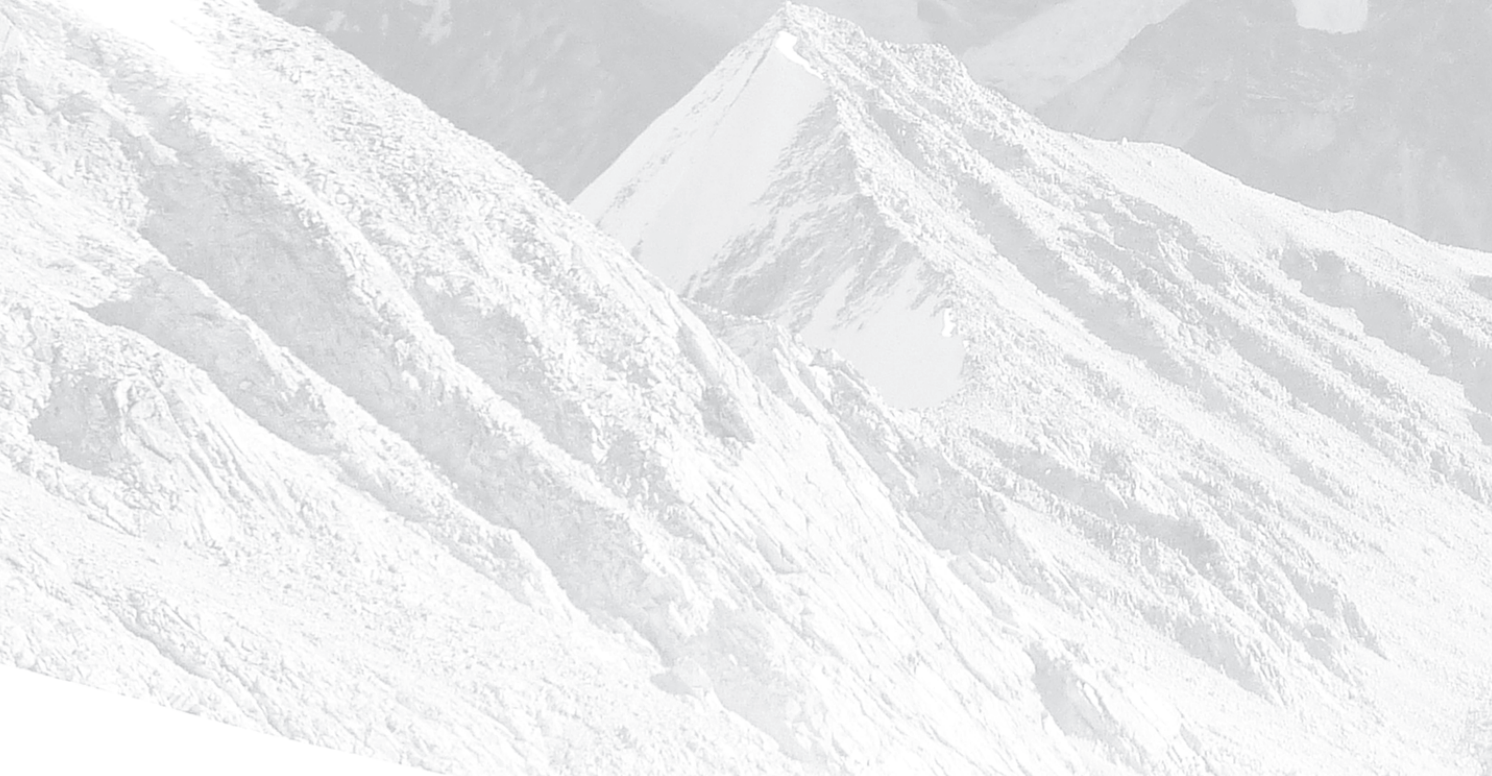



\section{Introductie}

Transplantatie van organen is een geaccepteerde medische behandeling bij orgaanfalen. Orgaantransplantatie is een effectieve en doelmatige behandeling, die patiënten met terminaal orgaanfalen meer kwaliteit van leven biedt en zelfs levensreddend kan zijn. Voor patiënten met terminale nierinsufficiëntie is niertransplantatie de beste behandeling. Echter, door het tekort aan donororganen krijgen veel mensen deze optimale zorg niet. Sinds het eerste succes van niertransplantatie als behandeling wordt er gezocht naar manieren om dit tekort te verminderen, onder meer door gebruik te maken van nieren van levende donoren ${ }^{1,2}$ en het liberale gebruik van organen van hersendode donoren ${ }^{3}$ (donation after brain death, DBD) met co-morbiditeit of hogere leeftijd. Daarnaast is het gebruik van organen van donoren die overlijden na stilstand van hart en bloedsomloop (circulatiestilstand, donation after circulatory death, DCD) een inmiddels geaccepteerde strategie om de pool donoren uit te breiden en zodoende de wachtlijst te verkleinen. ${ }^{4}$

Het gebruik van organen van deze groep donoren neemt wereldwijd toe. In 2013 oversteeg het aantal DCD-donoren het aantal donoren na hersendood in Nederland. ${ }^{5}$ De donatieprocedure van donoren die overlijden na een circulatiestilstand verschilt van de conventionele donatieprocedure na hersendood; het belangrijkste verschil is de periode van warme ischemie (de afwezigheid van zuurstofrijke circulatie) die optreedt bij DCDdonoren en die start vanaf het moment van circulatiestilstand, tot aan de orgaanpreservatie. De schade veroorzaakt door deze warme ischemie kan de oorzaak zijn van vroege complicaties na transplantatie. ${ }^{6}$ Ook zal door een te lange warme ischemische periode een aantal opgestarte DCD-procedures uiteindelijk niet tot transplantatie leiden.

Het doel van dit proefschrift is om het inzicht te vergroten in de kritische aspecten van het donatieproces na circulatiestilstand, om zo de procedure te kunnen verbeteren. Verschillende kritische aspecten werden daarvoor bestudeerd, om te beoordelen waar en hoe verbetering mogelijk is.

In dit hoofdstuk worden de resultaten van het onderzoek samengevat.

\section{Het moment van overlijden en toestemming voor donatie}

Het eerste aspect van het donatieproces dat we hebben bestudeerd, is de invloed van de omstandigheden waaronder en het moment waarop de potentiële donor overlijdt, op de toestemming voor donatie. Immers, alleen indien er toestemming is voor donatie kan een donatieprocedure starten. Een van de obstakels in het orgaandonatieproces is het hoge aantal weigeringen van families; in Nederland weigert ongeveer $60 \%$ van de families donatie indien een potentiële donor niet geregistreerd is in het landelijke Donor 
Register en de beslissing daardoor automatisch bij de familie ligt. ${ }^{7}$ In hoofdstuk 2 hebben we de toestemmingspercentages van families vergeleken onder twee verschillende omstandigheden: patiënten bij wie de dood onverwacht optrad na een niet-succesvolle reanimatie, en patiënten waarbij de dood werd verwacht, omdat er vermoeden was dat de patiënt hersendood was of omdat het besluit was genomen om de medisch zinloze behandeling te stoppen.

In het Maastricht Universitair Medisch Centrum (MUMC) werd gestart met het niertransplantatieprogramma in 1980. In eerste instantie werden alleen nieren van donoren na hersendood gebruikt, maar wegens de groeiende wachtlijst werd er gezocht naar additionele soorten orgaandonoren en werd de pool van donoren uitgebreid met DCD-donoren. ${ }^{6,8}$ Als een van de weinige centra in Nederland maakt het MUMC naast controlled DCD-donoren (patiënten op de intensive care die overlijden na het stoppen van medisch zinloze behandeling) ook gebruik van uncontrolled DCD-donoren (patiënten op de spoedeisende hulp die overlijden na een niet-succesvolle reanimatie). Nieren van deze laatste categorie kunnen een waardevolle uitbreiding zijn van het aantal donoren, mits een zorgvuldige selectie is gemaakt van de donornieren en de ontvangers. ${ }^{9}$ Echter, deze uncontrolled DCD-procedure is een gecompliceerde procedure, die onder hoge tijdsdruk moet worden uitgevoerd door het onverwachte overlijden van de patiënt. De kans op het niet slagen van de procedure is groter dan bij een gecontroleerde procedure, waarbij het overlijden wordt verwacht en voorbereidingen voor de donatieprocedure zijn getroffen. Voor de familie zijn de omstandigheden waaronder een besluit over donatie moet worden genomen ook anders; door de onverwachte dood is er minder tijd beschikbaar.

Daarom hebben we onderzocht of het toestemmingspercentage na een onverwachte dood (uncontrolled DCD) lager was dan het toestemmingspercentage na een verwachte dood (controlled DCD). Deze bevinding zou een herevaluatie van het uncontrolled DCDprogramma noodzakelijk maken. Over een periode van 8 jaar zijn retrospectief alle 523 potentiële orgaandonoren geanalyseerd. Twee groepen werden vergeleken, gebaseerd op het moment van overlijden en de daardoor beschikbare tijd voor het bespreken van de donatie met de familie; het potentieel van de controlled DCD en DBDdonoren (expected death group ED)met de groep met de potentiële donoren na een niet-succesvolle reanimatie (unexpected death group, UD).

Er werden geen verschillen gezien in registratie in het Donor Register tussen de twee groepen (rond de 40\%) noch in de keuze van de registratie. Toestemming van de familie was significant hoger in de UD-groep (52\%), vergeleken met de ED-groep $(29 \%)$ ( $p<$ $0.001)$. Univariate en multivariate regressieanalyse toonden aan dat donatie in een gecontroleerde setting (ED-groep) en oudere donorleeftijd onafhankelijke risicofactoren zijn voor donatieweigering. Deze studie laat zien dat de familie van potentiële donoren die onverwacht overleden, vaker toestemming gaven voor donatie dan familie van 
degene bij wie de dood werd verwacht. Dit suggereert dat de weigering van families geen belemmerend argument is om een uncontrolled DCD-programma te initiëren en implementeren, om zo de pool van te kunnen uitbreiden.

\section{Factoren geassocieerd met toestemming}

Hoewel het toestemmingsproces een complex en moeilijk te analyseren proces is, zijn er in onderzoeken verschillende belangrijke factoren geïdentificeerd die kunnen worden geassocieerd met toestemming voor donatie. Dat zijn onder andere het meest geschikte moment van het stellen van de donatievraag volgens de familie, de benadering en vaardigheid van de vraagsteller, het loskoppelen van de aankondiging van het overlijden en de donatievraag, de hoeveelheid informatie die aan de familie wordt verstrekt en de ervaren kwaliteit van de zorg voor de donor. ${ }^{10-12}$ Bijna alle studies hebben gekeken naar families van potentiële hersendode donoren, dit in tegenstelling tot onze studie.

Het hogere toestemmingspercentage van families van potentiële uncontrolled DCDdonoren suggereert dat het getuige zijn van de dood een duidelijke situatie is voor de familie, nadat er maximale medische inspanning is verricht (reanimatie) en er daardoor geen twijfel bestaat dat de donatie het moment van overlijden zal beïnvloeden of de zorg rondom het levenseinde.

\section{Voorspellen en vaststellen van de dood}

Een van de belangrijkste vraagstukken in het controlled DCD-proces is de onzekerheid of een donatieprocedure kan worden geëffectueerd. Dit hangt onder andere af van het moment waarop de dood intreedt na het stoppen van de behandeling op de intensive care. Indien de tijdsperiode tussen het stoppen van de behandeling en overlijden te lang is, zal dit van invloed zijn op de levensvatbaarheid van de organen, waardoor organen mogelijk ongeschikt zijn voor transplantatie.

De prospectieve multicenterstudie in hoofdstuk 3 heeft als doel om donorkarakteristieken te identificeren, die het interval tussen het stoppen van de behandeling en het overlijden beïnvloeden. Gedurende 25 maanden werden 242 potentiële DCD-donoren geïdentificeerd, waarvan er 211 werden geïncludeerd in de analyse. Binnen het eerste uur na het stoppen van de behandeling, wanneer donatie van de lever, alvleesklier en longen en nieren mogelijk is, overleden $76 \%$ van de donoren. Binnen twee uur na het stoppen van de behandeling, de tijdslimiet voor nierdonatie, overleed $83 \%$. De mediane tijd tot overlijden was 20 minuten. 
Factoren die geassocieerd zijn met snel overlijden werden geïdentificeerd: volledig gecontroleerde mechanische beademing, het toedienen van norepinephrine, de afwezigheid van reflexen, een neurologische doodsoorzaak, de afwezigheid van cardiovasculaire co-morbiditeit. Gecontroleerde mechanische beademing bleek een onafhankelijke risicofactor voor overlijden binnen 60 minuten in een multivariate logistische regressieanalyse (AUC 0.738, 95\% Cl 0.656 -0.819). Onafhankelijke risicofactoren voor overlijden binnen 120 minuten waren toediening van norepinephrine en afwezigheid van cardiovasculaire co- morbiditeit, (AUC 0.775 95\% Cl 0.693-0.857). Voor het stoppen van de behandeling werd het klinische oordeel van de behandelende intensivist over de verwachte overlijdenstijd genoteerd. De intensivisten konden de overlijdenstijd matig tot redelijk voorspellen met een sensitiviteit van $73 \%$ en $89 \%$ voor respectievelijk 60 en 120 minuten, maar de specificiteit was laag; respectievelijk 56\% en $25 \%$ voor 60 en 120 minuten.

Uit deze studie bleek dat in de klinische praktijk de dood van een potentiële DCD-donor niet met acceptabele zekerheid voorspeld kan worden. Wel zijn er variabelen geïdentificeerd die de kans op overlijden vergroten binnen 60 en 120 minuten na het stoppen van de behandeling. De voorspelling van de intensivist over de overlijdenstijd was niet voldoende betrouwbaar, omdat de sensitiviteit en met name de specificiteit te laag was om op basis hiervan een besluit te nemen om een donatieprocedure wel of niet te starten. Wegens het persisterende tekort aan organen voor transplantatie is het noodzakelijk een donatieprocedure te initiëren bij iedere potentiële donor, ongeacht de verwachte overlijdenstijd.

Verschillende studies wereldwijd hebben de laatste jaren getracht een model te ontwikkelen om de overlijdenstijd te voorspellen. Een recent gepubliceerde review van deze studies door Mushi et al. (2015) concludeerde dat consistente voorspellers voor de overlijdenstijd zijn: gecontroleerde mechanische beademing, hogere zuurstofbehoefte, toediening van vasopressoren, lagere Glasgow Coma Scale Score en de afwezigheid van hersenstamreflexen. Er werd slechts een matige sensitiviteit in de ontwikkelde voorspellingsinstrumenten gevonden. De voorspelling van de intensivist en de wijze waarop de behandeling wordt gestopt, door het gelijktijdig stoppen van alle ondersteuning, lijken veelbelovende voorspellers volgens Mushi. ${ }^{13}$

\section{Vaststellen van de dood na circulatiestilstand}

Een volgende belangrijke stap in het DCD-proces is het vaststellen van de dood door de arts, na een circulatiestilstand. Organen van DCD-donoren worden blootgesteld aan een periode van warme ischemie, de periode tussen het stoppen van de circulatie en het starten van de orgaanpreservatie, hetgeen een negatief effect heeft op de transplantatieresultaten. Er bestaat daarom tijdsdruk om de dood vast te stellen op het vroegst mogelijke moment na de circulatiestilstand dat wetenschappelijk, ethisch en 
professioneel acceptabel is, om zodoende de gevolgen van warme ischemie te beperken. $^{14}$

In hoofdstuk 4 worden de resultaten weergegeven van het onderzoek naar de huidige praktijk van het vaststellen van de dood na een circulatiestilstand door intensive careartsen in de Nederlandse intensive care-praktijk. Hiervoor werd een gevalideerde vragenlijst, the Determination of Cardiac Death Practise (DDePICt), naar alle intensivisten gestuurd. De respons rate was 55\% (311 intensivisten). De resultaten laten zien dat er een gebrek is aan lokale of landelijke richtlijnen voor het vaststellen van de dood na een circulatiestilstand. De meeste intensivisten hadden het geleerd vanuit de klinische praktijk. De meest gebruikte testen voor het vaststellen van de dood waren observatie van een vlakke arteriële curve, vlak elektrocardiogram (standaard drie afleidingen ECG) en de aanwezigheid van starre en verwijde pupillen. Nauwelijks gebruikte testen blijken een Echo-Doppler-onderzoek (testen afwezigheid van pulsaties), niet invasieve bloeddrukmeting (afwezigheid van bloeddruk) en toedienen van pijnprikkels (niet reageren op pijnprikkels). Er was geen uniformiteit in het gebruik van diagnostische testen en procedures, maar er was grote behoefte (80\%) aan standaardisatie van methodes voor het vaststellen van de dood. De meerderheid van de intensivisten geeft aan dat ze niet afwijken van de methode die ze gebruiken voor het vaststellen van de dood indien de patiënt een potentiële DCD-donor is. Een aantal intensivisten beschrijven de volgende verschillen indien donatie volgt na het overlijden: de tijdsdruk die bestaat na het overlijden en de nauwkeurige observatie van het overlijdensproces. Van de responderende intensivisten geeft $37 \%$ aan ooit autoresuscitatie (AR: spontane hervatting van hartactie en circulatie na een hartstilstand) te hebben gezien, niet alleen na een reanimatie, maar ook bij patiënten na het stoppen van de behandeling. In de literatuur is dit fenomeen tot nu toe vermeld bij patiënten na een reanimatie. Volgens zes respondenten trad de AR meer dan vijf minuten na de hartstilstand op, bij patiënten waarbij de behandeling was gestopt.

Concluderend blijkt er een grote variatie te zijn in de praktijk van het vaststellen van de dood na een circulatiestilstand. Er is volgens de intensivisten behoefte aan richtlijnen en standaardisatie, vooral indien na het overlijden een donatieprocedure volgt. Hoewel slechts anekdotisch gerapporteerd, vereist het optreden van autoresuscitatie zowel na een niet-succesvolle reanimatie als na het stoppen van de behandeling aandacht in prospectieve observationele onderzoeken.

Indien er een orgaandonatieprocedure volgt na een circulatiestilstand, is het belangrijk om duidelijk gedefinieerde uniforme criteria te hebben voor het vaststellen van de dood, net zoals er uniforme criteria bestaan voor het vaststellen van hersendood. ${ }^{15}$ De Gezondheidsraad heeft recentelijk (2015) een protocol gepubliceerd voor het vaststellen van de dood bij orgaandonoren; zowel voor het vaststellen van hersendood als voor het 
vaststellen van de dood na een circulatiestilstand. ${ }^{16}$ Volgens dit protocol zijn er bij het vaststellen van de dood bij een DCD-donor twee cruciale componenten:

1. het vaststellen van de circulatiestilstand (mechanische asystolie);

2. een observatieperiode na de circulatiestilstand zonder interventie; de zogenaamde 'no touch'-tijd.

De dood wordt geconstateerd door registratie van de afwezigheid van de intra-arteriële drukgolf of - indien de patiënt geen arteriële lijn heeft - een andere methode voor het monitoren van de circulatie. Daarna wordt de patiënt gedurende een periode van vijf minuten geobserveerd. Deze tijd is nodig om spontaan herstel van de circulatie of ademhaling uit te sluiten. Na vijf minuten continue circulatiestilstand is er sprake van een irreversibele circulatie- en ademhalingsstilstand, en kan de dood door de arts worden vastgesteld.

\section{Preservatiemethoden voor DCD-nieren}

Omdat nieren van DCD-donoren onvermijdelijk geassocieerd zijn met warme ischemische schade door de periode van afwezigheid van circulatie, is het noodzakelijk de nieren snel te koelen om deze schade te reduceren.

In een retrospectieve studie van een groot cohort van 165 controlled DCD-donoren beschreven in hoofdstuk 5 zijn twee in situ-preservatiemethoden onderzocht in twee donorregio's in Nederland. Bij de ene methode vindt perfusie van de nieren plaats door het inbrengen van een speciale catheter (de zogenoemde double-balloon triple-lumen, DBTL) ingebracht via de arteria femoralis in de aorta, waarbij na het opblazen van twee ballonnen in deze catheter, de abdominale aorta selectief kan worden geperfundeerd met een hypotherme preservatievloeistof, waardoor de nieren in situ worden gespoeld en gekoeld. Een andere methode is in situ-preservatie door middel van een spoedlaparotomie, waarna directe cannulatie van de aorta plaatsvindt. ${ }^{17}$ De eerste methode is een minimaal-invasieve chirurgische techniek en kan bedsite worden uitgevoerd, terwijl directe cannulatie in de operatiekamer moet plaatsvinden.

Een eerder onderzoek uit onze donatieregio laat zien dat complicaties met in situpreservatie met de DBTL-catheter de meest frequente oorzaak was voor het beëindigen van de donatieprocedure. ${ }^{18}$ Bij onverwachte donatie na een niet-geslaagde reanimatie is het gebruik van de DBTL-catheter een onmisbare techniek, die het mogelijk maakt om te voldoen aan de vereiste juridische en logistieke voorwaarden voor orgaandonatie, zonder de maximale warme-ischemieperiode te overschrijden. Indien de donatie aangekondigd is (controlled DCD) en de aan de vereiste voorwaarden is voldaan voordat de behandeling wordt gestopt, kan preservatie op de operatiekamer plaatsvinden. 
In het onderzoek werden 102 donoren uit de DBTL-groep en 63 uit de aortagroep (directe cannulatie na spoedlaparotomie) geïncludeerd. Het afkeuringspercentage was hoger in de DBTL-groep; $28,2 \%$ van de nieren werden niet getransplanteerd, vergeleken met $4,8 \%$ in de aortagroep $(P<0,001)$. Bij 26 nieren was dit afkeuren direct gerelateerd aan het gebruik van de DBTL-catheter (problemen met het inbrengen van de catheter en slechte afvloed). In de multivariate analyse bleek de belangrijkste onafhankelijke risicofactor voor het afkeuren van de nier de preservatie met de DBTL-catheter te zijn (OR 5,19,95\% Cl 1,88-14,36, $P=0,001$ ) en toenemende leeftijd van de donor (OR 1,05, $\mathrm{Cl}$ $1,02-1,07, P<0,001)$.

De overleving van de ontvanger was niet verschillend tussen beide groepen, echter de transplantaatoverleving was hoger in de aortagroep.

Uit dit onderzoek kan geconcludeerd worden dat directe cannulatie van de aorta de aanbevolen methode is voor controlled DCD.

De huidige, wereldwijd gebruikte technieken om nieren van DCD-donoren te preserveren zijn in hoofdstuk 6 onderzocht. Naast de twee beschreven technieken in hoofdstuk 5 (preservatie met de DBTL-catheter, voornamelijk gebruik bij onverwachte donatie, en de spoedlaparotomie met directe cannulatie van de aorta, gebruikt bij verwachte donatie) worden verschillende andere technieken gebruikt.

Bij de uncontrolled DCD-donoren, kan cardiopulmonale reanimatie (CPR) met een mechanische reanimator, worden gebruikt als overbrugging naar de orgaanpreservatie, met als doel de doorbloeding van de nieren te verbeteren en de schade door warme ischemie te verminderen bij een potentiële donor. In Parijs en Madrid wordt deze techniek gebruikt om potentiele donoren naar het ziekenhuis te vervoeren, nadat de reanimatie buiten het ziekenhuis heeft gefaald. ${ }^{19}$ Extracorporele membraanoxygenatie $(E C M O)$ is een techniek die gebruikt wordt bij intensive care-patiënten als tijdelijke ondersteuning van de circulatie en systemische oxygenatie. Deze techniek kan bij DCDdonoren gebruikt worden om met verwarmd en zuurstofrijk bloed de organen te voorzien van zuurstof in de periode tussen het overlijden en de uitname van de organen. Perfusie van het hart en de hersenen wordt voorkomen door de thoracale aorta af te sluiten met een balloncatheter, die wordt ingebracht via de arteria femoralis. Om onderscheid te maken tussen het gebruik van de ECMO-techniek bij donoren en intensive care-patiënten is de terminologie veranderd. ECMO bij donoren wordt normotherme regionale perfusie genoemd, omdat alleen de (abdominale) organen worden geperfundeerd. Er zijn slechts een paar onderzoeken gedaan met deze techniek, maar de uitkomst is steeds een beter transplantatieresultaat, bij zowel de uncontrolled DCD, waarbij de techniek voornamelijk wordt gebruikt, als bij de controlled DCD. ${ }^{20}$ 
Normotherme regionale perfusie lijkt een veelbelovende techniek en kan mogelijk de levensvatbaarheid van marginale donornieren verbeteren. Toch is in de huidige praktijk de gebruikte preservatiemethode voor DCD-nieren nog steeds afhankelijk van logistieke, ethische en juridische omstandigheden.

\section{Tevredenheid van familie over de einde leven zorg}

Indien een orgaandonatieprocedure volgt na het overlijden van een intensive care (IC)patiënt, zal dit van invloed zijn op de zorg rond het einde van het leven. De tevredenheid van de familie van IC-patiënten die donor werden na het overlijden en familie van ICpatiënten die niet doneerden, werd vergeleken in het onderzoek in hoofdstuk 7. Familieleden vervangen vaak de IC-patiënt bij het nemen van beslissingen omdat de ICpatiënt zelf, meestal door het toedienen van slaap- en pijnmedicatie, niet wilsbekwaam is en geen besluiten kan nemen. Onderzoek heeft zich de laatste jaren veel gericht op het meten en verbeteren van de einde-leven zorg op de intensive care. ${ }^{21,22}$ Uit deze onderzoeken blijkt dat de belangrijkste factoren voor familietevredenheid na het overlijden van de IC-patiënt zijn: goede communicatie, duidelijke en goede besluitvormig en het tonen van respect en medeleven naar de patiënt en familie. ${ }^{23,24}$

Een cohort van 158 familieleden van IC-patiënten die overleden op de intensive care (gemengd, 33 bedden) van ons Universitair Medisch Centrum werd gevraagd om een vragenlijst in te vullen. De vertaalde versie van de vragenlijst Family Satisfaction in the Intensive Care Unit (FS-ICU) werd hiervoor gebruikt. Toegevoegd werden specifieke vragen over het donatieproces. Het responspercentage was 72\%; 32 donor- en 80 nietdonorfamilies. Families van donoren scoorden hoger op alle drie de schalen die waren geïdentificeerd door middel van factoranalyse; de 'zorgschaal', de 'besluitvormigsschaal' en de 'einde-leven-zorgschaal'. Alleen op de 'einde-leven-zorgschaal' was het verschil significant $(P=0,024)$. Regressieanalyse identificeerde de opnameduur als mogelijke verstoorder (confounder). Na correctie voor de opnameduur werd alleen een klein tot matig positief effect gevonden van donatie op de tevredenheid van familie op de 'eindeleven- zorg'. De opnameduur liet een klein tot matig effect zien op de familietevredenheid op alle drie de schalen. Toename van de opnameduur verminderde de tevredenheid. Meer dan $80 \%$ van de (donor)families was zeer tevreden met betrekking tot het donatieproces. De niet-donorfamilies voegden meer negatieve commentaren toe; belangrijkste items waren de communicatie met de familie, het gebrek aan privacy gedurende het overlijdensproces, de ondersteuning van de familie en de atmosfeer in de wachtkamer. 
Hoewel slechts een klein tot matig positief effect werd gezien van donatie op de tevredenheid van familie, blijkt de donorprocedure op zich de perceptie van de familie op de einde-leven-zorg van de intensive care-patiënt niet negatief te beïnvloeden.

\section{Europees perspectief}

In hoofdstuk 8 en hoofdstuk 9 wordt het DCD-proces vanuit Europees perspectief beschreven. In hoofdstuk 8 zijn de beschikbare protocollen voor DCD in Europa geëvalueerd om een algemeen overzicht te geven van de Europese houding ten opzichte van DCD. Factoren die onderzocht werden in de protocollen waren: in- en exclusiecriteria voor orgaandonatie, wetgeving betreffende $D C D$, het vaststellen van de dood en de gebruikte methoden voor orgaanpreservatie. Van de tien Europese landen die een actief DCD-programma hebben, zijn er acht die specifieke DCD-protocollen hebben of de DCD-procedure in een algemeen donatieprotocol beschrijven.

Juridische restricties, ethische overwegingen en organisatorische problemen zijn redenen om geen DCD uit te voeren. In de meeste landen (70 \%) wordt toestemming voor donatie verkregen op basis van veronderstelde toestemming (presumed consent). Uitgangspunt is dat iemand donor is, tenzij degene zich anders heeft laten registreren. De uitvoering hiervan is verschillend in de protocollen.

Het gebruik van de verschillende Maastrichtse DCD-categorieën varieert, alsook het percentage DCD-donoren ten opzichte van het totale aantal overleden donoren. In Nederland, Engeland en Letland is het percentage DCD-donoren hoog. Een grote variatie in de protocollen werd gezien, van kleine verschillen tussen de in- en exclusiecriteria, tot grote verschillen in de beschrijving van het vaststellen van de dood. Sommige protocollen, zoals de Engelse, worden ondersteund door ethische en juridische raamwerken en consensusverklaringen. ${ }^{25}$

Concluderend, strategieën om donoren na circulatiestilstand te verwerven, verschillen binnen Europa, en de implementatie van protocollen verschilt nog meer. Het potentieel aan donoren na circulatiestilstand wordt in verschillende landen en in ziekenhuizen momenteel nog niet volledig benut. Degelijke protocollen, ondersteund door de verantwoordelijke autoriteiten en de transplantatie- en intensive care professionals, kunnen uiteindelijk leiden tot een verdere toename van DCD-transplantatie in Europa.

Tot slot worden in hoofdstuk 9 belangrijke aspecten van het DCD-proces belicht door experts uit verschillende landen met een actief DCD-programma, waarbij de focus lag op de ethische, juridische en psychologische aspecten van de procedure van zowel de verwachte als de onverwachte donatie na circulatiestilstand. 
Hierbij is het rapport van de Engelse ethische donatiecommissie (UK Donation Ethics Committee, UKDEC) gebruikt als referentiedocument. ${ }^{25}$

Aanbevelingen werden beschreven voor de volgende aspecten: het totale DCD-proces, de einde-leven-zorg voor de potentiële donor, het vaststellen van de dood, interventies die verricht worden voor en na het overlijden, communicatie met en begeleiding van de familie van de donor, de toewijzing van organen en tot slot het algemene beleid voor het invoeren van een DCD-programma.

Er werd een klinisch pad ontwikkeld voor de verwachte en onverwachte donatie na circulatiestilstand. Om een ethisch acceptabel DCD-programma te implementeren, moet worden voldaan aan een aantal voorwaarden. De beschikbaarheid van een landelijk DCD-protocol of een landelijke DCD-richtlijn is een noodzakelijke randvoorwaarde. Hierop kunnen lokale ziekenhuisprotocollen worden gebaseerd. Een tweede randvoorwaarde is het uitgangspunt dat alle besluiten omtrent de behandeling van de patiënt, inclusief de beslissing om de medisch zinloos geworden behandeling te stoppen (controlled DCD), of het stoppen van de reanimatie (uncontrolled DCD), gebaseerd moeten zijn op het belang van de patiënt en absoluut onafhankelijk zijn van donatieoverwegingen.

\section{Conclusie}

Dit proefschrift geeft inzicht in belangrijke kritische aspecten van het gehele proces van de donatie na circulatiestilstand. Het laat zien dat vaker toestemming wordt gegeven voor donatie, wanneer de beslissing bij de familie ligt na onverwacht overlijden van de potentiële donor, dan wanneer het overlijden werd verwacht.

Er zijn variabelen geïdentificeerd die de kans op overlijden binnen 60 en 120 minuten na het stoppen van de behandeling vergroten, hoewel in de klinische praktijk het overlijden van een potentiële donor niet met acceptabele zekerheid voorspeld kan worden, gebaseerd op deze variabelen.

In de praktijk blijft er een ruime variatie te zijn in de manier waarop de dood wordt vastgesteld bij patiënten die overlijden na een circulatiestilstand, aldus de Nederlandse IC artsen. Er is behoefte aan richtlijnen voor en standaardisatie van het vaststellen van de dood na een circulatietilstand. De gerapporteerde observatie van autoresuscitatie moet vervolgd worden in prospectieve observationele studies.

De beste preservatie methode voor de verwachte donatie na circulatiestilstand is directe cannulatie van de aorta nadat er een spoedlaparotomie is verricht. Voor de preservatie 
in geval van een onverwachte DCD kan de DBTL-catheter worden gebruikt om de warme ischemie tijd te beperken. Normotherme regionale perfusie is een veelbelovende techniek voor zowel onverwachte DCD als verwachte DCD.

De donatieprocedure op zich beïnvloedt de perceptie van de familie over de eindeleven-zorg van de intensive care-patiënt zeker niet negatief.

Het potentieel aan donoren die overlijden na een circulatiestilstand wordt tot nu toe niet ten volle benut; zorgvuldig geconstrueerde multidisciplinaire protocollen, die worden ondersteund door nationale medische organisaties, kunnen een belangrijke bijdrage leveren aan een verdere uitbreiding van dit grote donorpotentieel. Om een ethisch acceptabel DCD-programma te implementeren hebben we aanbevelingen geformuleerd op de meest belangrijke aspecten van het DCD-proces.

De in dit proefschrift geïdentificeerde kritische aspecten en andere aspecten van het donatieproces van donoren die overlijden na een circulatiestilstand, moeten voortdurend worden geoptimaliseerd, om zo de kwaliteit van de organen te optimaliseren en verdere uitbreiding van het donorpotentieel te realiseren. Met als uiteindelijke doel een toename van het aantal donororganen te bewerkstelligen. 



\section{Valorisation addendum}





\section{Valorisation addendum}

This chapter will touch upon the return of investment prospects for society from the knowledge gathered during this PhD-trajectory. The findings in this thesis are not only relevant from a scientific point of view, but also have social and economic value. The subject of the thesis, critical issues in organ donation after circulatory death, is of great importance for the health care community and also for the society as a whole. Insight in and improvement of the different aspects of the process of donation after circulatory death (DCD) can expand the use of organs from DCD donors and improve the donation procedure, which eventually will benefit patients on the transplant waiting list. This chapter will describe the relevance of the performed research in a broader perspective.

At the end of 2014,there were 1043 patients on the transplant waiting list in the Netherlands. Within the Eurotransplant region (the Netherlands, Belgium, Croatia, Germany, Luxembourg, Austria, Slovenia, Hungary) 14.928 patients were waiting for an organ transplant. ${ }^{1,2}$ The majority of these patients needed a kidney.

Kidney transplantation is the optimal therapy for patients with end-stage renal disease. It results in superior life expectancy and quality of life, compared to dialysis treatment. ${ }^{3,4}$ Next to improvement of the overall survival rates and quality of life, renal transplantation is a cost saving alternative compared with dialysis, even if only DCD kidney transplantation is compared to dialysis. ${ }^{5,6} \mathrm{~A}$ patient on dialyses costs about 55.000 euro per year, and the costs of nephrologic care after the patient is transplanted is about 8000 euro every year, after the first year. This means that every additional year of graft survival stands for a saving of 47.000 euro. (costs adapted from the Dutch Transplant Society).

In 2014 there were 271 post mortal organ donors in the Netherlands and 2041 organ donors within the Eurotransplant region. ${ }^{1,2}$ These numbers are by far not sufficient to treat all patients on the waiting list. As a result, patients die while waiting for an organ; in the Netherlands, there were 130 patients and within Eurotransplant 1318 patients who died in 2014 on the waiting list.

In the Netherlands, DCD increased over the last decades, and over the last years the number of DCD donors is equal to or exceeds the number of donors after brain death (DBD). Within the Eurotransplant region, the percentage DCD donor is only $10 \%$. Procurement of kidneys from DCD donors holds the potential to expand the donor pool 2.5 to 4 times. $^{7}$ However, an increased incidence of delayed graft function (DGF) and primary non function (PNF) is seen compared to kidney transplantation from conventional brain dead donors, due to the warm ischemic injury in DCD organs. ${ }^{8,9}$ Although the survival of functioning grafts is similar between DCD and DBD, the expansion of DCD kidney donation has not reached to its full potential. A study from Snoeijs et al. showed that patients who receive a standard criteria DCD kidney live 
longer, the overall mortality rate was reduced by $56 \%$, compared to patients who continue dialysis treatment with the option of waiting for a conventional DBD kidney transplantation. ${ }^{10}$ Widespread implementation of DCD may increase the life expectancy of patients on the waiting list for a kidney transplant by reducing the waiting times for transplantation.

The studies in Chapter 8 and 9 focus on the European perspective on DCD. From its results it was concluded that $D C D$ is not fully utilized yet within Europe. With the implementation of DCD in more countries, reduction of the waiting list can be realized. Implementation of solid protocols, supported by the responsible authorities, transplant and intensive care professionals may result in a further increase with DCD transplantation in Europe. Countries with less expertise with DCD can learn from the countries with a long experience with $D C D$. Therefore, with a group of experts on DCD from different countries, recommendations on several key aspects of the DCD process were formulated, a clinical pathway for DCD developed, and requirements to implement a DCD programme formulated.

We have shown that increasing the donor potential by the implementation of a DCD programme for patients who die after unsuccessful resuscitation, should not be restricted by the consent rate of the family. The consent rate of the family is not lower if a patient dies unexpectedly. The number of patients who die after failed resuscitation is higher than the number of intensive care patients, who die after withdrawal of treatment and meet donor criteria, and therefore a great potential to expand the donor pool. $^{11}$

An important aspect of DCD donation is the uncertainty whether a potential donor will die within a restricted time period after withdrawal of treatment. If a donation procedure will be abandoned, this obviously also has financial and logistic consequences, like the reservation of an operating room and operating team. With the multicentre study we performed, variables were identified that increased the odds of dying within 60 or 120 minutes after withdrawal of treatment of a potential DCD donor. However, in clinical practice, we cannot predict the time of death of a potential donor with absolute certainty, and therefore initiation of a donation procedure in every potential donor is important given the shortage of organs. Around $20 \%$ of the initiated DCD procedures do not lead to transplantation because the potential donor does not die within 120 minutes after withdrawal of treatment ${ }^{1}$. Further research is needed to develop an accurate and generalizable instrument to improve the predictions of death after withdrawal of treatment and the donation after circulatory death eligibility. ${ }^{12}$

Because kidneys from DCD donors are inevitably associated with warm ischemic damage, due to the period of circulatory arrest prior to preservation, it is important to use the best available method for preservation. In a retrospective study we showed that 
direct aortic cannulation is the preferred preservation method for controlled DCD, compared to preservation with the double-balloon-triple-lumen catheter. The preservation method of choice depends on logistic, ethical, financial and legal jurisdictional circumstances In a review about the currently used techniques to preserve kidneys, we concluded that the normothermic regional perfusion seems a promising technique and may improve the viability of marginal donor kidneys.

Further improvement should be made to optimize the quality and further expansion of the potential donor pool and thereby realize an increase in the organ donor rate. 


\section{References}

1. Dutch Transplant Foundation Annual report 2014 The Netherlands.

2. Eurotransplant International Foundation Annual report 2014

3. Wolfe RA, Ashby VB, Milford EL, Ojo AO, Ettenger RE, Agodoa LY, Held PJ, Port FK. Comparison of mortality in all patients on dialysis, patients on dialysis awaiting transplantation, and recipients of a first cadaveric transplant. N Engl J Med 1999;341: 1725-30.

4. Evans RW, Manninen DL, Garrison LP, Jr., Hart LG, Blagg CR, Gutman RA, Hull AR, Lowrie EG. The quality of life of patients with end-stage renal disease. N Engl J Med 1985;312: 553-9.

5. Wong G, Howard K, Chapman JR, Chadban S, Cross N, Tong A, Webster AC, Craig JC. Comparative survival and economic benefits of deceased donor kidney transplantation and dialysis in people with varying ages and co-morbidities. PLoS One 2012;7: e29591.

6. Snyder RA, Moore DR, Moore DE. More donors or more delayed graft function? A cost-effectiveness analysis of DCD kidney transplantation. Clin Transplant 2013;27: 289-96.

7. Daemen JW, Oomen AP, Kelders WP, Kootstra G. The potential pool of non-heart-beating kidney donors. Clin Transplant 1997;11: 149-54.

8. Wijnen RM, Booster MH, Stubenitsky BM, de Boer J, Heineman E, Kootstra G. Outcome of transplantation of non-heart-beating donor kidneys. Lancet 1995;345: 1067-70.

9. Nicholson ML MM, White SA, Waller JR, Doughman TM, Horsburgh T, et al. . A comparison of the results of renal transplantation fron non-heart-beating donation, conventional cadaveric, and living donors. . Kidney international 2000;58: 2585-91.

10. Snoeijs MG, Schaubel DE, Hene R, Hoitsma AJ, Idu MM, Ijzermans JN, Ploeg RJ, Ringers J, Christiaans MH, Buurman WA, van Heurn LW. Kidneys from donors after cardiac death provide survival benefit. J Am Soc Nephrol 2010;21: 1015-21.

11. Hoogland ER, Snoeijs MG, Winkens B, Christaans MH, van Heurn LW. Kidney transplantation from donors after cardiac death: uncontrolled versus controlled donation. Am J Transplant 2011;11: 1427-34.

12. Munshi L, Dhanani S, Shemie SD, Hornby L, Gore G, Shahin J. Predicting time to death after withdrawal of life-sustaining therapy. Intensive Care Med 2015;41: 1014-28. 


\section{List of publications}





\section{Publications}

Wind J, Bekkers SC, van Hooren LJ, van Heurn LW. Extensive injury after use of a mechanical cardiopulmonary resuscitation device. American journal of emergency medicine. 2009 Oct;27(8):1017

Keeris LM, Bergmans DC, van der Sande FM, Wind TJ, van Suylen RJ, van Mook WN. Kidney donor with severe disseminated intravascular coagulation: transplantation however successful. Nederlands tijdschrift voor geneeskunde. 2009;153:B418

Wind J, Hoogland ER, van Heurn LW. Preservation techniques for donors after cardiac death kidneys. Current opinion in organ transplantation. 2011 Apr;16(2):157-61

Wind J, Snoeijs MG, van der Vliet JA, Winkens B, Christiaans MH, Hoitsma AJ, van Heurn LW. Preservation of kidneys from controlled donors after cardiac death. The British journal of surgery. 2011 Sep;98(9):1260-6

Wind J, Snoeijs MG, Brugman CA, Vervelde J, Zwaveling J, van Mook WN, van Heurn LW. Prediction of time of death after withdrawal of life-sustaining treatment in potential donors after cardiac death. Critical care medicine. 2012 Mar;40(3):766-9

Wind J, van Mook WN, Willems ME, van Heurn LW. Higher organ donation consent rates by relatives of potential uncontrolled donors versus potential controlled donors after death. Nephrology, dialysis, transplantation 2012 Nov;27(11):4219-23

Snoeijs MG, Wind T, van Heurn E. Protocols for uncontrolled donation after circulatory death. Lancet $2012 \operatorname{Sep}$ 15;380(9846):974-5; Letter

de Vries EE, Hoogland PE, Wind J, Snoeijs MG, van Heurn EL. Transplantation of kidneys from paediatric DCD donors: a comparison with DBD donors. Nephrology, dialysis, transplantation 2013 Jan;28(1) 220-6.

Wind J, Faut M, van Smaalen TC, van Heurn EL. Variability in protocols on donation after circulatory death in Europe. Critical care. 2013;17(5):R217

Bernadette Haase, Michael Bos, Catherine Boffa, Penney Lewis, Chris Rudge, Ricard Valero, Tineke Wind, Linda Wright. Ethical, legal and societal issues and recommendations for controlled and uncontrolled DCD

Transplant International, accepted for publication, 2015 
Wind J, van Mook WNK, Dhanani S, van Heurn LW. Determination of death after circulatory arrest by intensive care physicians, a survey of current practise in the Netherlands

Journal of Critical Care, in press, 2015

D Gardiner, J Wind, B Cole, WKNA van Mook, Del Río F, Domínguez-Gil B, and the ELPAT Deceased Donation Working Group. European Vignettes in Donation after Circulatory Death

Submitted, 2015

Wind J, van Mook WKNA, Muijtjens AMM, van Heurn LWE. Family satisfaction of organ donors versus non-donors in the Intensive Care Unit

submitted, 2015

\section{Book contributions}

Gezondheidsraad. Vaststellen van de dood bij postmortale orgaandonatie-Protocollen en criteria, inclusief een geactualiseerd hersendoodprotocol.Obertop $H$, Christiaans M.H.L., van Dijk J.G., Donker D., Drost G., Dubbeld J., Erasmus M., Kompanje E.J.O., Kuiper M.A., Wind T., Ysebaert D., Smit W.H., Bos M.A., Engelfriet P.M. Den Haag: gezondheidsraad, 2015; publicatienr. 2015/13.

\section{Abstracts}

J. Wind, M.G.J. Snoeijs, J. Vervelde, C.A. Brugman, L.W.E. van Heurn. Prediction of death in potential non-heartbeating category 3 donors. Preliminary results of a prospective study. Oral presentation, Bootcongres NTV 2009

J.Wind, M.G.J.Snoeijs, J.Vervelde, C.A.Brugman, L.W.E. van Heurn. Prediction of death in non-heartbeating categorie 3 donors, results of a prospective study .Oral presentation, ESOT 2009 Paris

J. Wind, M.G.J.Snoeijs, A.J. Hoitsma, L.W.E. van Heurn .Comparison of two perfusion methods in controlled non-heartbeating donors. Short oral presentation ISODP\& EDTCO 2009 Berlin

J. Wind, M.G.J.Snoeijs , A.J. Hoitsma , L.W.E. van Heurn. Kidney preservation in controlled non-heartbeating donors: In situ preservation versus direct aortic cannulation. Oral presentation, Bootcongres NTV 2010 Rotterdam 
Wind J, van Mook WKNA, Willems MEC, van Heurn LWE Higher refusal rates for organ donation by relatives of potential controlled versus potential uncontrolled donors. Poster presentation, ESOT 2011 Glasgow

J. Wind, W.N.K.A. van Mook, M.E.C. Willems, L.W.E. van Heurn, Higher organ donation consent rates by relatives of potential uncontrolled donors versus potential controlled donors after death. Oral presentation, Bootcongres NTV 2012 Maastricht

Tineke Wind, Andrew Broderick, Nichon Jansen, Maryon McDonald, Tracy Long-Sutehall, Magi Sque, Family guidance in the donation after circulatory death process. Oral presentation, $6^{\text {th }}$ international conference on organ donation after circulatory death 2013 Paris

Wind J. Family guidance in the donation after circulatory death process. Invited speaker, EDTCO Budapest 2014

Jentina Wind, Walther N van Mook, Sonny Dhanani, Ernest W van Heurn. Determination of death after circulatory arrest by intensive care physicians. Poster presentation, 2015 Bournemouth

Tineke Wind. Family approach when circulatory death is expected to occur following the Withdrawal of Life Sustaining Treatment. Invited speaker, ESOT/ EDTCO 2015 Brussels 



\section{Dankwoord}

"De enige wijsheid die echt telt is weten dat je iets niet weet"

Socrates 



\section{Dankwoord}

Zo, met het schrijven van het dankwoord, komt nu echt het gevoel dat het bijna klaar is! Eindelijk iets schrijven wat niet gecorrigeerd hoeft te worden door anderen, alleen door mijzelf. Heel graag wil ik een aantal mensen bedanken die voor mij de laatste jaren van grote waarde zijn geweest in het tot stand komen van dit proefschrift.

Op de eerste plaats mijn promotor, Professor dr. L.W.E. van Heurn, beste Ernst, voor jouw begeleiding en steun gedurende vele jaren wil ik je hartelijk danken. Positieve ondersteuning zonder druk, de vrijheid die je me gegeven hebt, je ideeën en enthousiasme, de deur die altijd openstond. Na jouw vlotte correcties zagen de artikelen er altijd veel beter uit. Helaas werken we niet meer samen in het MUMC omdat je een prachtige nieuwe uitdaging hebt gevonden in Amsterdam, het is je zeer gegund.

Dr. W.N.K.A. van Mook, beste Walther, mijn co-promotor. Toen ik op de Intensive Care werkte, noemden we je al 'professor'. Zo'n dik promotieboek als de jouwe heb ik niet kunnen produceren. Veel dank voor je begeleiding; je enthousiasme stopt nooit, altijd een positief woord, je energie werkt aanstekelijk. Ik kwam altijd met een goed gevoel bij je vandaan en ik hoop nog lang met je samen te werken.

Graag wil ik de leden van de beoordelingscommissie; Professor dr. G.W.H.Schurink, Professor dr. G.M.W.R. de Wert, Professor dr. D. Ysebaert en Professor dr. J.H. Zwaveling, heel hartelijk danken voor de tijd die jullie hebben genomen voor het beoordelen van dit proefschrift.

Zonder donoren, geen transplantaties. Waardering heb ik voor alle donoren die belangeloos hun organen hebben afgestaan na overlijden voor transplantatie, de families van donoren die hebben meegewerkt aan het onderzoek wil ik bedanken.

Samenwerking is de essentie voor zowel goed onderzoek als een succesvolle donatie procedure, samenwerking met veel verschillende disciplines. Voor advies bij het analyseren van gegevens wil ik Bjorn Winkens en Arno Muijtjens hartelijk danken.

Alle co-auteurs wil ik bedanken voor hun waardevolle bijdrage aan onderzoeken en artikelen; Cees Brugman, Maarten Christiaans, Marloes Faut, Andries Hoitsma, Monique Willems, Janneke Vervelde, Daan vd Vliet.

Sonny Dhanani, thank you for your contribution to the determination of death research. Maarten Snoeijs, dank voor je wetenschappelijke ideeën en heldere analyses. Jan Harm Zwaveling, het begin van mijn onderzoek was je hierbij betrokken, fijn dat je bij de finale kan zijn. Pieter Hoogland en Tim van Smaalen, dank voor de bijdrage aan het onderzoek en de prettige samenwerking. 
Mijn fijne collega's; Corné, Jasper, Monique, Tim, Ruud en Monique, ex-collega's Marloes en Eva, wil ik bijzonder bedanken voor de samenwerking, steun, gezelligheid, belangstelling, discussies, kopjes koffie (die inmiddels van uitstekende kwaliteit zijn, dankzij onze barista Wim!), het altijd bereid zijn diensten over te nemen van elkaar, de collegialiteit. En Tim, voor jou zijn het ook de laatste loodjes! Wim, mijn collega van het 'eerste uur', we zijn jaren geleden samen vanuit de Intensive Care de donatie en transplantatie wereld binnengestapt. We kunnen trots zijn op hetgeen we hebben opgebouwd, jij inmiddels al heel wat jaren als leidinggevende. Altijd vind je een oplossing voor een 'probleem'. Maar soms denk je te weinig aan jezelf. We hebben een aantal prachtige werkreizen gemaakt, ik denk met veel plezier terug aan onder andere Philadelphia en Buenos Aires, interessante congressen, met daarnaast veel gezelligheid; we hebben vaak de bar gesloten maar altijd de volgende ochtend weer fit paraat!

Mijn collega transplantatiecoördinatoren in het land, een aantal hebben meegewerkt aan het verzamelen van data voor het onderzoek naar het voorspellen van overlijden, dank! We hebben toch een bijzonder beroep, vaak werken we individueel maar ons werk staat of valt met onze goede onderlinge en plezierige samenwerking!

De vele studenten geneeskunde die als 'kidneyracer' de laatste jaren voorbij zijn gekomen op het lab, wil ik danken voor jullie enthousiasme en de levendigheid die jullie meebrengen. Sinds kort is de naam gewijzigd in 'Transplant Technicien' en is de drukte enorm toegenomen sinds alle nieren machinaal geperfundeerd worden.

De intensivisten, intensive care verpleegkundigen, transplantatie-nefrologen, verpleegkundigen en verpleegkundig specialisten nefrologie, afdeling weefseltypering, afdeling pathologie, de vaatchirurgen en de chirurgen van het MOD team en het ZUT wil ik danken voor de prettige samenwerking.

Muis Mücher, een prachtige omslag heb je gemaakt voor mijn boekje, ik ben erg blij dat je dit wilde doen. Muis, binnenkort hoop ik weer met je te kunnen rennen!

Tiny Wouters, bedankt voor de mooie opmaak, Tiny, je staat in vele boekjes vermeld en terecht.

Zoals ieders leven ook gepaard kan gaan met tegenslag, was promoveren wel heel ver weg toen er een kwaadaardige tumor in mijn been werd ontdekt. Gelukkig lijkt alles nu goed na de succesvolle behandeling onder leiding van Dr. M. Bemelmans. Voor je deskundigheid, betrokkenheid, goede zorg en zeker ook je optimisme ben ik je dankbaar Marc! Een werkrelatie is gezonder dan een arts-patiënt relatie.....

Mijn paranimfen; Frans Wind en Corine Kooyman. Toen het boekje er toch nog ging komen, wist ik meteen dat ik jullie graag als paranimfen zou willen.

Frans, mijn jongste broer; 'Sassie', bedankt dat je hier vandaag aan mijn zijde staat, het voelt gewoon goed zou jij zeggen en dat is ook zo, meer hoeven we niet te zeggen. 
Positief en met een gezonde dosis humor sta je in het leven, altijd de slimste jongste, volgens jezelf...

Corine, we ontmoetten elkaar op 1 oktober 1990, de dag waarop we startten met de intensive care opleiding in het azM. Vanaf deze dag waren we vriendinnen en dat voelt nog altijd heel bijzonder maar zo vanzelfsprekend! Ik raak nooit uitgepraat met jou, jij raakt nooit uitgepraat zal iedereen zeggen die jou kent... Het hart op de juiste plaats, het leven levend, avontuurlijk en dapper, ik word vrolijker door jou. We hebben veel gemeen, oké, behalve dat sporten dan, hoor ik je zeggen....

Zonder vrienden is het leven lang zo leuk niet, mijn lieve vriendinnen en vrienden uit het noorden en hier uit het zuiden, dank ik voor de belangstelling en steun en met name voor de ontspanning door samen te sporten, wandelen, de kampeerweekenden, reizen, genieten van filmavonden, lekker eten, kaartavonden, borrelen, maar vooral er gewoon te zijn.

Echt even van de wereld ben ik in de bergen; al vele prachtige tochten en beklimmingen gemaakt met klimvrienden Herman en Maarten. De Makalu prijkt op de omslag Herman, gemaakt tijdens onze fantastische reis in Nepal. Vele toppen hebben we met z'n drieën gehaald maar ook vele niet, een plan gemaakt bij de warme kachel bleek vaak optimistischer dan de werkelijkheid op de berg. Maarten, eindelijk kan je dan met Frau doctor de bergen in.

Mijn familie en schoonfamilie wil ik danken voor de steun en belangstelling. Met name mijn lieve broers Henk, Harjo, dierbare zus Janny en de 'koude kant' die bij ons heel warm is: Ina, Han en Rianne bedank ik voor hun liefde en betrokkenheid. Heel verdrietig dat Maria dit niet meer mee mag maken.

Mijn leven begint bij mijn ouders, die mij een onbezorgde jeugd en alle kansen hebben gegeven en ook de wijsheid dat gewoon al bijzonder is, ik had jullie graag samen apetrots in de zaal willen zien zitten, mijn moeder glunderend van trots en mijn vader hoor ik zeggen: " butn'gewoon". Jammer dat jullie er niet meer bij kunnen zijn.

De laatste woorden zijn voor de allerbelangrijkste mannen in mijn leven; Dick, Daan en Kas.

Lieve Daan en lieve Kas, mijn grote zonen, jullie kleuren mijn leven prachtig. Ik ben er trots op jullie moeder te zijn, trots op wat jullie doen en vooral wie jullie zijn! En Dick, de liefde van mijn leven, mijn rots in de branding, samen met jou is zoveel meer, laten we nog veel avonturen beleven samen! 



\section{Curriculum Vitae}
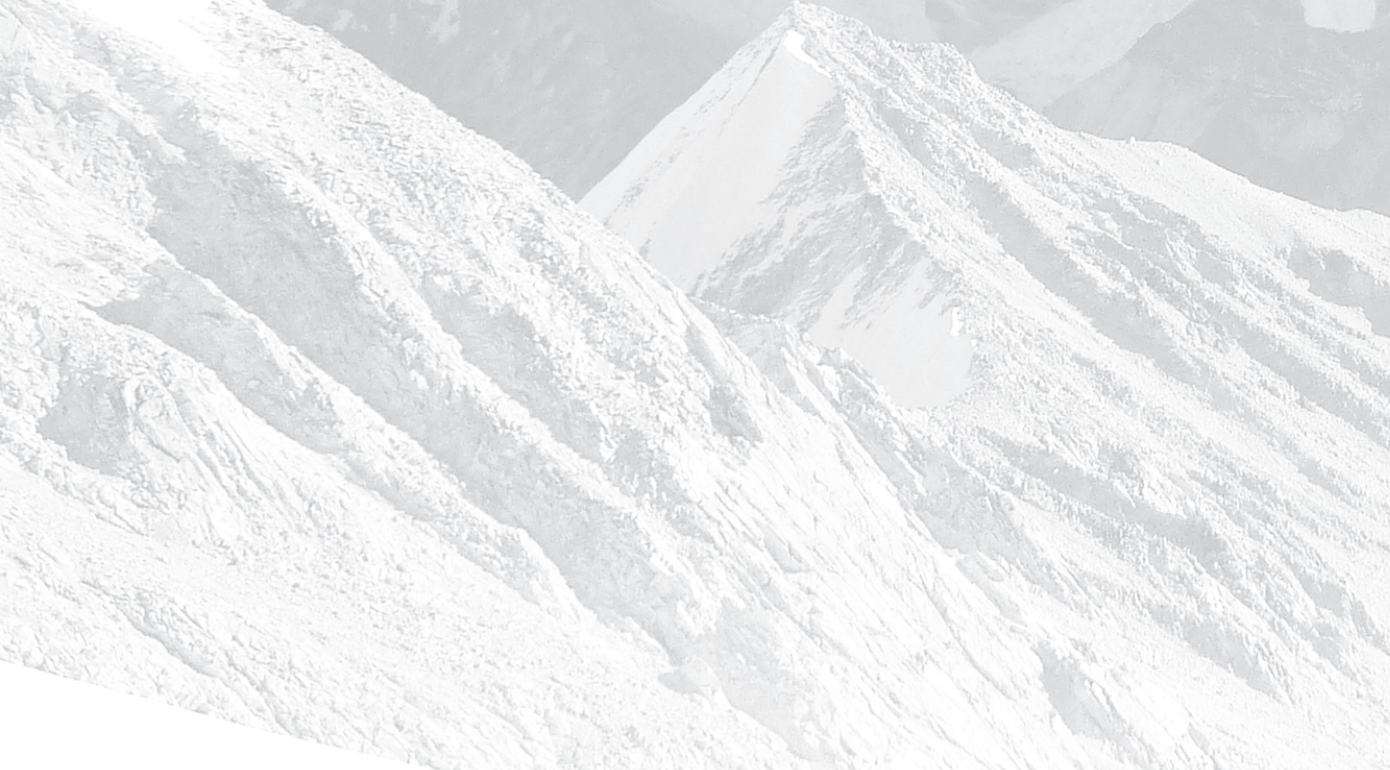



\section{Curriculum Vitae}

Tineke (Jentina) Wind was born on September $26^{\text {the }} 1961$ in Meppel. After secondary school (Rijksscholengemeenschap Meppel, VWO), she started her nursing education in the Diaconessenhuis Meppel (1979-1983). After a nursing specialisation in children's nursing (1983-1984), she moved in 1987 to Utrecht, to study neonatology nursing (19871988) and worked until 1990 in the Wilhelmina Children Hospital Utrecht. In 1990 she started working in the Maastricht University Hospital, azM, and studied Intensive Care nursing (1990-1992). From august 2000, she combined the intensive care work (until 2007) with the work as Transplantcoordinator; coordinating organ donation procedures. In 2003, she started the study Health Sciences at the University Maastricht and received her Master in 2007. During the last years, she combined the work as Transplantcoordinator with research, combining science with practice, with a special focus on the donation after circulatory death process. The research was under supervision of Prof. dr. L.W.E van Heurn and dr. W.K.N.A. van Mook, which resulted in this thesis. She is a member of the ELPAT, a European platform that brings continuity and progress in European research and dialogue on "Ethical, Legal and Psychosocial Aspects of organ Transplantation". From 2011 until 2015 she was a member of the advice committee 'determining death in postmortal organ donation' of the Health Counsel of the Netherlands. She lives in Maastricht and is married to Dick Nagelhout, together they have two sons; Daan (1993) and Kas (1995). 
